\title{
Modelling of Reinforced Concrete Beam-column Joint for Cyclic Earthquake Loading
}

\author{
Khalid Abdel Naser Abdel Rahim* \\ Researcher in the Department of Civil Engineering, University of Coimbra, Coimbra, Portugal \\ *Corresponding author: khalid.ar@outlook.com \\ Received January 14, 2019; Revised March 22, 2019; Accepted April 11, 2019
}

\begin{abstract}
This paper presents a reinforced concrete beam-column joint model that was carried out for cyclic earthquake loading. The beam-column joint is the most important part of a building and modelling such an element and determining its structural behavior under the effect of seismic citations is essential to avoid losing lives and money. The non-linear analysis consisted of two types: (1) Non-linear static analysis that includes applying cyclic earthquake loading and (2) Non-linear dynamic analysis that involves applying three real historic earthquakes with different frequencies and magnitudes. The crack pattern analysis was established for non-linear static and non-linear dynamic to determine the worst-case scenario in terms of crack size. Another beneficial analysis was seismic analysis, which targeted the critical response time by which the maximum axial force, displacement and stress has occurred for applied real earthquakes. It was found that the structure sustained all the applied real earthquakes, however failure of the structure took place during the third cycle $(50 \mathrm{~mm})$ of cyclic earthquake loading. After comparing the results with previous published work it was observed that the size of the reinforcement bars plays a major role in terms of load carrying capacity of the structure. It was observed that cracks occurred mostly under the Friuli earthquake due to the highest magnitude among other earthquakes. There was a variation in the location of cracks within the structure for each earthquake. Intermediate and major cracks occurred during the third cycle $(50 \mathrm{~mm})$ of cyclic earthquake loading within the joint. The cracks were developed and increased as the cycle was increased leading to cracks across the joint after the forth and fifth cycles and failure of the structure. Although the critical response time for the Friuli earthquake was lower than the other earthquakes it was the most active and had a larger effect on the model. This is because the Friuli earthquake had the highest magnitude among applied earthquakes. The results obtained from the author's model were used to suggest some recommendations on Eurocode 8: Design of structures for earthquake resistance. General rules, seismic actions and rules for buildings (2004) BS EN 1998-1: 2004 to improve the performance of beam-column joints during earthquakes. The main reasons for beam-column joint failure are due to the transverse steel which crosses diagonal cracks and begins yielding, anchorage failure of reinforcement, loss in moment carrying capacity of columns near joints and the opening and closing of cracks due to cyclic loading.
\end{abstract}

Keywords: structural modelling, $R C$ beam-column joint, cyclic earthquake loading, static analysis, dynamic analysis

Cite This Article: Khalid Abdel Naser Abdel Rahim, "Modelling of Reinforced Concrete Beam-column Joint for Cyclic Earthquake Loading." American Journal of Civil Engineering and Architecture, vol. 7, no. x (2019): 67-114. doi: 10.12691/ajcea-7-2-4.

\section{Introduction}

\subsection{Background: Modelling Beam-column Joints}

Beam Column joints are an important part of any construction and their behavior is a significant factor and plays an important role in the overall behavior of framed structures (reinforced concrete) when confronted with seismic waves or excitation [1,2,3]. The most important reason for failure and catastrophic collapse during earthquakes is inadequate availability of shear reinforcement in joints of reinforced concrete structures [4] and [5]. Experimental research is the most important tool used for finding the parameters which both affect joint performance and those that need to be improved in order to enhance joint performance [6]. A large number of publications giving detailed recommendations for the design of reinforced concrete column joints were published in the USA and Europe in the last two or three decades.

According to [7] a beam-column joint ought not to fail in the event of an earthquake due to certain reasons which include: (1) gravity loads must be sustained at the joints; (2) large energy dissipation and ductility cannot be allowed in joints; and (3) joints are not easy to repair after a seismic event such as an earthquake. While some damage may be tolerable, this is as long as it does not have any unwanted impacts on the general structural behavior of a 
building. Over the years, there has been significant interest and progress in the modelling of beam-column joints due to these reasons outlined above. A building in Japan failed under an earthquake due to the shear stress in the beam-column joint connection. The weak reinforced connection between beam and column were the main reason for failure. Thus, the beam-column joint is considered to be the most essential part of the structure and appropriate considerations should be maintained during the design stage for a safe structure against earthquakes.

\subsubsection{Performance Requirements of Beam-Column Joints}

The design is automatically classed as satisfactory when column reinforcement passes through the joint as the gravity load and flexure are considered. Nevertheless, there can be a difference in shear in a joint with that of a column or a beam and the joint should be designed in a manner that can handle brittle shear failure. However, some cracking due to this shear is acceptable in the design. At the same time anchorage of bars should be done so as to maintain and develop a weak beam strong column resistance method. Significant slippage of bars and shear failure of the panel in a joint must be prevented up to a limit of deformation defined for the structure. This is defined as beam ductility or a strong drift angle by which they should be considered in relation to the joint.

\subsubsection{Shear Mechanism in Beam-column joint}

In Figure 1 shown below, the actions acting on an interior joint from its connecting columns and beams is shown: [8] have studied the shear transfer mechanism acting in a joint. This is defined as "main strut mechanism" and another is defined as "sub strut mechanism". On the main diagonal, the main strut occurs as a result of vertical and horizontal compression that acts along the section of column and beam. It is to be noted that the main strut exists without consideration of bond situation of bars present within the joint section. Diagonal compression stress, which is uniformly distributed over the panel regions, forms the sub strut mechanism. This diagonal strut mechanism must equalize or balance the tensile strength present in horizontal and vertical reinforcement and bond stress, which acts along exterior column bars and the beam. There may also exist a third kind of mechanism that is called a transfer mechanism or truss mechanism. This truss mechanism is produced due to lateral reinforcement and column exterior reinforcement along with diagonal concrete struts.

If bond is absolutely correct in the case beam reinforcement, the main strut mechanism takes part of the shear that is nearly equal to tension force. As a result of this contribution of sub strut mechanism with shear resistance it is quite comparable to that of main strut mechanism. The sub strut mechanism exists in joints when a good bond stress is maintained along column and beam reinforcement. It is not feasible however to have a perfect bond along the beam reinforcement and as a result beam deterioration starts because of tension on the side of beam reinforcement. Once bond deteriorates sub strut mechanism looses shear transfer and as a result, the effectiveness of lateral reinforcement deteriorates. It is the main strut mechanism, which has to carry the complete shear in its joint. Shear transfer method in the beam column joint changes as a bond starts deteriorating with reinforcement in the beam. Tension force that is not transferred to joint concrete must be resisted by compression on the face of the joint. With an increase in compression stress in the main strut the concrete is weakened as a result because of reversed cyclic loading, and overall compressive strength decreases by increasing the tensile strain acting perpendicular to the direction of the main strut. Shear capacity decreases and finally fails under shear comparison. The main role of lateral reinforcement is to confine the cracked joint. Truss mechanism is effective at this stage. An index defined as a beam bar bond index is discussed, which corresponds to the chances of bond degradation, which occurs alongside beam reinforcement. The average bond over column for yielding beam reinforcement in compression and tension on both sides of the joint could be expressed as:

$$
U_{b}=\frac{f_{y} \times D_{b}}{2 \times H_{c}} .
$$

In the above equation $\mathrm{f}_{\mathrm{y}}$ denotes strength of beam bars, $D_{b}$ is diameter of beam bars, $H_{c}$ is the width of the column. If bond strength varies with the square root of compressive strength $\mathrm{f}_{\mathrm{C}}$, then the feasibility of bond degradation by bond index BI can be expressed as:

$$
B I=\frac{U_{b}}{\sqrt{f c^{\prime}}}
$$

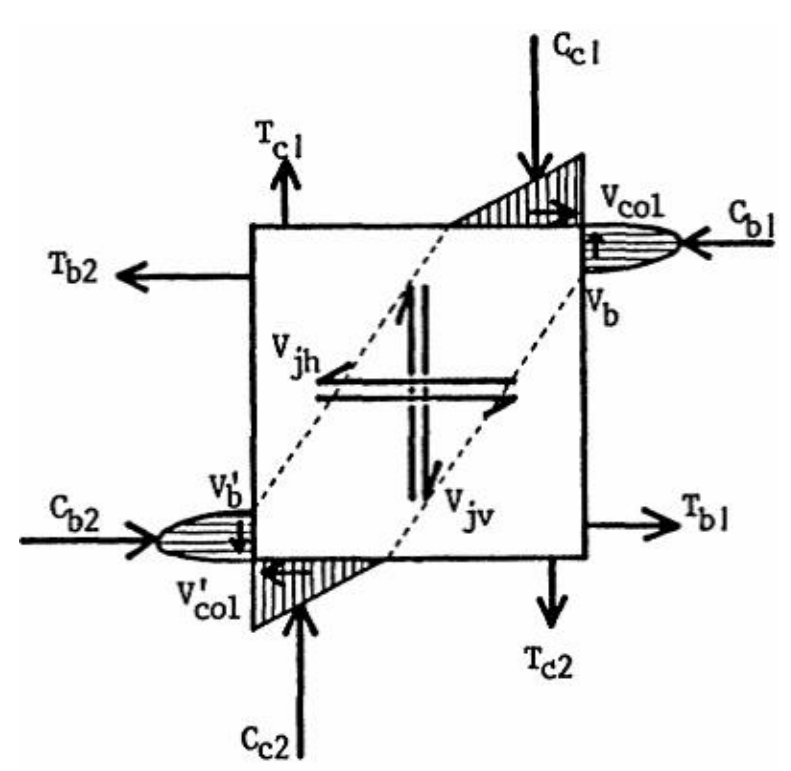

Figure 1. Beam Column Joint by [8]

The value of this index is high for beam bar strength. Bars with narrow column width have a larger diameter of beam bars and as a result have a weak concrete strength. Bond deteriorates at a higher index value. In most common cases observed it is found that the size of beams is governed by drift or its design criteria, instead of depending upon flexural strength requirements. Ductile strength of connections helps in the formation of beam hinging over global frame mechanism having large hysteretic energy capacity as a result reducing force on the columns. The behavior of structures discussed above 
depends majorly on connection response and a major portion of study emphasizes what steel concrete frames with strength (partial) has given to the development of systems with connections and relative study of behavior when put to seismic and cycle loading.

\subsection{Aims and Objectives}

The main aim of this research is to model a beam-column joint and subject it to cyclic earthquake loading sequentially to examine the behavior of the joint and its performance in the event of an earthquake. The following objectives of the research should be achieved:

- To conduct a thorough review of literature on investigations of modelling approaches and experimental tests used for reinforced beam-column joints in seismic studies including previous and contemporary methods.

- To use the appropriate tools and methods from the investigated published work in modelling a beam-column joint under cyclic earthquake loading using computer software.

- To find the outcomes of final model subjected to real earthquakes.

- To compare the investigated experimental results with the results obtained from the proposed model in terms of seismic cyclic loading.

- To come up with some recommendations for improving current design codes for the design of beam-column joints under cyclic earthquake loading and to produce guidelines for future work and further study.

\subsection{Scope of the Research}

The period of the research did not allow a parametric study to be conducted on the author's proposed beam-column joint model in order to create a set of statistical data on the seismic behavior of the joint with different parameters. Therefore, the project focused on studying the non-linear static and non-linear dynamic behavior of the beam-column joint within the available resources and time restrictions.

- The author's proposed beam-column joint was modelled and simulations were carried out using Lusas Finite Element package. There was no possibility to pursue or test the joint through experimental work.

- The column was fixed from both top and bottom to represent a real life structural situation of the element during seismic loadings.

- The testing of the joint was performed with different loads being applied on the beam, which represents the cyclic loading.

- The dynamic analysis was carried out on three types of real earthquakes. The UDL (floor load) of the beam was included. Conversely, the effect of the loads created by stories above the column was not included in the study.

\subsection{Significance of the Research}

The modelling of reinforced concrete beam-column joints can be beneficial for many reasons but this research specifically reviews its application in cyclic earthquake loading situations. By analyzing the modelling approaches found within contemporary literature, this research will not only present a summary of the status-quo, but also project a futuristic direction for such studies. Accordingly, the research will endeavor to provide an overview of computational tools as well as aspects of the World Wide Web through collaborative tools for beam-column research and investigations.

This research topic is worthy of consideration because it will firstly, provide a comprehensive and up to date review and analysis of literature in modelling RBC joints. It will essentially reveal the state-of-the art approaches used in tackling the problem of reinforced beam-column (RBC) joints by looking at the techniques and tools applied in different parts of the world for modelling and investigating RBC's. This will be beneficial for evaluating the most effective modelling method or combination of methods to be used in the proposed non-linear model in this aspect of seismic research.

The proposed refined component model will aid in predicting the inelastic monotonic behavior of the exterior beam to column joints with partial strength composite steel having moment resisting frames of concrete. The cyclic earthquake loading results obtained from the proposed model will be compared with the published experimental results to suggest some changes in the current design codes of beam-column joints. The research will also provide an objective method for evaluating the features, benefits and challenges in different modelling approaches for RBC's, which should be of benefit for future researchers, who may wish to quickly adopt a modelling method.

\subsection{Methodology}

The previous published experimental studies on the beam-column joint as presented in the literature review section of this report were an important part of the research. It has aided in finding out the most appropriate method and parameters by which the model was created. The computer software (Lusas 14.4) was used to model and perform non-linear static, non-linear dynamic, seismic and cracking pattern analysis on the joint element. The behavior of the structure and specially the joint under seismic loading and real earthquakes were analyzed. Moreover, the results obtained from each analysis in terms of displacements, stresses, strains, maximum shear force and bending moments were compared with previous published experimental work. Accordingly, the conclusion is given and some recommendations for improving the design of beam-column joints were produced based on the comparison made between the model and experimental results.

\subsection{Potential Problems}

Problems that may be encountered by this research include the following:

- Time constraints: Depending on the findings from the literature review, it may be desirable to pursue or test some modelling through experimental work. However, it is not possible due to the duration of the course. 
- Availability of resources: The need for applying earthquake simulations on the proposed model using an open-source, object-oriented software framework such as OpenSees is essential as reviewed in the literature (more details are given in chapter 2 - literature review). Nevertheless, this kind of software is not available or accessible.

- Required expertise: The required level of skill and experience to successfully run modelling codes and obtaining results may take time.

\subsection{Structure of the Report}

This report is structured according to the key research findings arranged in a quasi-historical way but also according to subject matter. It begins with a literature review with a general background to modelling of beamcolumns starting with simple experimental scaled models of beam-columns done from the 1980s to an example of seismic modelling work done in the 1990s. Afterwards, the review focuses on a more contemporary aspect of seismic beam-column modelling, through the review of research on fiber-reinforced plastic (FRP) joints. In this section, three aspects of seismic related studies were covered which are: (1) the use of FRP jacketing and near surface mounted (NSM) rods; (2) the use of FRP for interior beam-column joints; and (3) the use of FRP for exterior joints. The report concludes with a brief insight into prediction models used or applicable to seismic studies of beam-columns. This section covered issues such as predicting shear failure and the use of OpenSees, which is an open-source modelling environment. In addition, the literature review will go through an experimental study on the strengthening of reinforced concrete beam-column joints with steel fiber during earthquake loading done by the visiting researcher [9] at the University of Leeds.

The methodology section of this report will present the computer software that has been used in modelling and the reason behind using this software with general information about it. Furthermore, the general properties of the model such as material, physical, structural and geometrical properties will be identified along with mesh formation and the characteristics of the three members of the structure, for instance, joint, cantilever and column members. The method of using and assigning the types of earthquakes including cyclic earthquake loading will be discussed. Additionally, the four types of analysis and simulations that has been carried out will be examined such as non-linear static analysis, non-linear dynamic, cracking pattern and seismic analysis.

The results presentation section will include the findings from the analysis and simulations. This will be presented in terms of graphs, tables and contour maps showing the distribution of stresses and strains in the model. This will be followed by results, analysis and discussion of the results and comparing the results with the previous published experimental work, for example, the findings from the literature review. Based on the comparison made the conclusion will be drawn summarizing the most important findings along with general reasons for beam-column joint failures. Finally, some recommendations for improvement in current designs of such an element under the dynamic effect of an earthquake will be given with suggestions for future work on carrying out more types of seismic analysis.

\section{Literature Review}

[10] and [11] used a refined beam-column joint to minimize the computational time and effort needed for modelling such elements and for obtaining more accurate results. Their research utilized $2 \mathrm{D}$ models of precast structural elements and is an example of judicious use of resources in seismic modelling of RBC's. [12] applied a microplane-based Finite Element (FE) to seismically model and analyze a three-dimensional reinforced beam-column joint under cyclic loading. This was for the purpose of investigating weaknesses in the structure of buildings with old frames. The FE tool they used was MASA, and their studies looked at the impact of variables such as axial loading on columns and on bonding.

[13] applied experimental methods to investigate the strengthening characteristics that fiber-reinforced plastic (FRP) materials have on beam-column joints. They adopted three kinds of loads: gravity beam, axial column and reverse load to carry out their studies. Their findings were used to produce guidelines for engineers who wish to strengthen existing structures with FRP. Similarly, $[14,15,16]$ used experiments to evaluate the performance of as-built RC joints under seismic conditions, which they then compared with carbon fiber-reinforced polymers (CFRP's). They had two sets of specimens: control specimens; repaired specimens and CFRP strengthened specimens. Their findings indicated that the bonding of CFRP externally to joints enhances shear strength and ductility of the joints. [17] investigated the behavior of RC beam-column joints under seismic forces by using simulation of earthquakes specimens in a laboratory. The objective of their research was (1) to validate 3D nonlinear FE models; and (2) to investigate the effects that seismic loading has on transverse beams. They concluded that as the transverse beam loses the torsional capacity its strength is maintained and the axial loads prejudice the seismic behavior of the beam-column.

[18] used RC beam-column joints modelled to a small-scale and subjected them to a large cyclic displacement under two different frequencies, for example, $2.5 \times 10^{-3}$ and $1.0 \mathrm{~Hz}$. The aim was to assess damage using free vibration tests. The modelling results they obtained were subjected to reliability screening by comparing them with results for slower rates of vibration and those obtained from full scale testing of prototype beam-column joints. Moreover, they used three identical beam-column joints where the first specimen used was for preliminary testing to define yield displacement and for checking of the instrumentation. The second specimen was subjected to cyclic loading at a frequency of $2.5 \times 10^{-3} \mathrm{~Hz}$, which is the slow rate. The third specimen was subjected to a frequency of $1.0 \mathrm{~Hz}$, for instance, a fast rate. To illustrate this, the scaled specimen and the experimental set up used by [18] are shown in Figure 2 and Figure 3 respectively. 


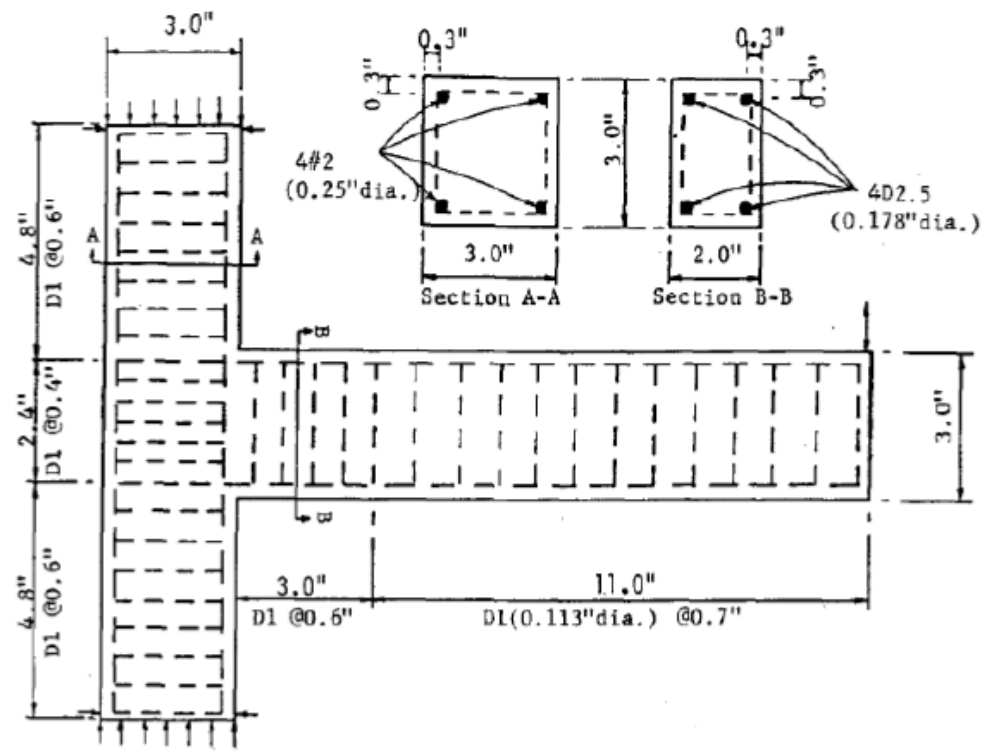

Figure 2. Scaled model specimen design of [18]

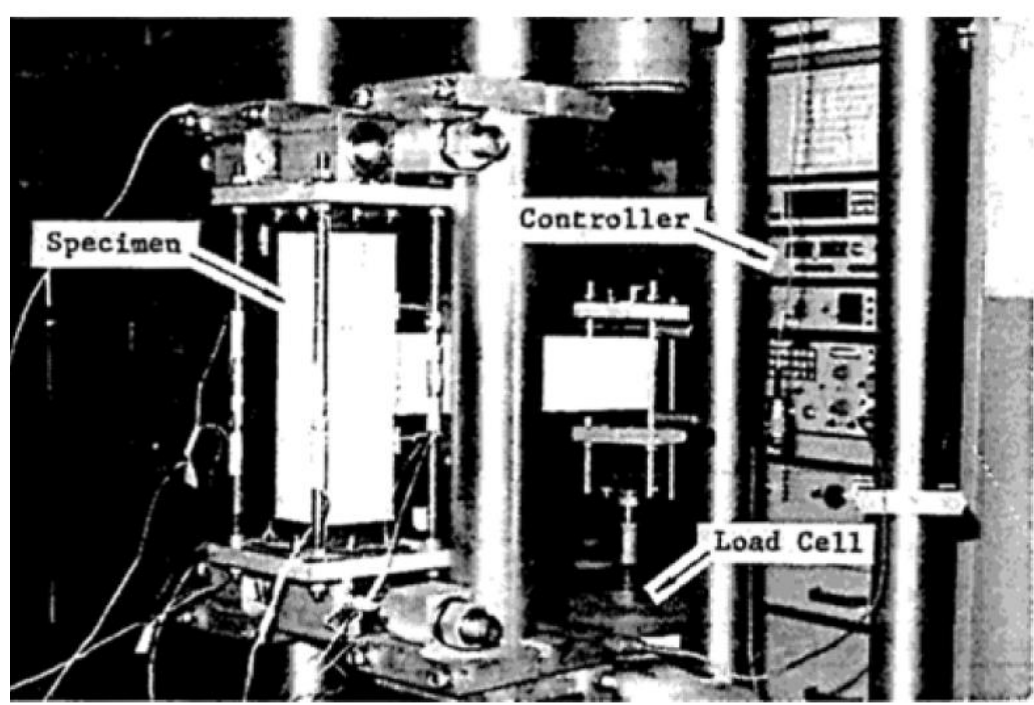

Figure 3. Experimental set up used by [18]

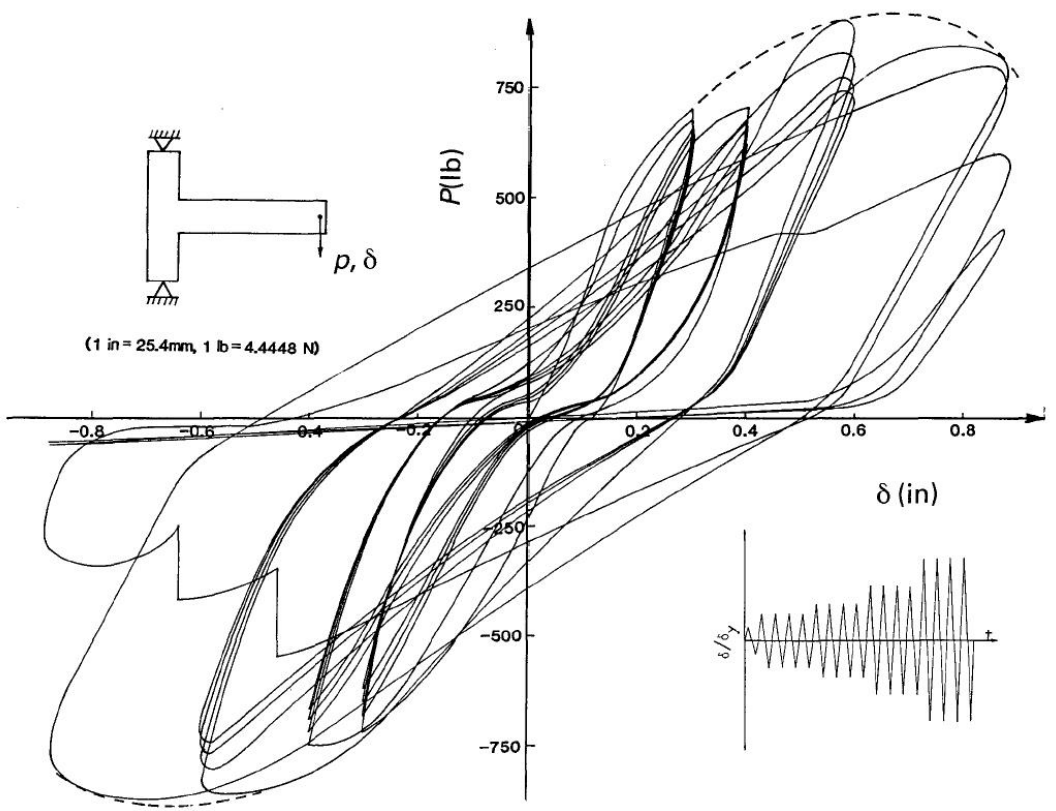

Graph 1. Load vs. deflection graph obtained by [18] 
They found that the faster loading rate was more damaging than the lower rate of vibration. Specifically, with the faster rate, the maximum load-bearing capacity of the specimen became higher, although it created a large quantity of dissipated energy. Furthermore, the faster rate of vibration produced less but more localized cracks in the specimen compared to the situation with a slower vibration rate. This suggested that the vibration rate had an effect, which is linked to the transfer of load between reinforcement bars and the concrete itself. Graph 1 demonstrates the results obtained by [18] in terms of load and deflection.

[19] investigated the inelastic behavior of RC frames, which were under the influence of strong ground motions. They focused on actual modelling of the elements and the developing of an efficient numerical technique for analyzing nonlinear dynamics. The authors then proposed a new girder model based on Soleimani's nonlinear beam element. Besides this, the girder, which is revealed in Figure 4 comprised of three main parts: a nonlinear member which represented the beam; nonlinear rotational springs which described fixed-end rotations at the interface of beams and column; and rigid offset zones that were meant to represent the beam-column panel zone.

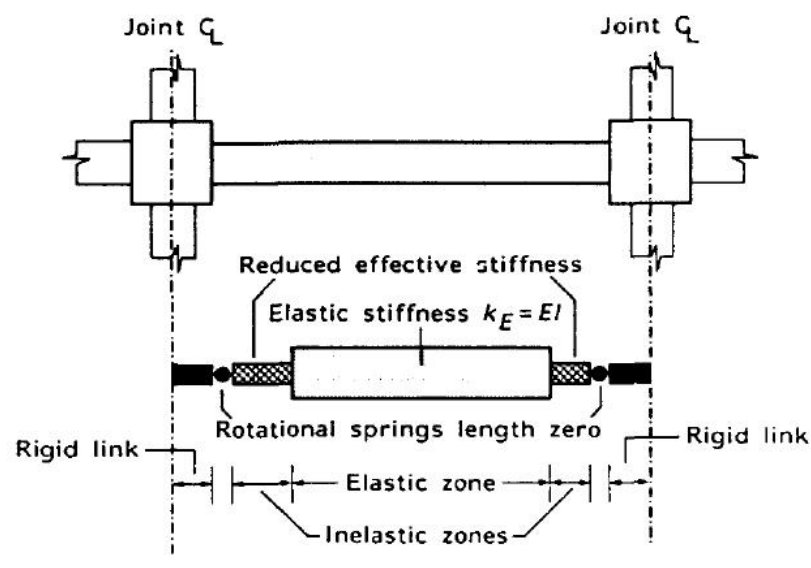

Figure 4. The proposed girder element by [19]

This girder element was then modelled in a computer programme (RCDYNA) which calculated the dynamic response of the RC frames, which are moment resisting. The structural model's nodes were located at the point of intersection of the beam-column and each node had two degrees of freedom (DOFs). Only one horizontal translation DOF was used to model the displacement of all nodes on the floor because it was assumed indefinitely rigid. The columns were modelled as being linearly elastic throughout the response time history and the effects of $\mathrm{P}-\Delta$ were represented with linear geometric stiffness. As the floor had only one DOF horizontally, the matrix of geometric stiffness depended on summation of axial loads on each floor. This sum is dependent on gravity loads, which were left as constant throughout the response time history. Figure 5 demonstrates the model used in determining the stiffness matrix of the girder element with two DOFs. The authors tested their model on a six-storey plane frame RC building that was designed according to the 1982 Uniform Building Code and the ACI 318-83 standards. They then concluded at the end that the definition of the damping matrix had a significant impact on the structural response, but they also recommended the investigation of certain parameters on the structural response. These included moments of inertia, yield moments, stiffness ratios between girders and joints and strain-hardening ratios.

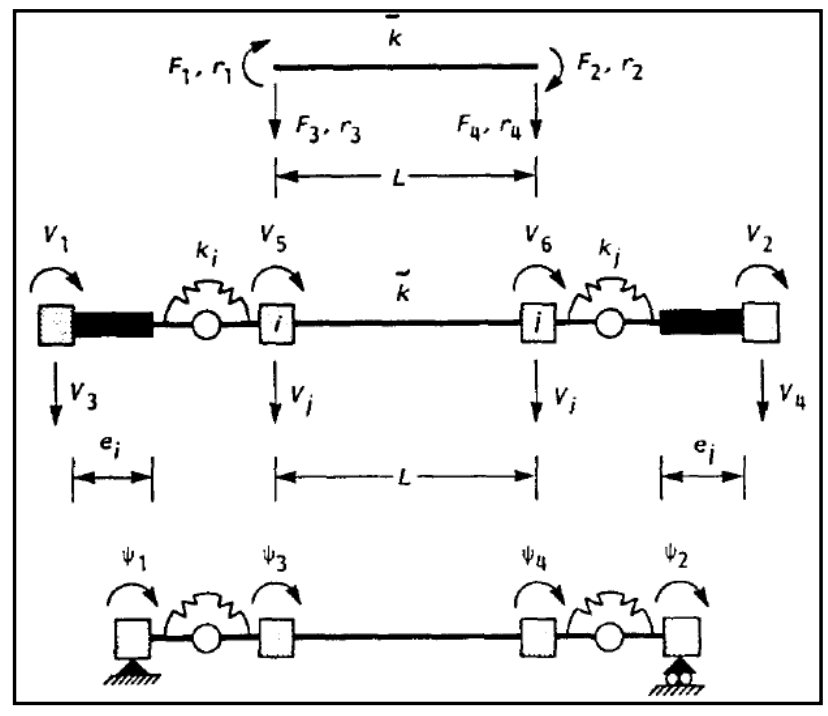

Figure 5. Model used by [19] to determine stiffness matrix of girder element with two DOFs

[11] identified some problems with finite element (FE) modelling of frame structures including the inaccuracies obtained when strain field is being approximated at zones where shear forces are high. In addition, they inferred that even though an approach like the fiber element model is rather popular in concrete frame analysis. The authors identified it as lacking the sort of generality for application in zones of large shear forces within framed structures. As a result, they introduced a continuum modelling approach for dealing with the two-dimensional (2D) state of stress and strain with the high shear zone of beams and columns. Their study was based on the fact that since continuum beam elements are actually $2 \mathrm{D}$ models of the strain field in which the kinematic constraints are like the Reissner-Mindling bending model and therefore, the displacement field along the beam's thickness can be expressed according to rotation and displacement of the cross section. Considering that refinement techniques had previously seen application in shell and plate structures, and also because the majority of techniques available for refinement are inapplicable to continuum elements, the model introduced by the authors sought to use refinement to provide greater accuracy in approximation of strain and stress fields. The refined beam-column utilized in their work was formulated using the total Langrarian approach, which allowed for large deformations and by using the beam-column element represented in Figure 6 they were able to carry out a computerized analysis using the ABACUS programme.

The beam-column joint of Figure 6 above is shown as a refined solid FEM model in Figure 7 below.

[11] used three type of loading conditions for the analysis, which are Load Case A, Load Case B and Load Case C. In Load Case A, concentration $(\mathrm{Fa}$ ) was applied at the end of the beams; representing simple idealized lateral loading in opposite directions within a frame system. Load Case B simulated the impacts of dead 
loading on the joints in which two concentrated forces $(\mathrm{Fb})$ were applied at two sides of the model joint. In Load Case $\mathrm{C}$, the investigators wanted to account for effects of axial loading on the joints and this was achieved by applying a force $(F c)$ on the column. These loading conditions are further described in Figure 8.

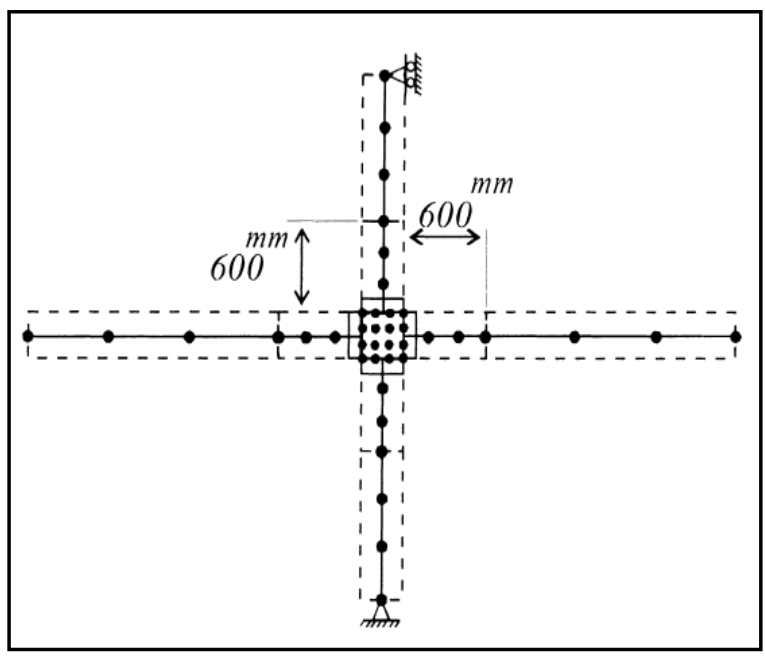

Figure 6. Beam-column element used by [11]

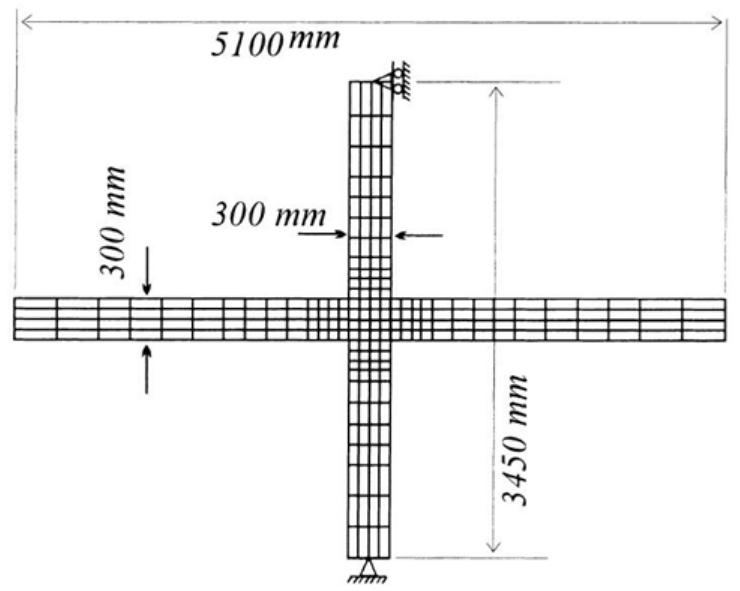

Figure 7. Refined solid FEM beam-column model by [11]

These studies by [11] emphasized that the importance of accuracy in high shear zones of reinforced concrete (RC) structures is beneficial for determining the potential behavior of the structure. Hence, by the application of the refined beam-column approach, the computational resources needed for analyzing concrete frames are reduced. For large frame systems, the accuracy of analysis is also enhanced. Additionally, the accuracy of approximating the strain field as well as the versatility possible in defining boundary conditions, the model was expected to be useful for 2D modelling of other structural elements, such as, precast frame members and deep beams.

Factors such as insufficient reinforcement ratio in beam-column joints; the weak bonding properties of reinforcement in the longitudinal direction as well as the deficient anchorage of reinforcement bars with end-hooks leads to brittle failures, which can be aggravated under seismic loading. As such, [12] utilized microplane based FE for modelling and analyses of a three-dimensional $\mathrm{RC}$ beam-column joint under cyclic loading during earthquakes.

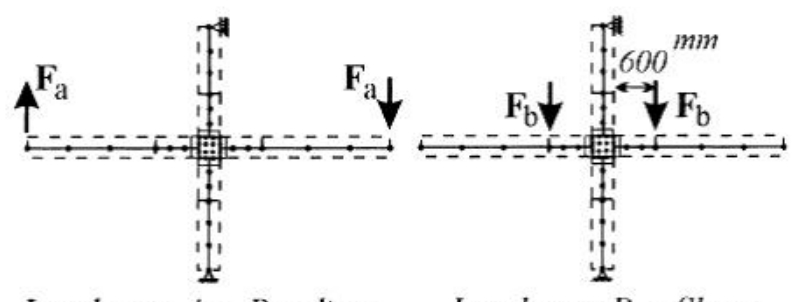

Load case A -- Bending $\quad$ Load case B -- Shear

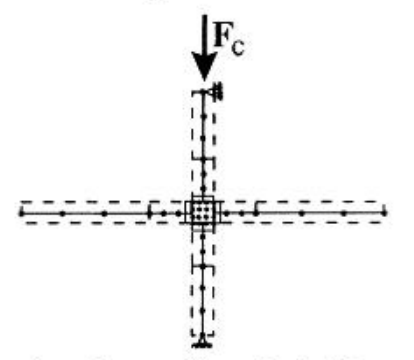

Load case C -- Axial force

Figure 8. Loading conditions A, B and C in studies by [11]

The objective was to investigate the structural weaknesses of inadequately detailed joints specifically in older frame buildings. They conducted tests on such poorly detailed beam-column joints, which were basically designed to support gravitational loads with the aim of assessing their performance under seismic conditions. With the aid of FE analysis software (MASA), which was able to model and analyze quasi-brittle materials for example, concrete in $3 \mathrm{D}$, the authors carried out numerical studies to meet their objectives. They investigated different parameters such as variations in axial load on the columns as well as the influence which modelling has on concrete to reinforcement bonding. The test specimens they used are summarized in Table 1.

Table 1. Properties of the test materials used by [12]

\begin{tabular}{llcccccc}
\hline \multicolumn{2}{l}{ Test Specimen } & \multicolumn{2}{c}{ TDD1 } & \multicolumn{2}{c}{ TDP2 } & \multicolumn{2}{c}{ THR3 } \\
\hline Steel & Bar size & R6 & D10 & R6 & R10 & R6 & R10 \\
& Fy [MPa] & 424 & 324 & 408 & 333 & 352 & 347 \\
& Fu [MPa] & 495 & 457 & 482 & 467 & 436 & 474 \\
& Es [GPa] & 177 & 191 & 191 & 206 & 224 & 219 \\
Concrete & Fcc [MPa] & 22.9 & & 25.0 & & 26.8 & \\
& Ec [GPa] & & & 28.7 & & & \\
\hline
\end{tabular}

[12] then quantified the impacts of the parameters on beam-column joint performance and also experimented with the joint behavior under reverse cyclic by comparing the model with experimental work. Their findings are included in Graph 2, which shows the variations in axial load applied to the column in one of the specimens (TDP2) as well as Graph 3, which shows the numerical results that were compared with and without discrete bond model.

The hysteretic behavior of test specimen TDP2 was also reported by revealing the results obtained from both the numerical and experimental results and this is illustrated in Graph 4. In this result, it was deduced that the behavior was correspondent up to a top drift of $2.0 \%$ when a difference of approximately $10 \%$ in ultimate joint capacity is observed. After this $2.0 \%$ top drift (in the numerical model) degradation in strength of the beam-column connection due to slippage and buckling is pronounced. Conclusively, both experimental and numerical models confirmed the 
influence of axial load variation during cyclic push-pull tests, although the FE model overestimated initial strength and stiffness capacity of the joint. This drawback could likely be overcome by a refinement of the model.

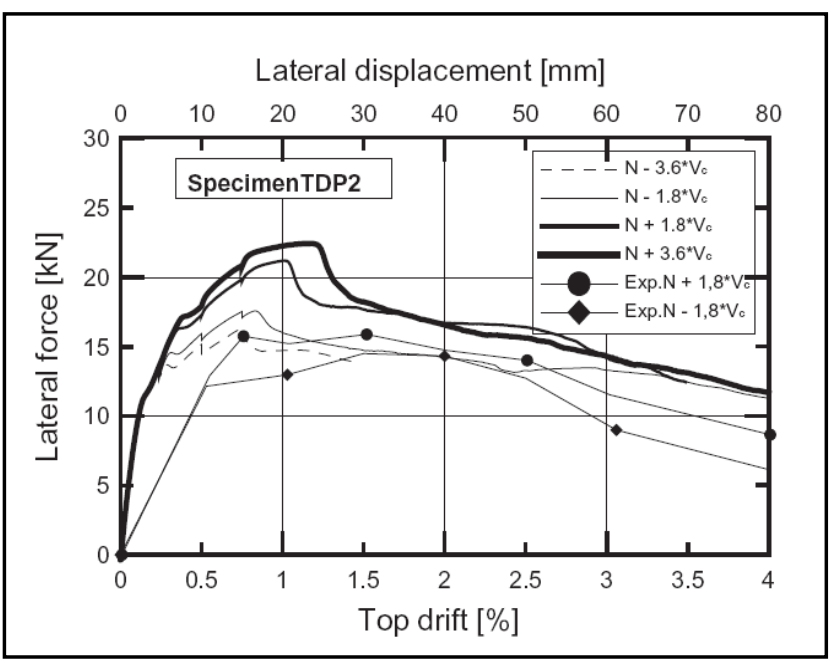

Graph 2. Variations in axial loading on columns in a specimen used by [12]

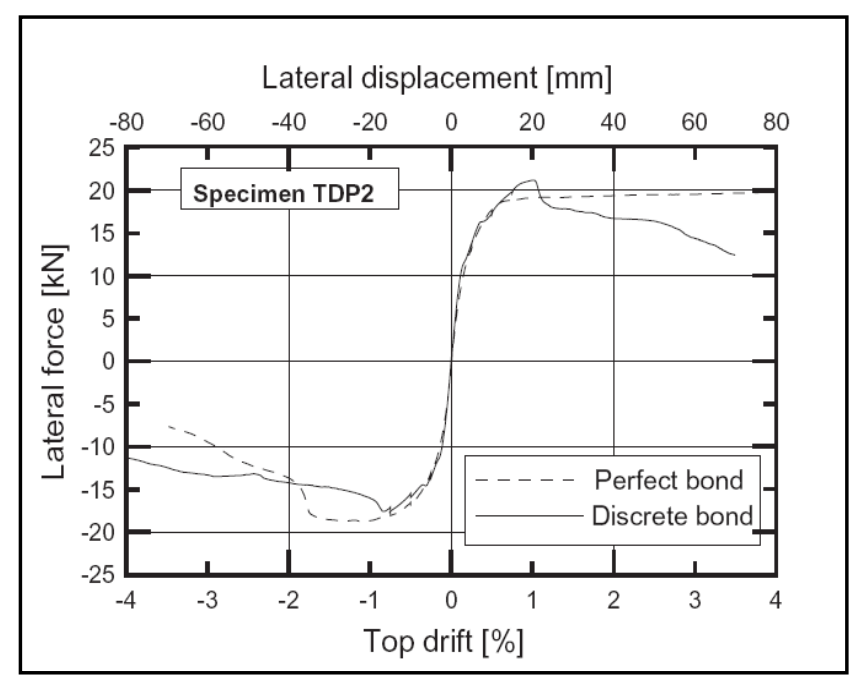

Graph 3. Numerical results with/without discrete bond model compared by [12]

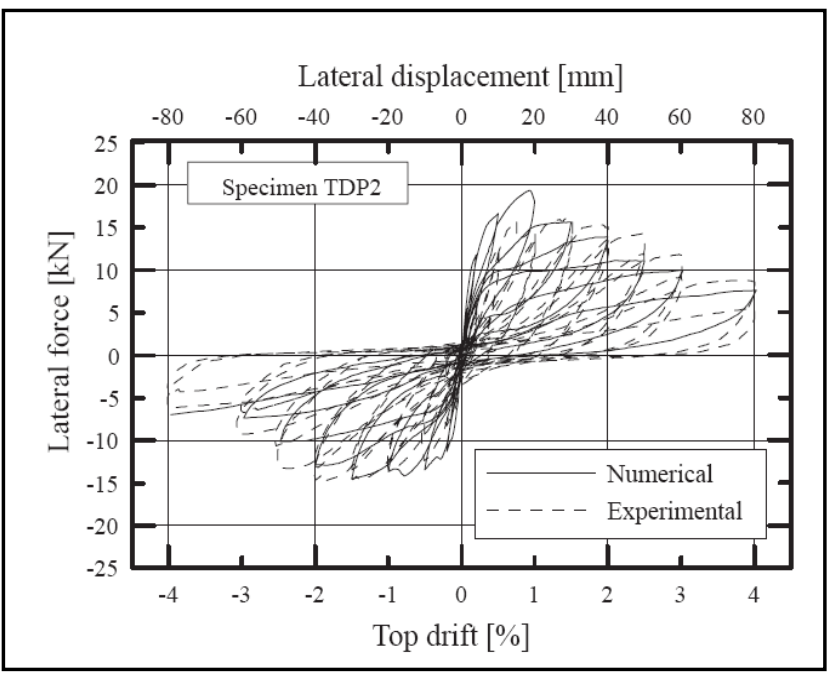

Graph 4. Hysteretic behavior of a specimen: experimental vs. numerical [12]

\subsection{Seismic Studies on Fiber-reinforced Plastic (FRP) Joints}

This section overviews seismic studies on FRP joints by focusing on its use through jacketing and near surface mounted (NSM) rods of beam-column joints as well as applications on interior and exterior joints.

\subsubsection{FRP Jacketing and Near-surface Mounted (NSM) Rods}

[13] and [20] investigated the impact of FRP reinforcement on the behavior of beam-column joints, the mechanisms of failure as well as the ductility of such joints. They used experimental models to demonstrate that by targeted strengthening of joints, a strength hierarchy number could be established. The hierarchy begins from column failure (lowest level) with a 'virgin joint'; and subsequently the first upgrade with FRP goes to the failure panel, and with more strengthening goes to the beam. The authors sought to use their findings to produce design guidelines for different circumstances allowing engineers to increase the structural performance of existing structures with the aid of technology in an economical way. Three loading applications were made using specimens modelled specifically for these studies including an axial column loading, gravity beam loading and reversed loading cycles.

A total of 12 experimental tests were done which were planned in two series of six specimens each. In all instances, the same axial load was applied on columns but there were differences among the series regarding the extent of upgrading that would define steps in the hierarchy described earlier. The first specimen comprises of the 'virgin joint' named as either 1a or $2 \mathrm{a}$, which modelled elements not having seismic provisions in their design. The remaining five specimens then had upgrades of FRP reinforcement in a systematic way. Two specimens had wrappings (1b or $2 b$ ) and wrapping in combination with near surface mounted (NSM) rods in the column (1c or $2 \mathrm{c})$. In others, columns and panels are both strengthened (with sheets for $1 \mathrm{~d}$ or $2 \mathrm{~d}$ ) as well as sheets and rods (1e and 2e). The final specimens had beam wrappings in addition to the strengthened columns and panels (1f or $2 \mathrm{f}$ ). Table 2 summarizes this programme of test specimens and their characteristics. Figure 9 shows the typical specimen being (a) prepared for and (b) after casting.

In the first application, the specimen had a prefixed load (P) applied on the column during which beam ends were kept free to enable minor transverse displacements. In the second application, when axial loads have attained a specific value and are constant, beam loading is enabled with two equal shear forces applied to beam ends in order to simulate gravitational loading. In the third instance, earthquake simulation commences and when the beam shear forces become unequal at each end, shear forces and flexural moment are created in the column for equilibrium to take place.

Results obtained by [13] supported the combination of FRP jacketing and FRP rods which are near surface mounted (NSM) for retrofitting purposes. With the possibility of modifying either the strength or ductility of such joints using jacketing or NSM rods, the retrofitting can be designed to produce a more desirable collapse if it occurs in the upgraded frame structure. Average 
displacement recorded for the virgin joints and upgraded joints are shown in Graph 5; while results of column moment-sheet strain at different locations are demonstrated in Graph 6.

Table 2. Summary of the experimental program used by [13]

\begin{tabular}{|c|c|c|c|c|c|c|c|c|c|c|c|c|c|c|}
\hline \multirow[b]{2}{*}{ SET } & \multirow[b]{2}{*}{ Spec. } & \multicolumn{5}{|c|}{ Column } & \multicolumn{4}{|c|}{ Panel } & \multicolumn{4}{|l|}{ Beam } \\
\hline & & $\begin{array}{l}\text { Axial load } \\
\text { Kips }\end{array}$ & $\begin{array}{l}\text { C } \\
\text { in. }\end{array}$ & $\begin{array}{l}\text { Acol } \\
\text { bars }\end{array}$ & $\begin{array}{l}\mathrm{s} \\
\text { in. }\end{array}$ & $\begin{array}{c}\text { FRP sheet s } \\
\text { layers }\end{array}$ & $\begin{array}{l}\text { FRP NSMr } \\
\text { rods number }\end{array}$ & upgraded by & $\begin{array}{l}\mathrm{C} \\
\text { in. }\end{array}$ & $\begin{array}{l}\text { D } \\
\text { in. }\end{array}$ & $\begin{array}{l}\text { As } \\
\text { rods }\end{array}$ & $\begin{array}{l}\text { As' } \\
\text { rods }\end{array}$ & $\begin{array}{l}\text { s' } \\
\text { in. }\end{array}$ & $\begin{array}{c}\text { FRP sheet } \mathrm{s} \\
\text { layers }\end{array}$ \\
\hline \multirow{5}{*}{1} & 1.a & 56 & 8 & $2-\# 5$ & 8 & 0 & 0 & - & 8 & 14 & $3-\# 7$ & $2-\# 6$ & 4 & 0 \\
\hline & $1 . b$ & 56 & 8 & $2-\# 5$ & 8 & 2 & 0 & - & 8 & 14 & $3-\# 7$ & $2-\# 6$ & 4 & 0 \\
\hline & 1.c & 56 & 8 & $2-\# 5$ & 8 & 2 & $8-\# 3$ & - & 8 & 14 & $3-\# 7$ & $2-\# 6$ & 4 & 0 \\
\hline & 1.d & 56 & 8 & $2-\# 5$ & 8 & 2 & $8-\# 3$ & sheets & 8 & 14 & $3-\# 7$ & $2-\# 6$ & 4 & 0 \\
\hline & 1.e & 56 & 8 & $2-\# 5$ & 8 & 2 & 8 -\#3 & sh.+NSMr & 8 & 14 & $3-\# 7$ & $2-\# 6$ & 4 & 0 \\
\hline \multirow{7}{*}{2} & 1.f & 56 & 8 & $2-\# 5$ & 8 & 2 & $8-\# 3$ & sh.+NSMr & 8 & 14 & $3-\# 7$ & $2-\# 6$ & 4 & 2 \\
\hline & 2.a & 28 & 8 & $2-\# 5$ & 8 & 0 & 0 & - & 8 & 14 & $3-\# 7$ & $2-\# 6$ & 4 & 0 \\
\hline & $2 . b$ & 28 & 8 & $2-\# 5$ & 8 & 2 & 0 & - & 8 & 14 & $3-\# 7$ & $2-\# 6$ & 4 & 0 \\
\hline & 2.c & 28 & 8 & $2-\# 5$ & 8 & 2 & $8-\# 3$ & - & 8 & 14 & $3-\# 7$ & $2-\# 6$ & 4 & 0 \\
\hline & 2.d & 28 & 8 & $2-\# 5$ & 8 & 2 & $8-\# 3$ & sheets & 8 & 14 & $3-\# 7$ & $2-\# 6$ & 4 & 0 \\
\hline & 2.e & 28 & 8 & $2-\# 5$ & 8 & 2 & 8 -\#3 & sh.+NSMr & 8 & 14 & $3-\# 7$ & $2-\# 6$ & 4 & 0 \\
\hline & 2.f & 28 & 8 & $2-\# 5$ & 8 & 2 & $8-\# 3$ & sh.+NSMr & 8 & 14 & $3-\# 7$ & $2-\# 6$ & 4 & 2 \\
\hline
\end{tabular}

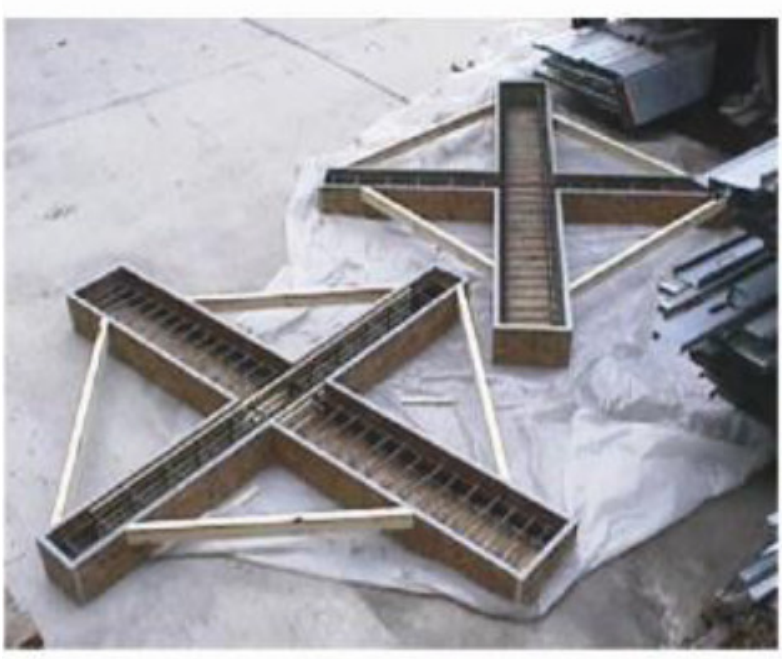

(a)

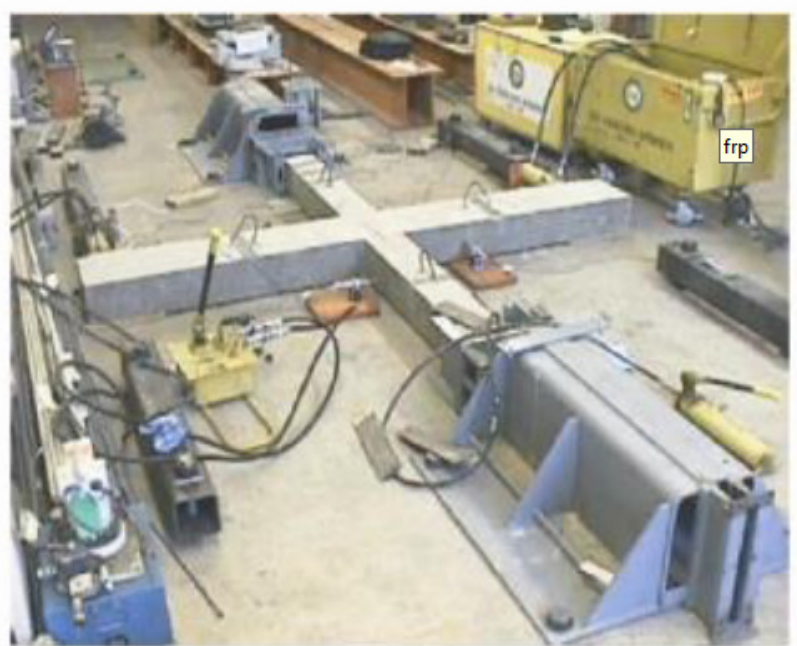

(b)

Figure 9. Specimens being (a) prepared for and (b) after casting by [13]

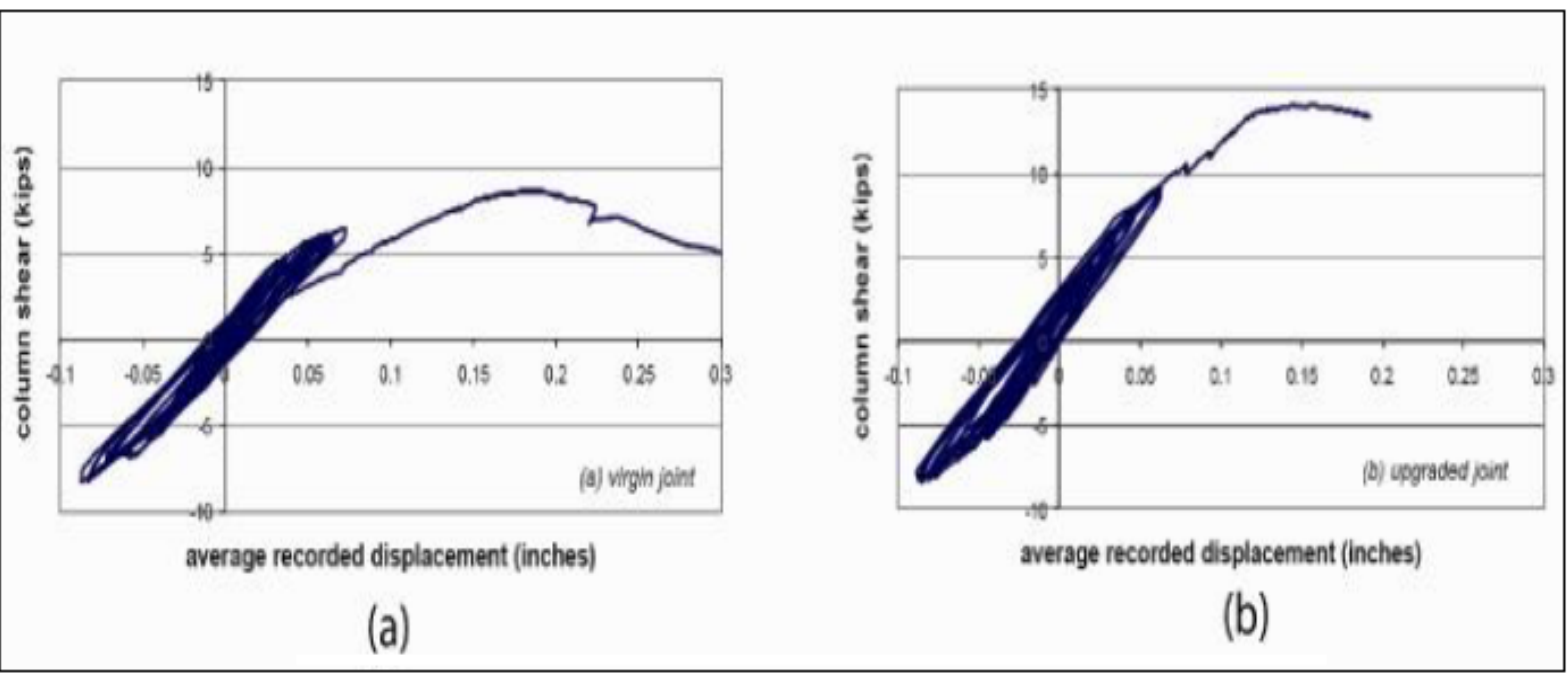

Graph 5. Average displacement recorded for (a) virgin joints and (b) upgraded joints 

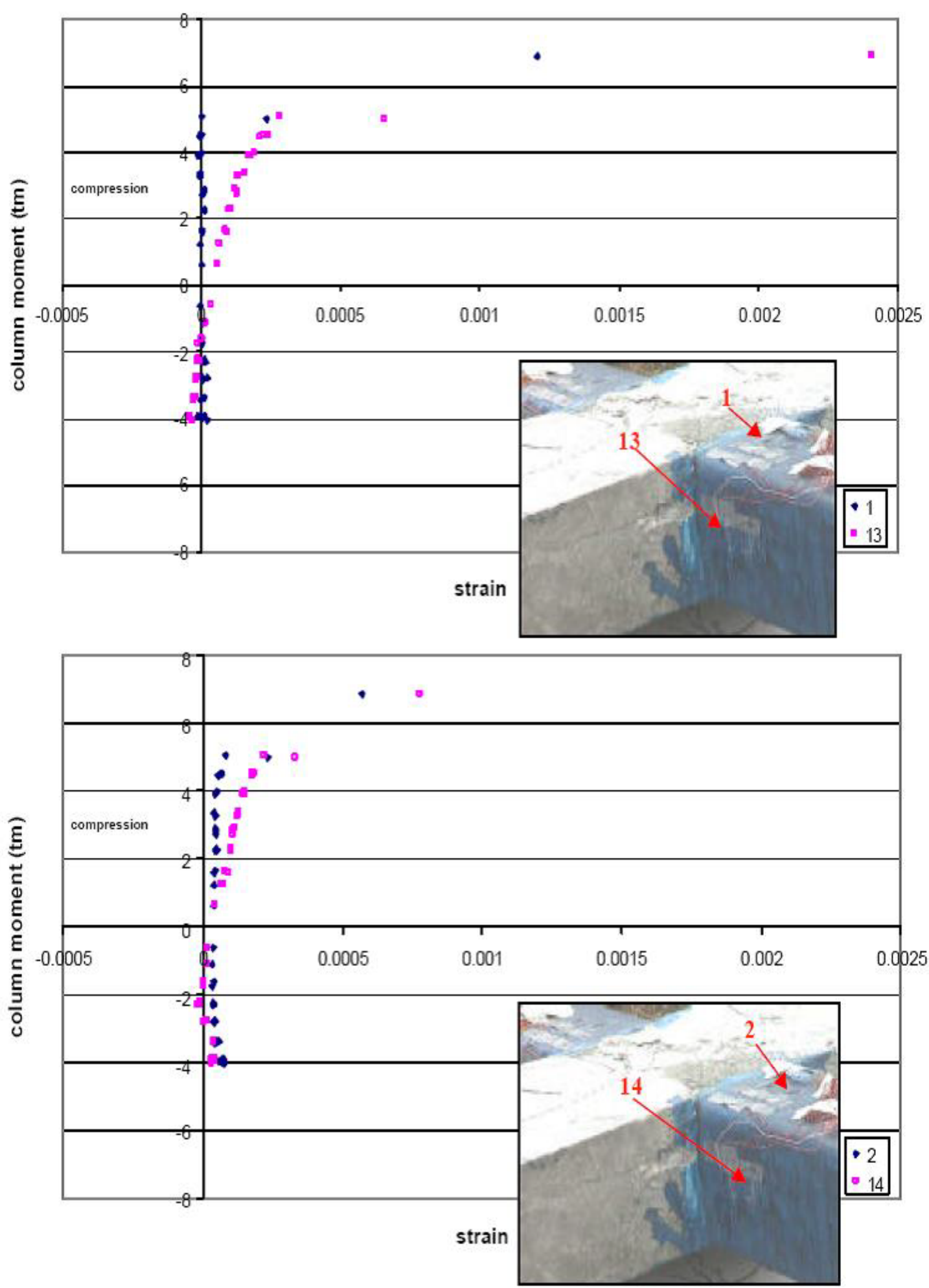

Graph 6. Results of column moment-sheet strain at different locations by [13]

\subsubsection{FRP on Interior Joints}

[15] embarked on experimental work to evaluate the seismic performance of as-built RC joint connections and then to further compare this performance with carbon fiber-reinforced polymers (CFRPs). The CFRP performance was sought for two scenarios: when it is used for repair such as, CFRP-repaired of joints and when the CFRP is used for the strengthening of joints. Specimens were prepared for these studies and they are described in
Figure 10, which shows the initial reinforcement details. Among these specimens there were two control specimens (IC1 and IC2), two repaired specimens (IR1 and IR2) and two strengthened specimens (IS1 and IS2). These gave rise to two schemes (Figure 11) in which scheme 1 had CFRP sheets bonded with epoxy to the beams, joints and some parts of the column. In scheme 2, the CFRP sheets were only attached to the joint areas but had extra preventive measures through anchorages to eliminate debonding. 


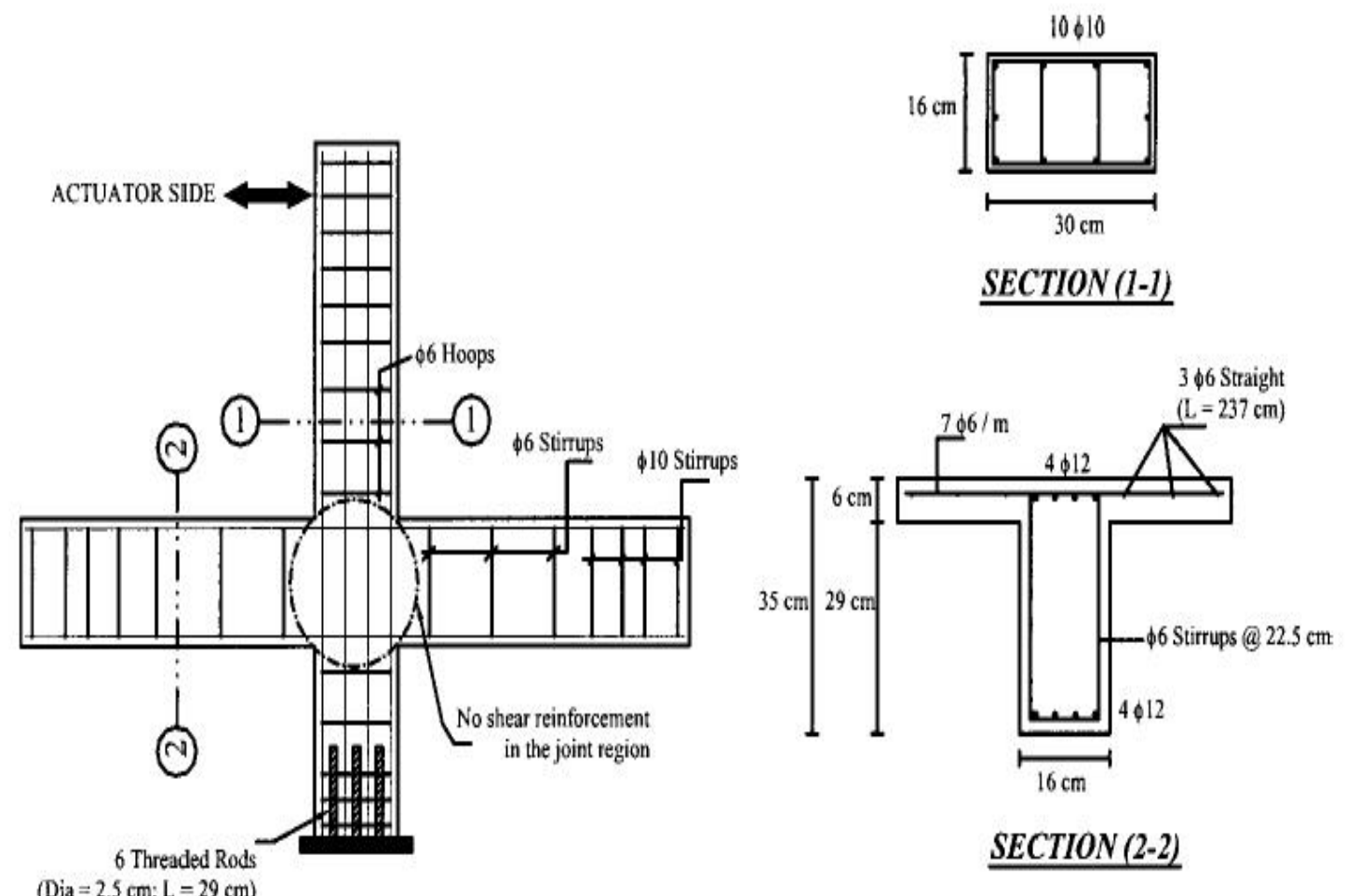

Figure 10. Initial specimen reinforcement details
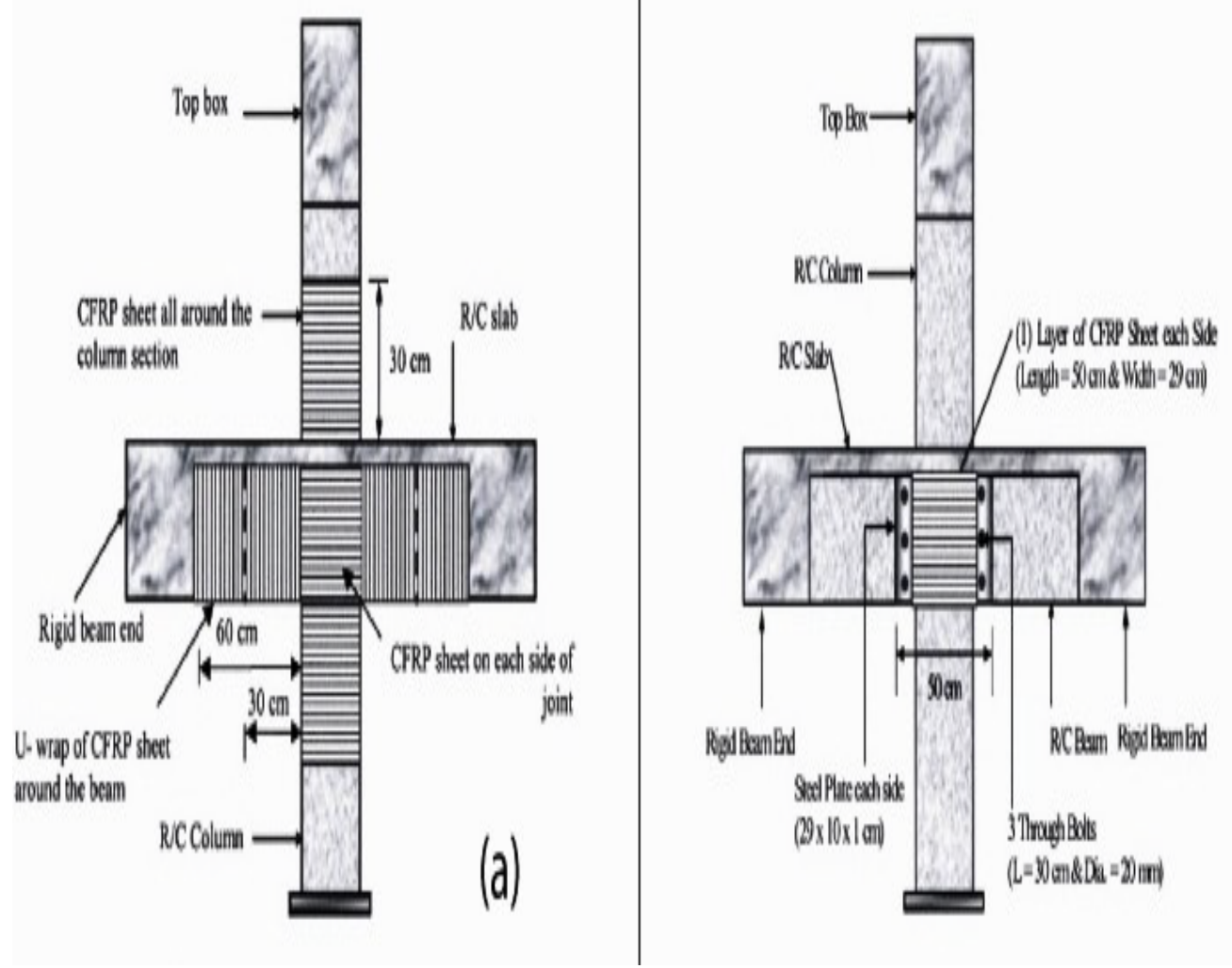

(b)

Figure 11. Scheme 1 and 2 for CFRP joints by [14] and [15]

The tests consisted of simulating seismic loading in a cyclic manner on the specimens using a $500 \mathrm{KN}$ servo-controlled hydraulic actuator. This actuator was connected to a reaction steel frame that stood on a rigid concrete floor and is schematically described in Figure 12.

The displacement relationships for loads in the control, strengthened and repaired specimens are revealed in Graph 7 where the hysteretic behavior is shown as curves. 


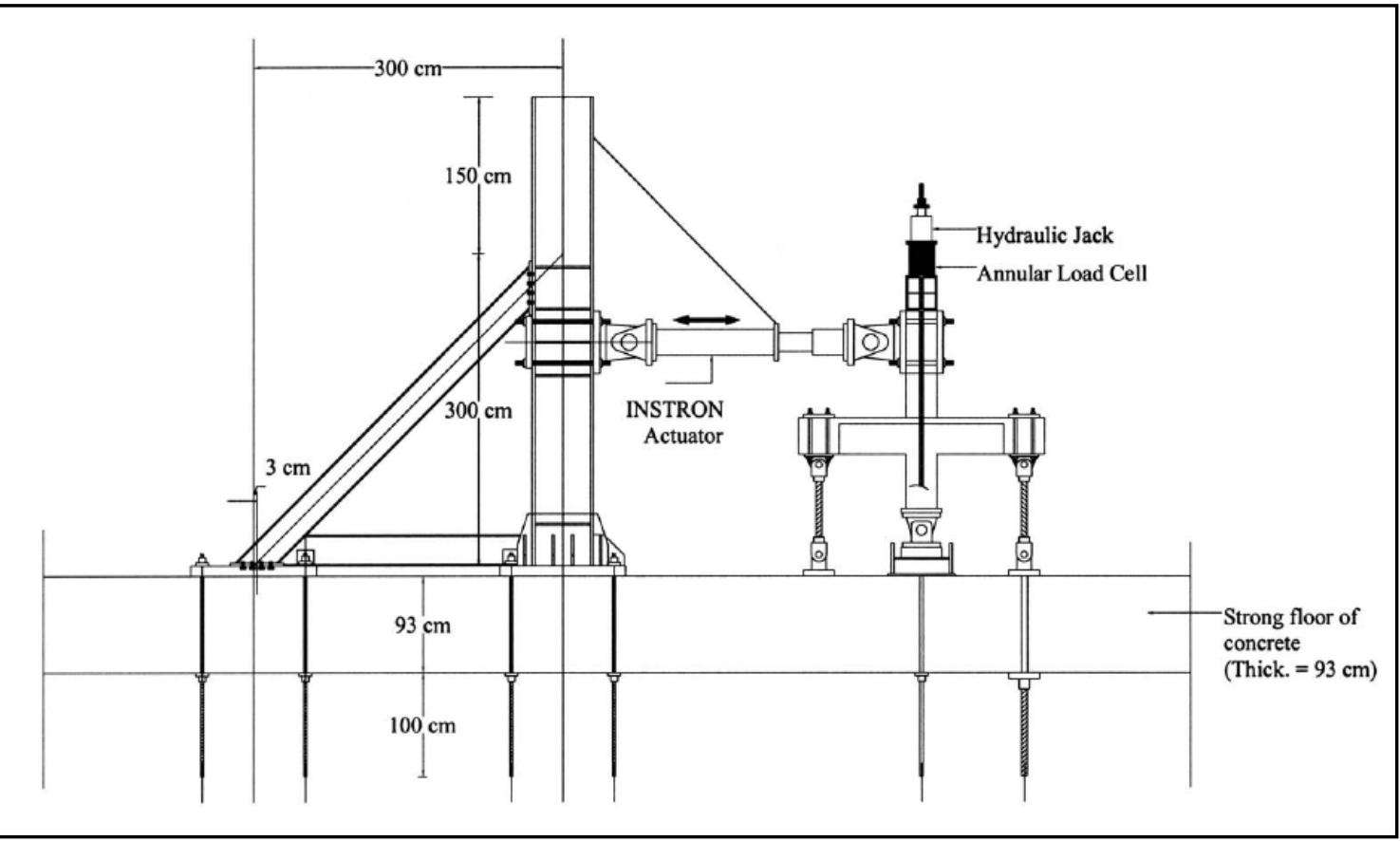

Figure 12. Schematics of the test set-up used by [14] and [15]

(a)

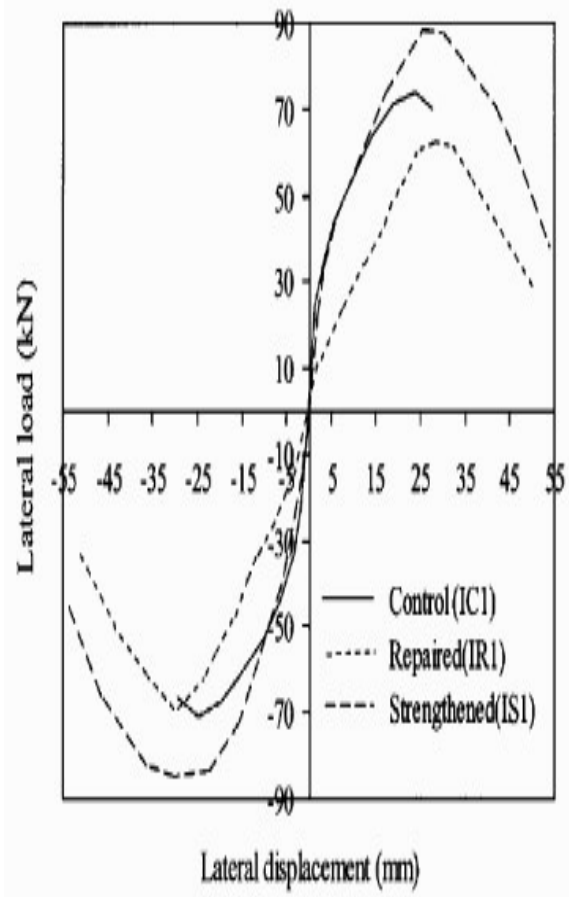

(b)

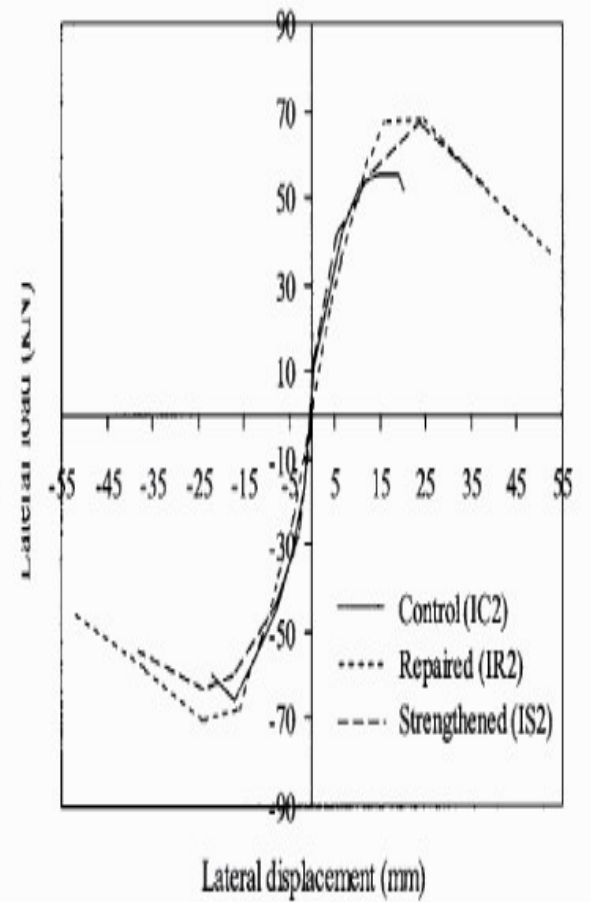

Graph 7. Hysteretic loops for (a) scheme 1 and (b) scheme 2 specimens by $[14,15]$

Results from these tests by $[14,15]$ show that CFRP when externally bonded to joints can improve the ductility and shear strengths. The extent of effectiveness is a factor of the way the sheets are bonded to the joint as well as the presence of mechanical anchors. Scheme 1 was considered efficient because of its impact on both joint and beam, but de-bonding took place as a result of lack of anchorage at higher loading. Scheme 2 was more economical for joint strengthening and any failures were attributed to the beams.

As a follow up on this investigation the authors $[14,15,16]$ also presented an analytical prediction procedure for joint shear strength with regards to interior beam-columns that were bonded externally with CFRP sheets. The results obtained when compared to the experimental work were found to be in harmony. These added validity to the mathematical models utilized. Additionally, the formulations were also applied to computation of tensile diagonal stresses, within both the control and the FRP-strengthened joints. It was deduced that as the amount of FRP increased, there was a subsequent increase in confinement as well; which then led to an increase in the shear strength of such joints. On the other hand, there is a limit, after that it leads to brittle joints. 


\subsubsection{FRP on Exterior Joints}

Further to the work of $[14,15,16]$ on interior beam-column joints, Alsayed et al. (2010) also used laboratory tests on physical models to explore the seismic response of fibre-reinforced plastic (FRP)-upgraded exterior RC beam-column joints. Their specific research objective was to investigate the efficiency and effectiveness of CFRPs for improving the ductility and shear strength of exterior beam-column joints that are seismically deficient. Details of the properties of their laboratory specimens are demonstrated in Table 3 below.

Table 3. Properties of specimen used by Alsayed, et al. (2010)

\begin{tabular}{ll}
\hline Parameter & Properties \\
\hline Concrete and steel & 30 \\
Concrete strength, f'c (MPa) & 420 \\
Yield strength of steel, fy $(\mathrm{MPa})$ & \\
CFRP composite system & Unidirectional \\
Type of FRP & CFRP sheet \\
& $61.5 \mathrm{X} 10^{3} \mathrm{MPa}$ \\
Elastic modulus in primary fibers direction & $34.5 \mathrm{MPa}$ \\
Elastic modulus of CFRP 90 to primary fibers & $1.2 \%$ \\
Fracture strain & $1.0 \mathrm{~mm}$ \\
Thickness, tf & $2.51 \mathrm{X} 10^{3} \mathrm{MPa}$ \\
Shear modulus & 0.25 \\
Poisson's ration & \\
\hline
\end{tabular}

Alsayed et al. (2010) had four as-built joints created using non-optimal design parameters. Specifically they had inadequate shear strength of joints without any transverse reinforcement, which represented pre-seismic code design/construction procedures. Two of the model joints were left as baseline specimens (control) while the others were sheathed with the CFRP using epoxy to represent two major strengthening schemes. The details of the specimen reinforcement used by the authors are shown in Figure 13 while a schematic of the exterior joint is revealed in Figure 14.

A schematic representation of CFRP joints by the authors is shown in Figure 15a (scheme 1) and 15b (scheme 2). These images explain the different approaches and extent of cover provided by the CFRP sheets as they were applied to the beam-column joints.

The testing apparatus and conditions are similar to those used previously by $[14,15,16]$. Eventually, Alsayed et al. (2010) concluded that CFRP sheets that were externally bonded could improve the deformation capacity and shear strength of beam-column joints. As part of their results, they found that in scheme 1 when CFRP sheets were bonded with epoxy to beams, joints and part of the columns, the efficiency was increased due to impact on both joint and beam. Although without mechanical anchorage, when high loading occurred, de-bonding (bulging) of such externally bonded sheets took place leading to cracks, which widened under the fiber sheets. In addition, they found that in scheme 2 when the sheets were bonded with epoxy to the joint region only, this presented a more economical and effective option for strengthening of joints. In this case, however, the CFRP sheets were fixed such that the de-bonding that took place in scheme 1 did not occur. Further interesting reading on modelling of exterior beam-column joints for seismic analysis include [21] who incorporated rotational spring elements in a programme for analysis of nonlinear static and dynamic loads. [17] also studied seismic behavior of $\mathrm{RC}$ beam-column joints by applying simulated earthquake loads to laboratory specimens through quasi-static load reversals. Their results were used in the validation of $3 \mathrm{D}$ nonlinear FE models and other benefits came from findings about the effects of seismic loads on transverse beams.

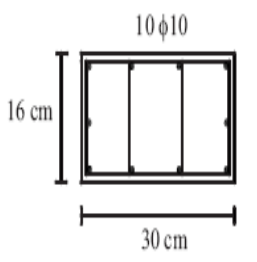

\section{$\underline{\operatorname{SECTION}(1-1)}$}

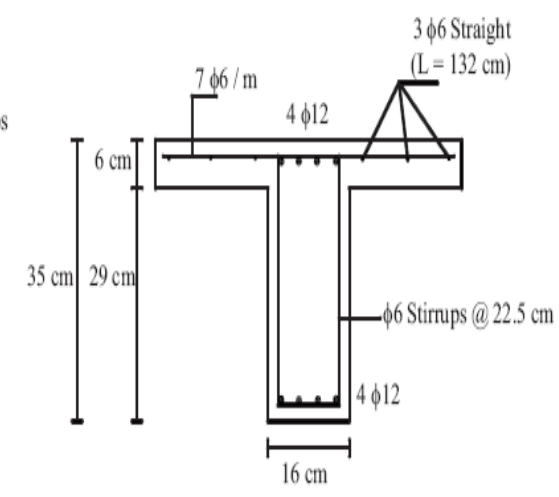

$\operatorname{SECTION(2-2)}$ 


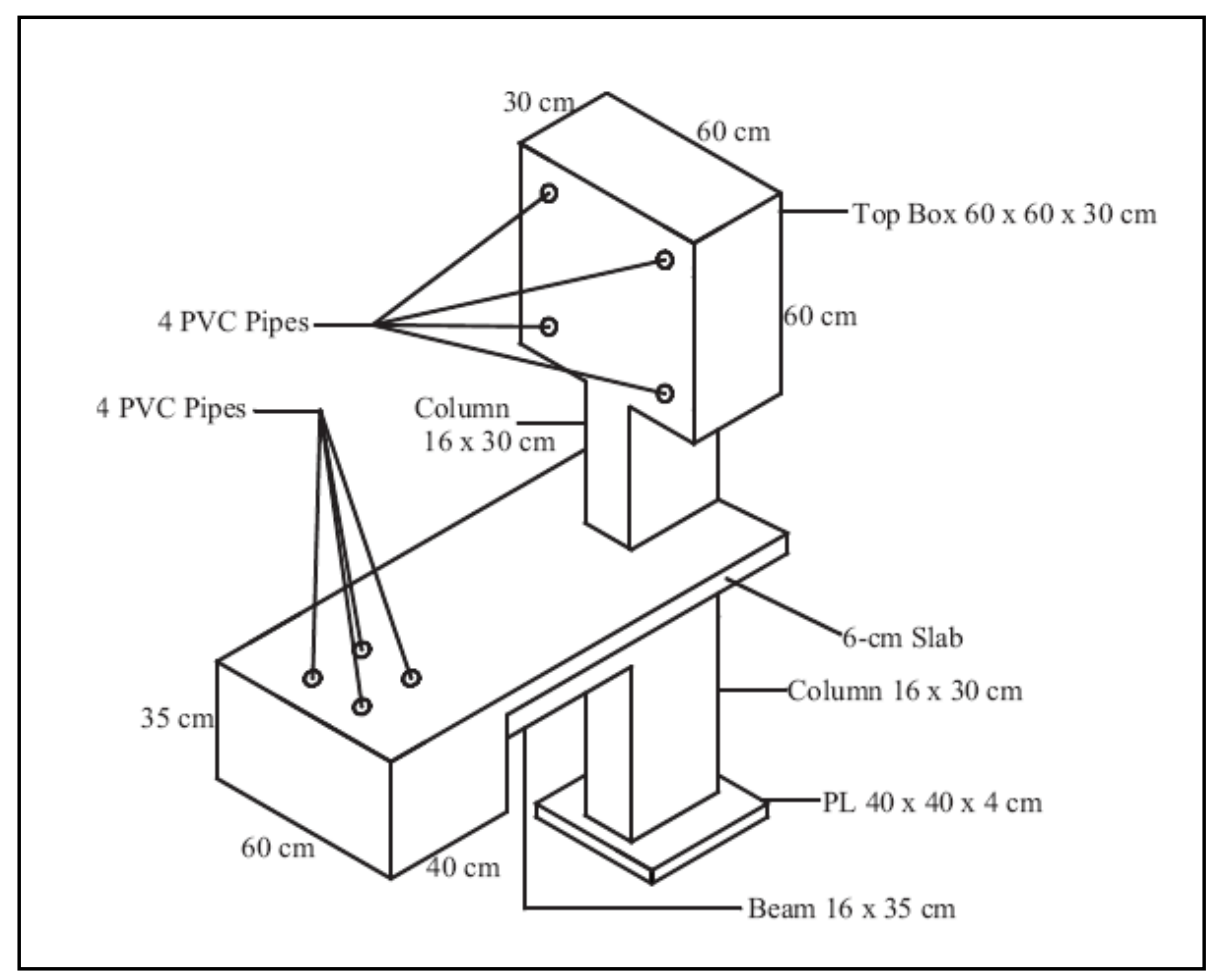

Figure 14. A schematic of the exterior joint constructed by Alsayed et al. (2010)
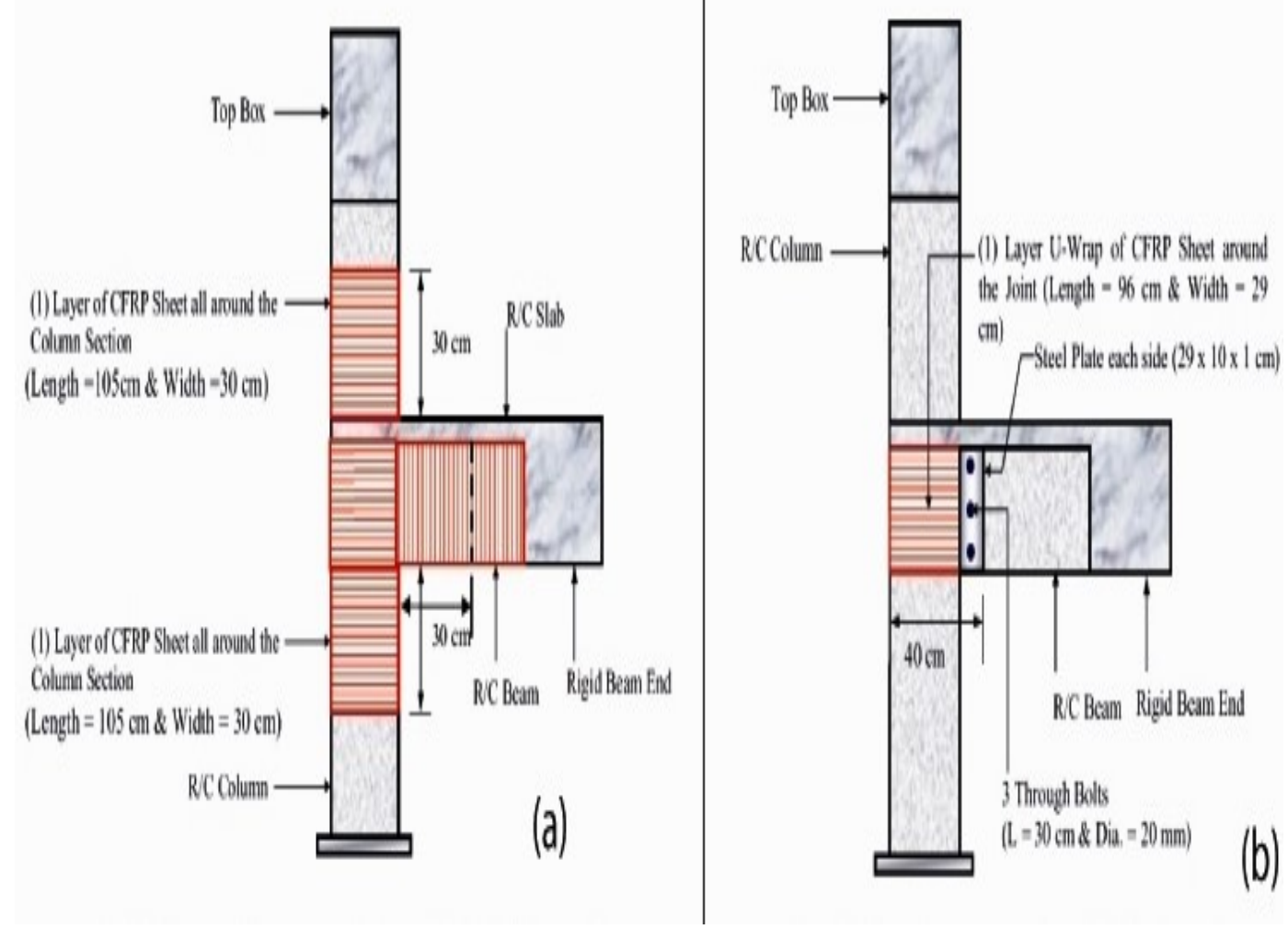

Figure 15. Schematic of CFRP joints for (a) scheme 1 and (b) scheme 2 by Alsayed et al. (2010)

\subsection{Predicting Shear Failure}

[22] proposed a technique for predicting shear failure in the ductile capacity of RC beam-column joints sequel to the development of plastic hinges at the extremes of adjacent beams. Their review of the degradation of shear strength in joints is summarized through the longitudinal strain distribution, strength reduction of concrete structure and the concrete shear contribution $(\mathrm{Vc})$ including effective compressive strength of concrete (Vf' $\mathrm{c}$ ) - deflection $(\Delta)$ relations are shown in Figure 16. Subsequently, they developed a prediction method for shear failure. 


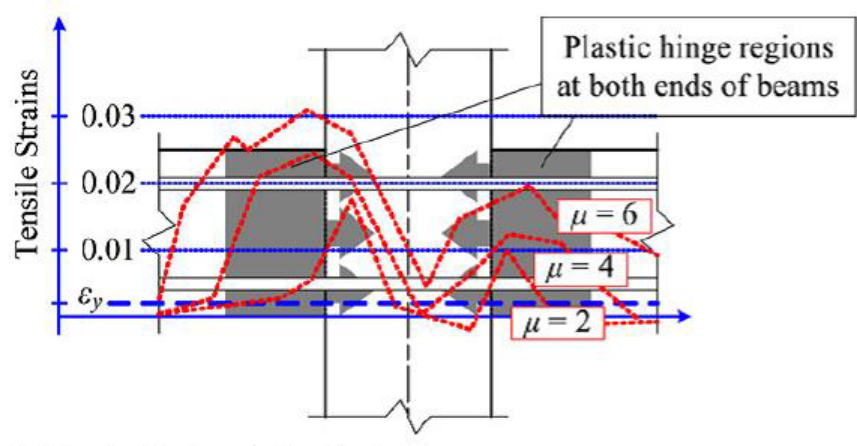

(a) Longitudinal strain distribution.

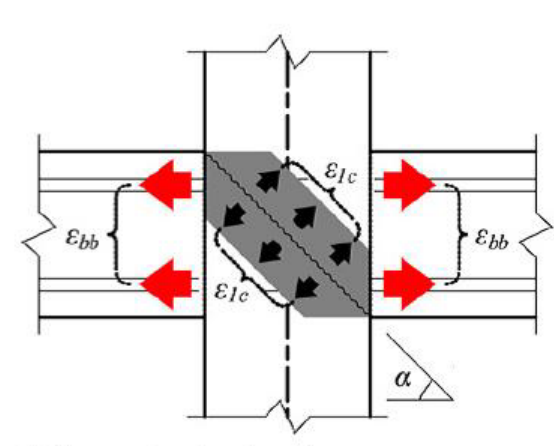

(b) Strength reduction of concrete strut.

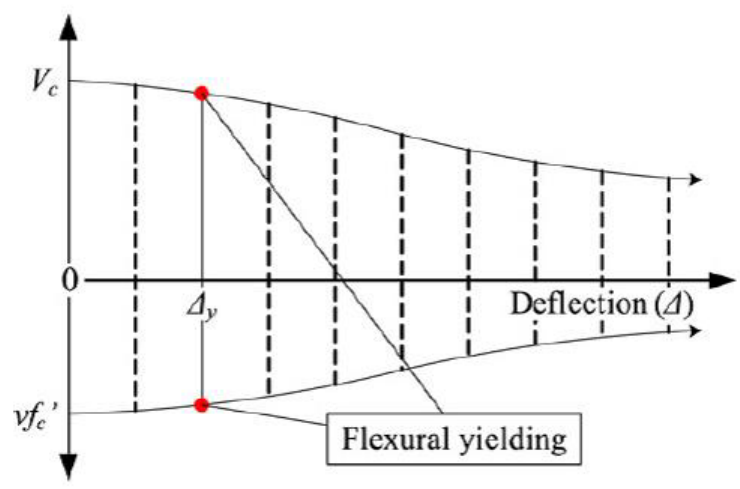

(c) Concrete shear contribution $\left(V_{c}\right)$ and effective compressive strength of concrete $\left(v f_{c}^{\prime}\right)$ - deflection $(\Delta)$ relation.

Figure 16. Shear strength reduction in joints by [22]

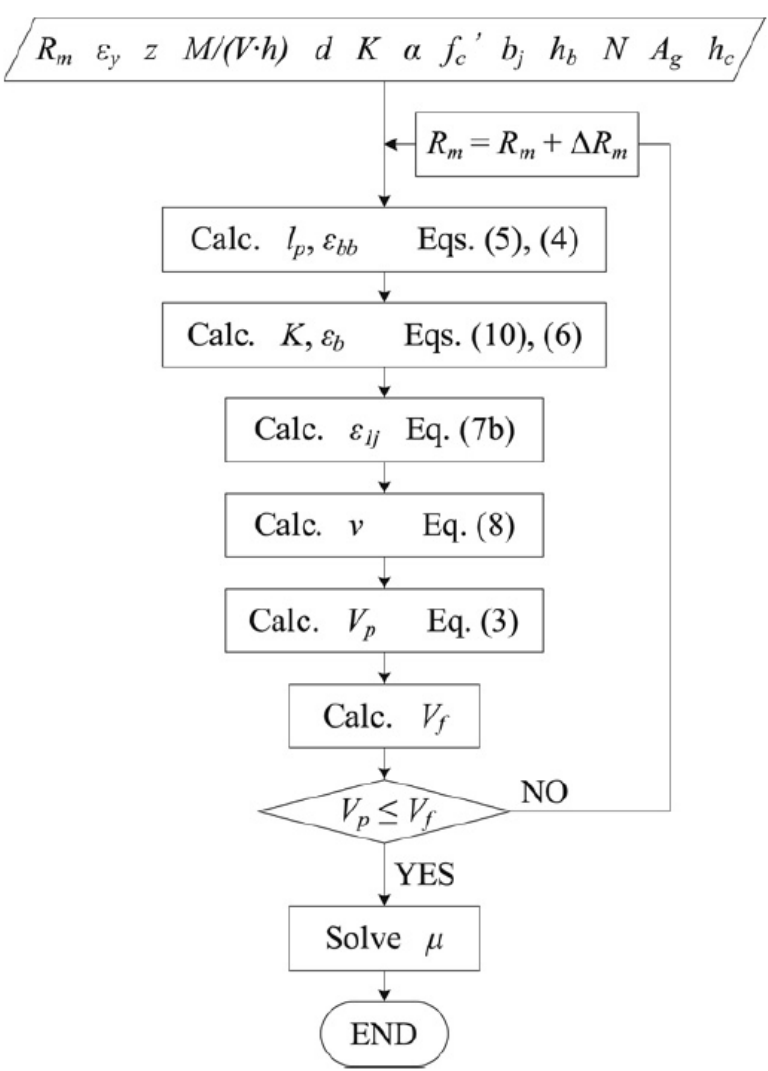

Figure 17. Iterative step-by-step process for ductility of Type 2 joints

The deformability prediction method that was developed by [22] utilizes degradation of concrete, which is diagonally compressed due to strain penetration of the reinforcement beam. The algorithm for this process is represented in Figure 17. This method incorporates the impact of longitudinal axial strain of beams in the region of a plastic hinge on joints as well as the longitudinal strain/strength deterioration of the joint. In developing this prediction model, they carried out studies on five specimens as revealed in Table 4 . The five specimens of the test programme were $\mathrm{RC}$ interior beam-column joints introduced as $\mathrm{J} 1, \mathrm{BJ} 1, \mathrm{BJ} 2, \mathrm{BJ} 3$, and $\mathrm{B} 1$.

In the loading set up, the specimens were held in vertical positions while servo-controlled hydraulic actuators were used to apply quasi-static cyclic lateral load from the top of the column. At the bottom of the columns, beam ends were held by mechanical hinges and to further prevent movement out-of-plane, four rollers were situated within the set up.

The results obtained included cracking patterns in each of the joint specimen and is illustrated in Figure 18 (a to e) above. The variation in the amount of beam bars was shown to have led to significant differences in failure modes among the specimens. In $\mathrm{J} 1$ for example, there was shear failure before flexural yielding took place. For specimens BJ1, BJ2 and $\mathrm{BJ} 3$ failure was observed to have occurred after yielding of the beam bars. It was also observed that while the quantity of beam bars decreased, so did damage to the joints except in the plastic hinge areas in adjacent beams, where the damaged actually increased. With these results, the authors came up with three kinds of predictions. These are:

- Prediction of deformability

- Prediction of axial strain in the beam direction

- Prediction of strain in the diagonal direction 
Table 4. Properties of specimen used by [22]

\begin{tabular}{|c|c|c|c|c|c|c|c|c|c|c|c|c|c|c|c|c|c|c|c|}
\hline \multirow[t]{3}{*}{ Specimens } & \multirow{2}{*}{$\begin{array}{c}\text { Beam } \\
\text { Reinforcing bar } \\
\text { (Upper and lower each) }\end{array}$} & \multicolumn{12}{|c|}{ Column } & \multirow{3}{*}{$\begin{array}{c}\text { F'c } \\
(\mathrm{MPa})\end{array}$} & \multirow{3}{*}{$\begin{array}{c}\mathrm{Vjl} \\
(\mathrm{kN})\end{array}$} & \multirow{3}{*}{$\begin{array}{l}\mathrm{Vj} 2 \\
(\mathrm{kN})\end{array}$} & \multirow{3}{*}{$\begin{array}{l}\text { Vjby } \\
(\mathrm{kN})\end{array}$} & \multirow{3}{*}{$\mathrm{Vj} 1 / \mathrm{Vj} 2$} & \multirow{3}{*}{$\mathrm{Vj} 2 / \mathrm{Vjby}$} \\
\hline & & & & Stirrup & & & & Reinforcing bar & & & Hoop & & & & & & & & \\
\hline & $f_{\text {by }}$ & $\mathrm{Pb}_{\mathrm{u}}{ }^{\prime}$ & $\mathrm{N}_{\mathrm{b}}$ & $\mathrm{f}_{\mathrm{sy}}$ & $\mathrm{P}_{\mathrm{s}}$ & $\mathrm{S}_{\mathrm{b}}$ & $\mathrm{N}_{\mathrm{s}}$ & $\mathrm{F}_{\mathrm{cy}}$ & $\mathrm{P}_{\mathrm{c}}$ & $\mathrm{N}_{\mathrm{c}}$ & Fhy & $\mathrm{Ph}$ & $\mathrm{Sh} \mathrm{Nh}$ & & & & & & \\
\hline $\mathrm{J} 1$ & 509.9 & 0.0116 & 10-D16 & 510.4 & 0.0048 & 100 & D10 & 514.4 & 0.0629 & $12-\mathrm{D} 29$ & 510.4 & 0.0081 & $50 \mathrm{D} 10$ & 40 & 1194 & 896 & 1231 & 0.97 & 0.73 \\
\hline BJ1 & 509.9 & 0.0099 & 6-D16 & 510.4 & 0.0048 & 100 & D10 & 514.4 & 0.0629 & $12-\mathrm{D} 29$ & 510.4 & 0.0081 & $50 \mathrm{D} 10$ & 40 & 1194 & 896 & 802 & 1.49 & 1.12 \\
\hline $\mathrm{BJ} 2$ & 509.9 & 0.0083 & $5-\mathrm{D} 16$ & 510.4 & 0.0024 & 200 & D10 & 514.4 & 0.0629 & $12-\mathrm{D} 29$ & 510.4 & 0.0054 & 75 D10 & 40 & 1194 & 896 & 614 & 1.95 & 1.46 \\
\hline BJ3 & 509.9 & 0.0066 & 4-D16 & 510.4 & 0.0024 & 200 & D10 & 514.4 & 0.0629 & 12-D29 & 510.4 & 0.0054 & $75 \mathrm{D} 10$ & 40 & 1194 & 896 & 500 & 2.39 & 1.79 \\
\hline B1 & 509.9 & 0.0050 & 3-D16 & 510.4 & 0.0024 & 200 & D10 & 514.4 & 0.0629 & 12-D29 & 510.4 & 0.0054 & $75 \mathrm{D} 10$ & 40 & 1194 & 896 & 382 & 3.13 & 2.35 \\
\hline
\end{tabular}

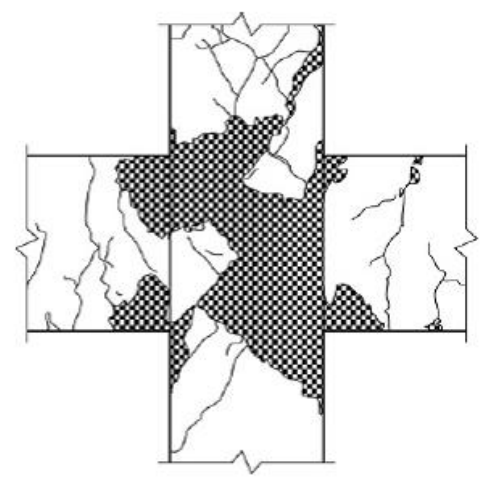

(a) $\mathrm{J} 1$

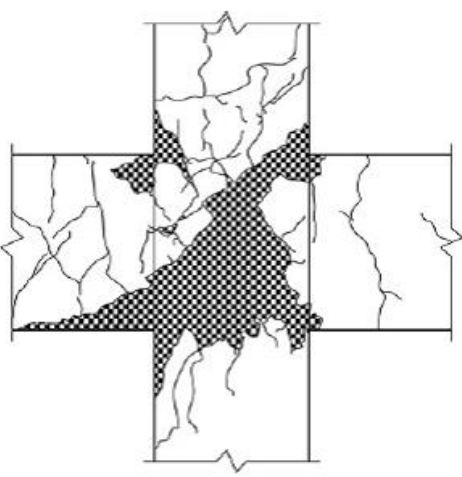

(b) BJ1

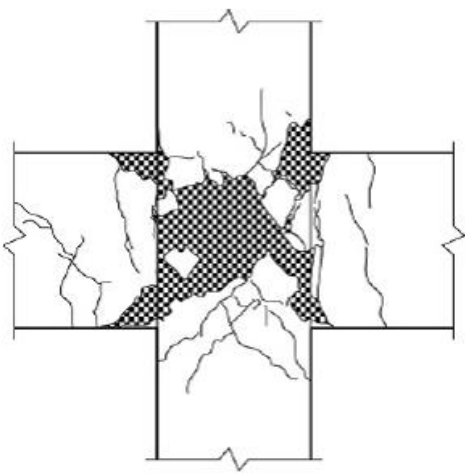

(c) $\mathrm{BJ} 2$

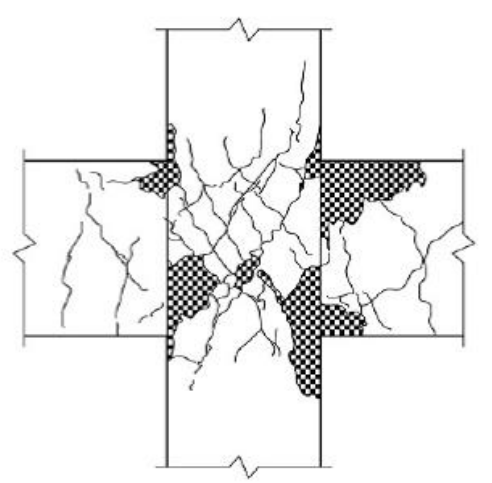

(d) $\mathrm{BJ} 3$

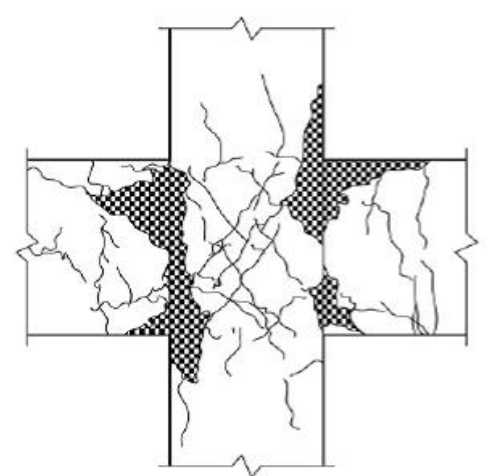

(e) $\mathrm{Bl}$

Figure 18. The pattern of crack observed by [22]

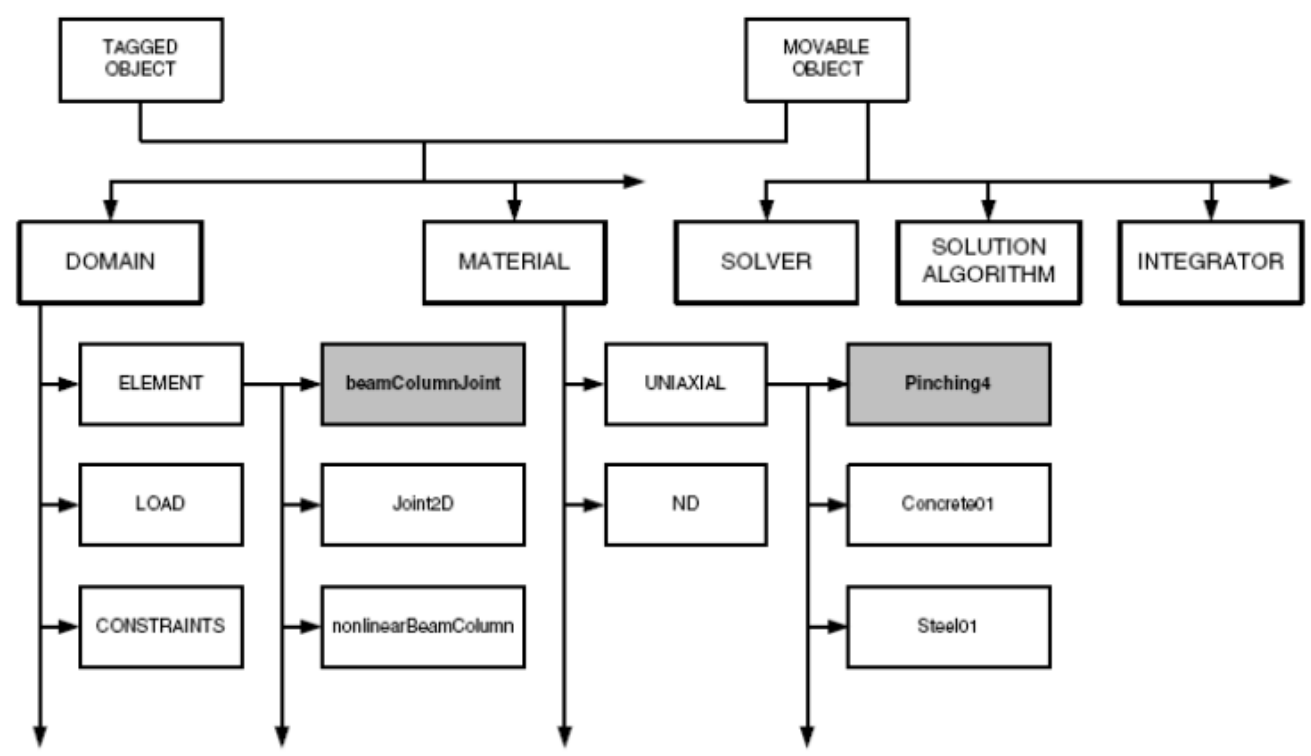

Figure 19. The Open Sees framework of class structures and the beam-column element 


\subsubsection{Open Sees Framework - An open Source Model}

As part of the OpenSees initiative, [23] developed and implemented a joint model, which was designed to be used for 2D frame analysis to predict the inelastic response of RC beam-column joints under seismic loading. There were certain characteristics, which the proposed model had to posses including: compatibility with traditional beam-column structural line elements; efficiency of computation; transparency of model parameters; objective specifications during calibration and robustness of the algorithm. The research and its role in the wider Open Sees framework is shown in Figure 19. The Open Sees is essentially an open-source, object-oriented software framework created for earthquake engineering simulations through FE methods. Within the OpenSees framework, the beam-column joint is an element that is categorized as a child of the abstract base Element class, which was introduced as the beam Column Joint class as shown in Figure 19 above. This beam-column joint element needs an internal solution to establish the internal displacement of nodes, which meet the internal equilibrium of the element. Thus, the beam Column Joint class has many methods that assist the internal solution algorithm. Essentially, the proposed model is capable of simulating inelastic responses made by most beam-column joints in $2 \mathrm{D}$ nonlinear analysis of RC frames. The mechanism used by this model can resolve inelastic beam-column behavior via combinational effects of shear-panel, interface components and bar-slip. The responses simulated with this model were also observed and found to be in agreement with basic characteristics of joints, which are under moderate shear loads.

[24] did a comparative study of current computer analysis methods for seismic performance of RC members by utilizing many analysis methods to a benchmark problem. To validate and assist with comparisons, they obtained data from experimental tests, which involved flexural and shear performance of the RC column. Furthermore, the analysis of cyclic and monotonic forces was done with a degrading plastic hinge model, a fiber beam model as well as a 3D FE model. Part of the results obtained from both experimental and numerical investigations are summarized in Table 5, which shows peak lateral forces, peak top moment and peak bottom moment.

[25] examined the seismic behavior of beam-column connections in bridges, which are made of pre-stressed concrete. Their method of research involved having four pre-stressed concrete beam-column connections being tested under an axial force of $200 \mathrm{KN}$ constantly; and then reversed cyclically for horizontal loading. Table 6 shows a summary of the material properties used in their specimens.

The four specimens were about a quarter-scale in size pre-stressed concrete beam-column connections that were isolated from the frame of a bridge. Using the rationale of a strong beam and weak column for bridge design, a plastic hinge was modelled to occur in the column, which is near to the beam. The beams and columns were designed according to the seismic standards given by AASHTO and New Zealand Codes. The specimens were tested upside down as revealed in Figure 20 and mounted with a bottom beam secured by two hinges. An actuator with a capacity of $500 \mathrm{KN}$ with an ability to displace the column $75 \mathrm{~mm}$ in positive and negative directions was employed. The specimens were all tested under forces of displacement according to a laid down history of displacement designed as column drift percentages. The displacement history is shown in Figure 21 and comprises of 22 cycles having column drifts of up to $5.36 \%$. Crack development in this study was observed and recorded carefully through marks at the peaks of each cycle of displacement. Crack patterns that appeared on all four specimens are shown in Figure 22 and it was noticed that most of the damage due to cracks appeared to be concentrated in the column near the beams, which is the region of plastic hinge. [25] concluded that both AASHTO and New Zealand Codes were adequate in terms of strength and ductility for earthquake-resistant designs. Their results also compared favorably with values obtained from theoretical studies, and included loaddisplacement relationship, ductility factor as well as moment-curvature.

Table 5. Experimental and numerical results compared by [24] for the plastic hinge model

\begin{tabular}{lccc}
\hline & Experimental value analysis & Value from present & Ratio of results \\
\hline $\begin{array}{l}\text { Peak lateral force } \\
\text { (push) kips }(\mathrm{kN})\end{array}$ & $8.10(36.0)$ & $8.45(37.6)$ & 1.04 \\
Peak top moment & $348(39.3)$ & $377(42.6)$ & 1.08 \\
$\begin{array}{l}\text { Kips in }(\mathrm{kN} \mathrm{m}) \\
\text { Peak bottom moment } \\
\text { Kips in }(\mathrm{kN} \mathrm{m})\end{array}$ & $326(36.8)$ & $379(42.8)$ & 1.16 \\
\hline
\end{tabular}

Table 6. Specimen properties used by [25]

\begin{tabular}{|c|c|c|c|c|c|c|}
\hline Specimen & code & $\mathrm{fc} c^{\prime}(\mathrm{MPa})$ & $\begin{array}{l}\text { Plastic hinge } \\
\text { region }(\mathrm{mm})\end{array}$ & $\begin{array}{l}\text { transverse reinforcement at } \\
\text { plastic hinge region }\end{array}$ & $\begin{array}{c}\text { Transverse } \\
\text { reinforcement at joint }\end{array}$ & $\begin{array}{c}\text { vertical reinforcement at } \\
\text { joint }\end{array}$ \\
\hline $\mathrm{AN}$ & AASHTO & 39.4 & 450 & $\begin{array}{c}4-\# 5 @ 80 \mathrm{~mm} \\
\text { fyh }=356.5 \mathrm{MPa}\end{array}$ & $\begin{array}{c}4-\# 5 @ 80 \mathrm{~mm} \\
\text { fyh }=356.5 \mathrm{MPa}\end{array}$ & 0 \\
\hline $\mathrm{AH}$ & AASHTO & 45.0 & 450 & $\begin{array}{c}5-\# 5 @ 85 \mathrm{~mm} \\
\text { fyh }=457.7 \mathrm{MPa}\end{array}$ & $\begin{array}{c}5-\# 5 @ 85 \mathrm{~mm} \\
\mathrm{fyh}=457.7 \mathrm{MPa}\end{array}$ & 0 \\
\hline $\mathrm{ZN}$ & $\begin{array}{l}\text { New } \\
\text { Zealand }\end{array}$ & 43.0 & 400 & $\begin{array}{c}\text { 4-\#4@80mm } \\
\text { fyh = 416.1 MPa }\end{array}$ & $\begin{array}{c}4-\# 4 @ 100 \mathrm{~mm} \\
\text { fyh }=416.1 \mathrm{MPa}\end{array}$ & $\begin{array}{c}2-\# 5 @ 60 \mathrm{~mm} \\
\text { fyh }=356.5 \mathrm{MPa}\end{array}$ \\
\hline $\mathrm{ZH}$ & $\begin{array}{l}\text { New } \\
\text { Zealand }\end{array}$ & 61.2 & 400 & $\begin{array}{c}4-\# 5 @ 80 \mathrm{~mm} \\
\text { fyh }=356.5 \mathrm{MPa}\end{array}$ & $\begin{array}{c}\text { 4-\#4@100mm } \\
\text { fyh =416.1 MPa }\end{array}$ & $\begin{array}{c}2-\# 5 @ 60 \mathrm{~mm} \\
\text { fyh }=356.5 \mathrm{MPa}\end{array}$ \\
\hline
\end{tabular}




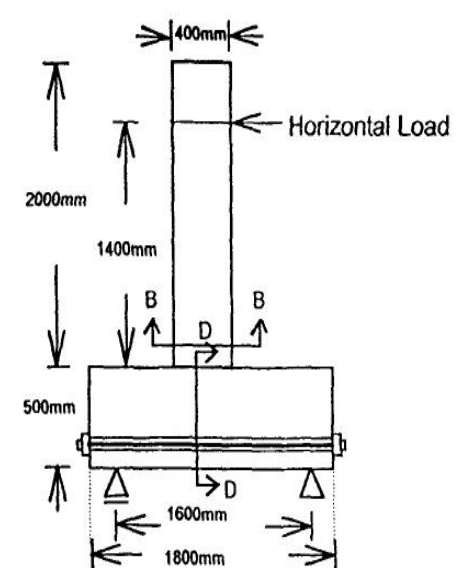

(a) Elevation

(Dimensions not to scale)

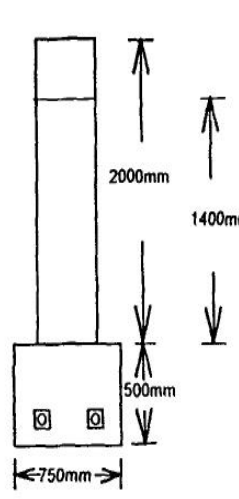

(b) Side View

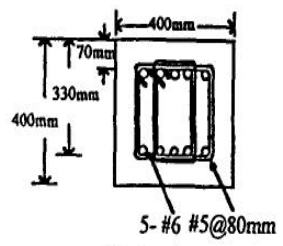

(c) Section B-B

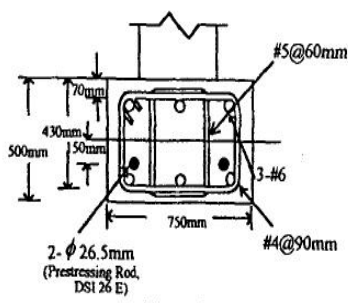

(d) $\underline{\text { ection D-D }}$

Figure 20. Reinforcement details of a specimen used in [25]

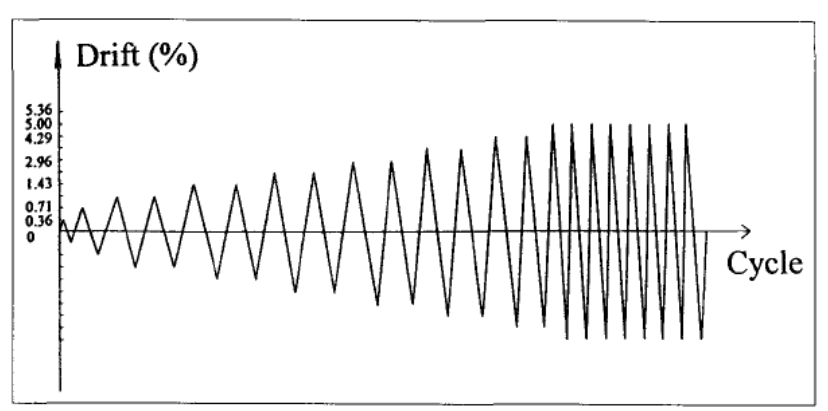

Figure 21. Displacement history from [25]

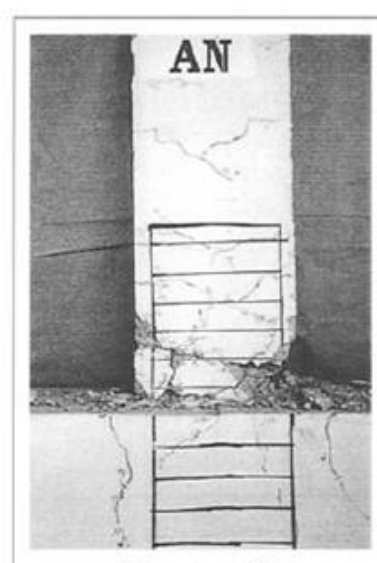

(a) Specimen $A \mathrm{~N}$

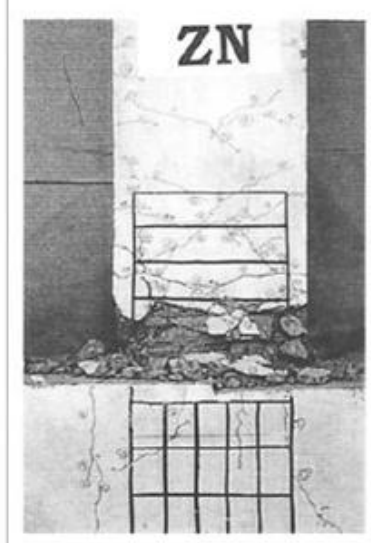

(c) Specimen $\mathrm{ZN}$

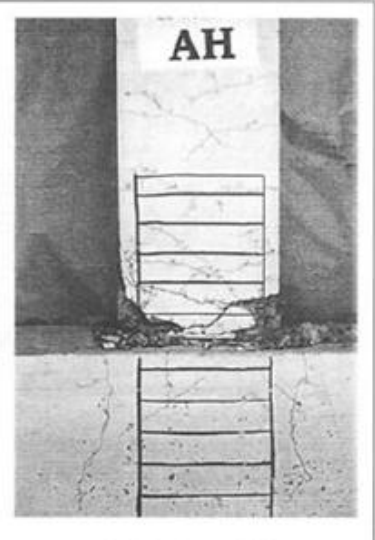

(b) Specimen AH

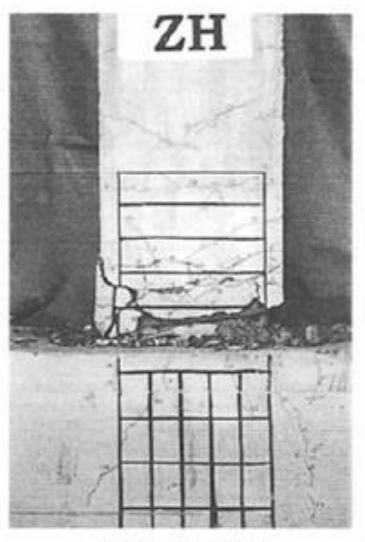

(c) Specimen ZH

\subsubsection{Experimental Study on the Strengthening of Reinforced Concrete Beam-column Joint with Steel Fiber during Earthquake Loading}

The visiting researcher [9] applied experimental methods to investigate the strengthening characteristics that steel fiber reinforced concrete (SFRC) materials have on beam-column joints within a high-rise building under the effect of cyclic loading. The main aim of his study was to investigate how the usage of SFRC in frame buildings improves and strengthens the performance of beam-column joints during the event of an earthquake. His experimental study was done by applying quasi-static hysteretic earthquake loading on the testing specimens. [9] used six cycles to represent the quasi-static hysteretic earthquake loading. Each cycle had a different maximum displacement at the loading point. Figure 23 presents the pattern of cyclic loading of the six cycles. The maximum displacement at the loading point for the first cycle was $12 \mathrm{~mm}$, which represents the slow mode. The fast mode was set at the sixth cycle with a maximum displacement at a loading point of $200 \mathrm{~mm}$. The load was increased dramatically for each cycle until the desired maximum displacement at load point was achieved.

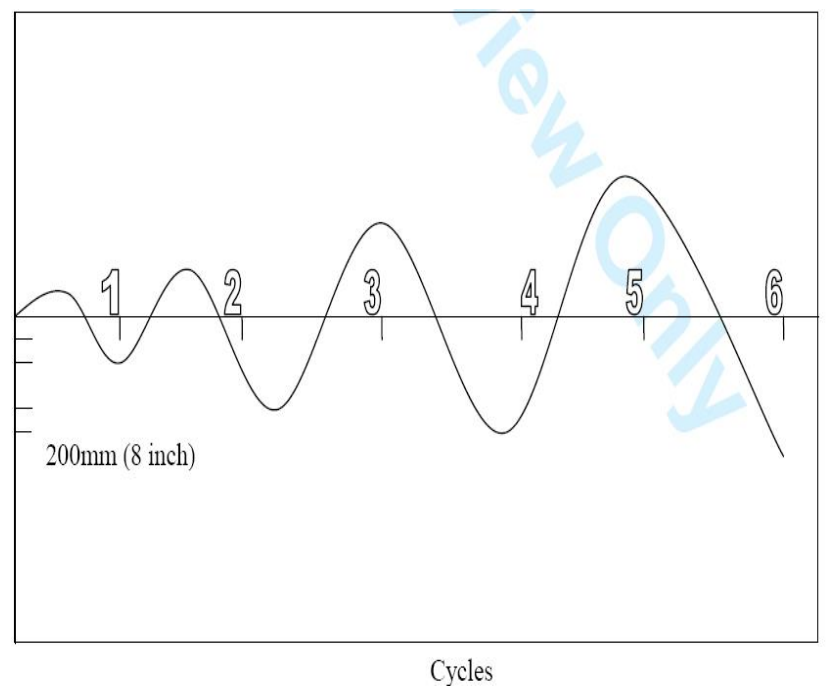

Figure 23. Pattern of cyclic loading from [9] 
The testing specimen that [9] used had column cross sectional dimensions of $500 \mathrm{~mm}$ by $400 \mathrm{~mm}$ with a longitudinal reinforcement of $4-25 \mathrm{~mm}$ (bars diameter). In addition, the cantilever/beam had a cross sectional dimension of $400 \mathrm{~mm}$ by $600 \mathrm{~mm}$ with a longitudinal reinforcement of $8-20 \mathrm{~mm}$ (bars diameter). The diameters of the stirrup bars were $8 \mathrm{~mm}$ or number 3 at $100 \mathrm{~mm}$. Figure 24 illustrates the experimental specimen and cyclic loading set up.

During his experimental study [9] discovered minor cracks starting to appear during the second cycle for all the testing and obviously as the load was increased cracking depth increased until the model failed. Figure 25 shows the minor cracks in the joint member of the element.

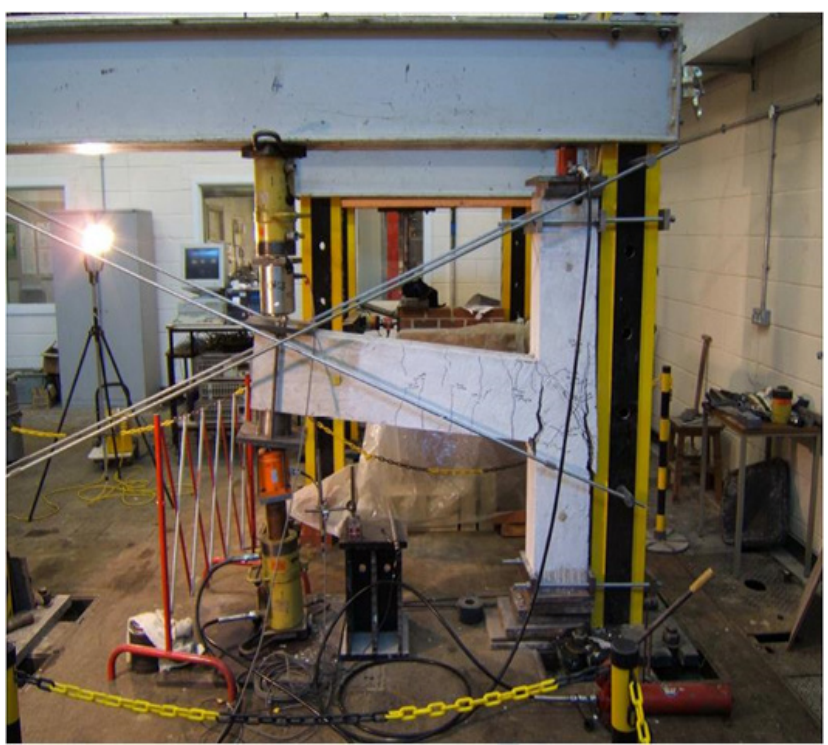

Figure 24. Failure of the joint at the $4^{\text {th }}$ cycle [9]

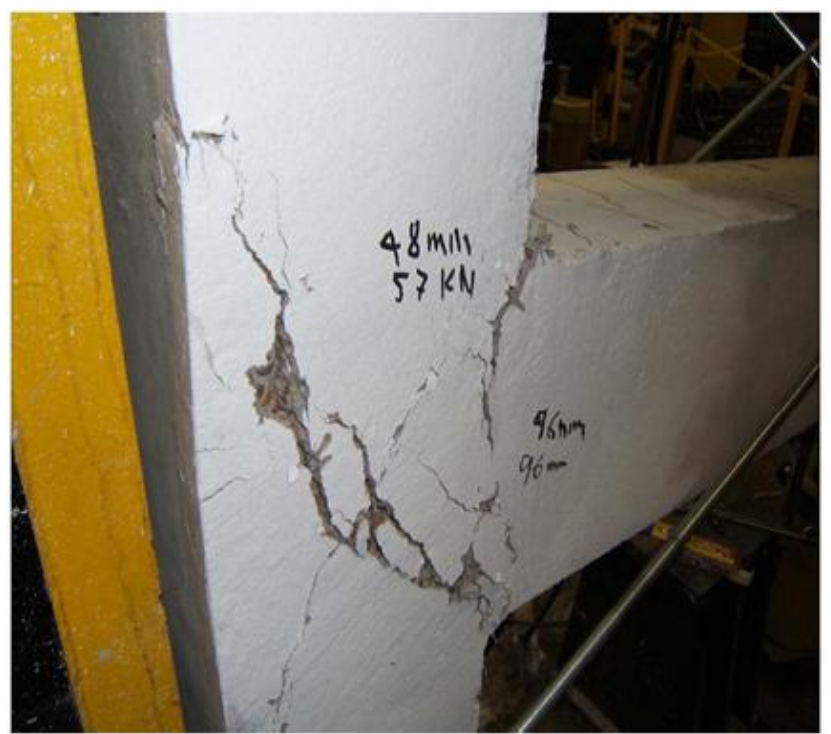

Figure 25. Cracking pattern of specimen by [9]

[9] investigated the behavior of RC beam-column joints under cyclic earthquake loading by using the simulation of earthquakes specimens in a laboratory. The simulations were then used to plot load against deflection hysterises graph for specimens with fibers and without fibers. Graph 8 shows the load against deflection graph for the specimen without fibers, while Graph 9 shows the hysterises graph of a specimen with fibers. [9] concluded that using fibers in the joint has (1) increased its strength when compared with a regular specimen without fibers, (2) can sustain loads with higher peak, and (3) improved the performance, resistance and ductility of the joint during an earthquake by reducing cracks, thus, prevents an unexpected collapse.

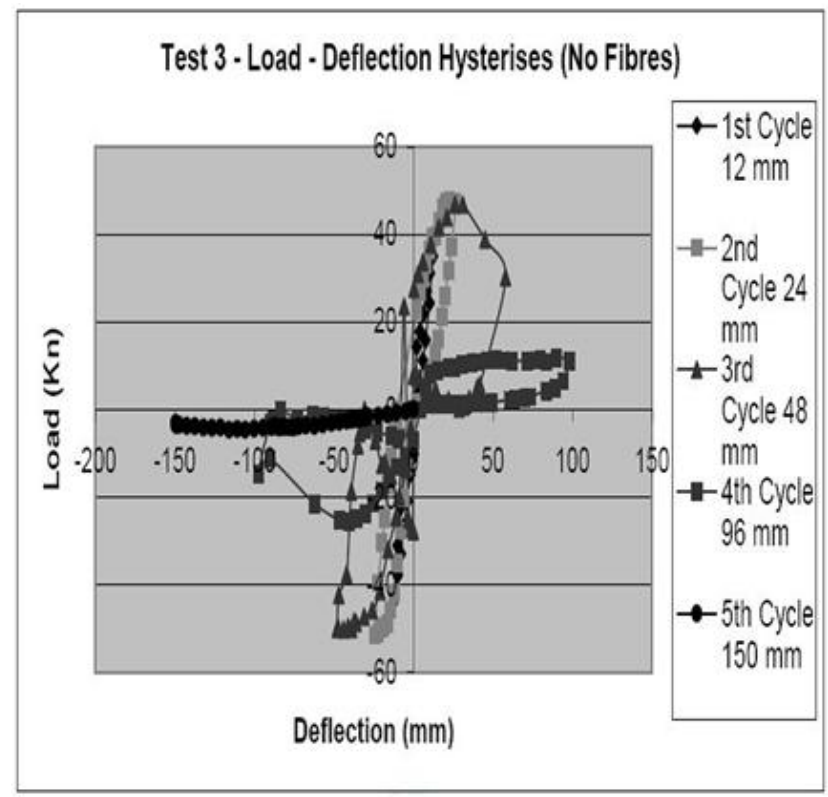

Graph 8. Load vs. Deflection graph without fibers by [9]

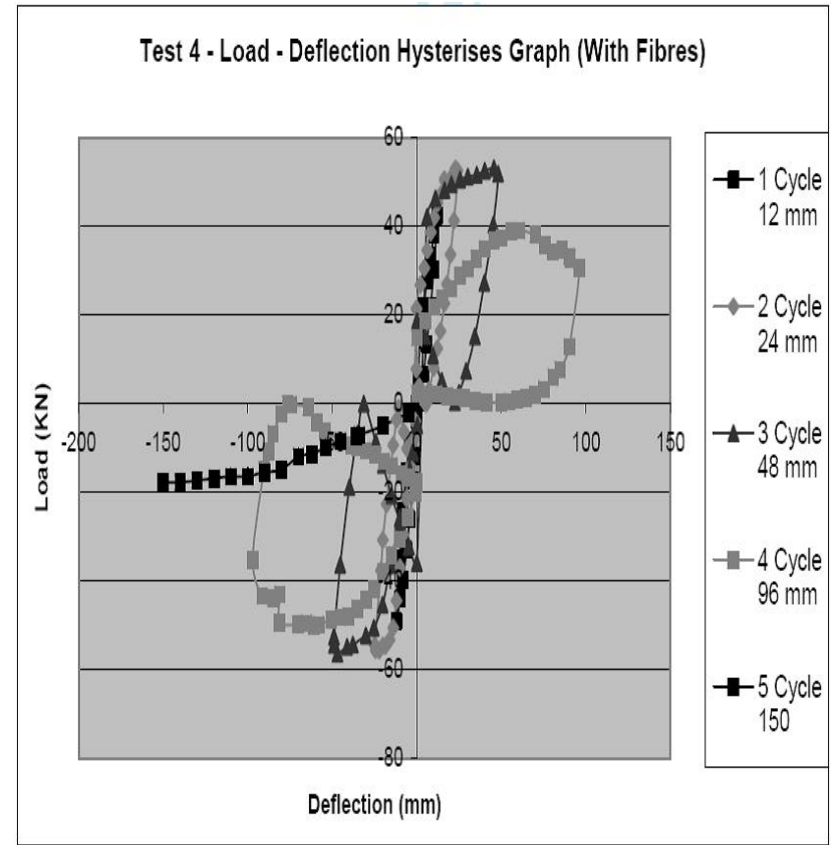

Graph 9. Load vs. Deflection graph with fibers by [9]

\subsection{Summary}

In conclusion, it is evident that seismic modelling of beam-column joints is an essential tool in the safe design of structures. The applicability and complexity of modelling approaches has advanced from mini-sizes to significantly large models. There are other approaches to modelling as evident from this review. This includes use of numerical or theoretical processes in which formulations or mathematical models are applied to beam- 
column problems; or the use of computational software. The popularity of such finite element computational tools like LUSAS appears to be on the increase. Predictive modelling of beam-columns is also an area that was covered in this chapter and it was shown to be capable of producing results that are valid. Another interesting aspect of computational processes for beam-column modelling is the potential to work on a free open source framework (as evident from Open Sees) will enable many more interested parties to participate in this research. This will bring a new dimension to research collaboration especially with the power of internet connectivity, which complements the growing power of processors. Finally, more strength, and better performance of the structure can be maintained by adding fibers to the concrete as proven by the experimental study conducted by [9]. The fibers give the structure more resistance and ductility against earthquakes by absorbing the loads, therefore, preventing an unexpected collapse of the element.

\section{Methodology and Programme}

\subsection{Computer Software}

The research has been carried out with the aid of computer structural software LUSAS version 14.4 (Finite Element Package). This software was chosen for many reasons such as its efficiency in conducting static analysis, and it allows the conduct of various simulations and accuracy in carrying out non-linear analysis calculations. Also the software allows the running of different loading magnitudes on the structure, which in this case will represent the cyclic earthquake loading. Additionally, the SMDN (Strong Motion Database Navigator) tool that is available with the software permits uploading the model, searching historic earthquakes and determining its accelerations in $\mathrm{x}, \mathrm{y}$ and $\mathrm{z}$ directions. The accelerations can then be used in non-linear dynamic and seismic analysis by which it gives an indication of behavior of the joint under real earthquakes.

\subsection{General Properties of the Model}

The structure consists of three parts: a joint, cantilever and column members. The concrete cover depth was identified as $50 \mathrm{~mm}$, which is the distance between the concrete surface and the reinforcement bars. This value for the cover depth was extracted from specifying, detailing and achieving cover to reinforcement done by [26], which is a document published by the concrete society. Additionally, the thickness of the model was recognized as $400 \mathrm{~mm}$, which represents the width of the concrete. Furthermore, the support conditions of the structure were a fully fixed column from top and bottom and the beam was free at the end. The total cross sectional area of the model was $3.14 \mathrm{~m}^{2}$. In terms of the cross sectional dimensions of the column it has been identified as $500 \mathrm{~mm}$ by $400 \mathrm{~mm}$ and $400 \mathrm{~mm}$ by $600 \mathrm{~mm}$ for the beam. These cross sectional dimensions represent a full-scale model. The cross sectional dimensions of the column and the beam that has been used in the proposed beam-column joint model were extracted from the experimental study done by visiting researcher [9] in the University of Leeds. Although [9] carried out the testing on half scale $(1.5 \mathrm{~m} \times 1.5 \mathrm{~m})$, the author has decided to conduct a full-scale model $(3 \mathrm{~m} \times 3 \mathrm{~m})$ as presented in Figure 26.

Mild steel was used in the reinforcement bars as shown in Figure 26 and the concrete of grade C30 was used on rest of the structure. Furthermore, the concrete was applied on all the surfaces and the lines of the model to achieve a strong bond connection between reinforcement bars and concrete and also to prevent the slippage of bars. This also helped in achieving satisfactory results after the analysis phase. Table 7 and Table 8 show the elastic and plastic material properties recognized for steel, while Table 9 and Table 10 show the elastic and plastic material properties recognized for concrete.

Table 7. The elastic properties identified for steel

\begin{tabular}{ll}
\hline \multicolumn{2}{c}{ Material name: Mild Steel (Elastic properties) } \\
\hline Elastic properties & Magnitude \\
Young's Modulus & $210 \mathrm{kN} / \mathrm{mm}^{2}$ \\
Mass density & $7.8 \times 10^{-12} \mathrm{kN} / \mathrm{mm}^{3}$ \\
Poisson's Ratio & 0.3 \\
Coefficient of Thermal Expansion & $11.0 \times 10^{-6}$ \\
Stiffness Rayleigh damping constant & $0.314 \times 10^{-3}$ \\
Mass Rayleigh damping constant & 0.453114 \\
\hline
\end{tabular}

Table 8. The plastic properties identified for steel.

\begin{tabular}{lc}
\hline \multicolumn{2}{c}{ Material name: Mild Steel (Plastic properties) } \\
\hline Plastic properties & Magnitude \\
Initial uniaxial yield stress & 0.4 \\
Hardening Gradient (Slope) & 0.21 \\
Hardening Gradient (Plastic strain) & 1.0 \\
\hline
\end{tabular}

Table 9. The elastic properties identified for concrete

\begin{tabular}{ll}
\hline \multicolumn{2}{c}{ Material name: Concrete (Elastic properties) } \\
\hline Elastic properties & Magnitude \\
Young's Modulus & $42 \mathrm{kN} / \mathrm{mm}^{2}$ \\
Mass density & $2.5 \times 10^{-12} \mathrm{kN} / \mathrm{mm}^{3}$ \\
Poisson's Ratio & 0.2 \\
Coefficient of Thermal Expansion & $11.0 \times 10^{-6}$ \\
Stiffness Rayleigh damping constant & $0.314 \times 10^{-3}$ \\
Mass Rayleigh damping constant & 0.453114 \\
Concrete Grade & $\mathrm{C} 30$ \\
\hline
\end{tabular}

Table 10. The plastic properties identified for concrete

Material name: Reinforced Concrete model 94 (Plastic properties)

$\begin{array}{ll}\text { Plastic properties } & \text { Magnitude } \\ \text { Uniaxial compressive strength } & 0.03158 \\ \text { Uniaxial tensile strength } & 3.158 \times 10^{-3} \\ \text { Constant in interlock state function } & 0.425 \\ \text { Initial relative position of yield surface } & 0.6 \\ \text { Strain at peak uniaxial compression } & 2.2 \times 10^{-3} \\ \text { Strain at end of softening curve } & 3.5 \times 10^{-3} \\ \text { Biaxial to uniaxial stress ratio } & 1.15 \\ \text { Dilatancy factor } & -0.1 \\ \text { Contact multiplier on e0 } & 0.5 \\ \text { Final contact multiplier on e0 } & 5 \\ \text { Shear intercept to tensile strength } & 1.25 \\ \text { Slope of friction asymptote for damage } & 1 \\ \text { Angular limit between crack planes } & 1 \\ \text { Concrete Grade } & \mathrm{C} 30\end{array}$




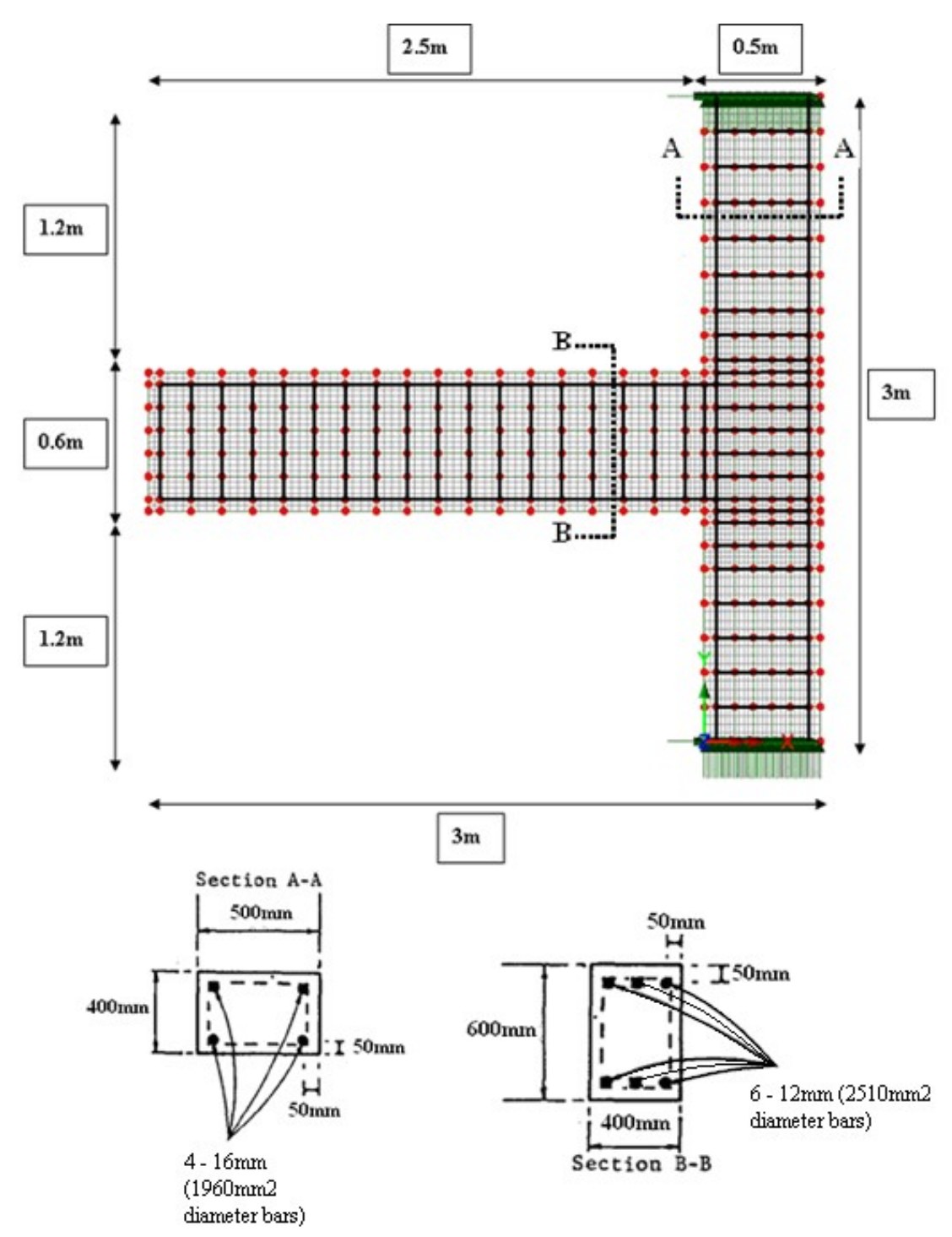

Figure 26. Dimensions and reinforcement bars within the structure

The reinforcement bars were divided in to three sections according to the cross sectional area of each bar. The bars were divided into horizontal, transverse and stirrup/hoop bars. The horizontal bars had a cross sectional area of $400 \mathrm{~mm}^{2}$, the transverse bars had a cross sectional area of $500 \mathrm{~mm}^{2}$ and the hoops had the lowest cross sectional area of $160 \mathrm{~mm}^{2}$.

\subsubsection{Model Mesh Generation}

The mesh part of the model is considered to be an important part of modelling such a structural element. This means the better and finer the mesh is the more reliable the results obtained will be during the analysis stage. Therefore, the mesh process went though many stages to come up with the finest and most appropriate form. This was achieved by identifying more nodes, lines and surfaces, by which divisions were applied on lines. Table 11 presents the number of nodes, points, lines, elements and surfaces that is available within the model. During this phase the structural types of the divisions were divided into parts according to the material assigned to the line, for instance, the steel bars and concrete. For the steel bars the structural element type was a $2 \mathrm{D}$ bar for the number of dimensions and quadratic for interpolation order. Additionally, the number of divisions identified for steel was: (1) Four divisions assigned on horizontal and longitudinal bars (cantilever and column main bars), (2) two divisions assigned on joint edges and (3) four divisions applied on all hoops. On the other hand, the concrete had two types of divisions, for instance, two divisions and four divisions. Moreover, the two divisions were assigned to the lines, which represent the concrete cover and the four divisions were applied on the top and bottom lines of the column. Figure 27 shows the final mesh arrangement of the model. Finally, the structural properties of the mesh were as follows:

- Plane stress for the structural element type

- Quadrilateral element shape

- Interpolation order: Quadratic

Table 11. The properties of the model.

\begin{tabular}{cc}
\hline Geometric properties & Number \\
\hline Nodes & 145771 \\
Points & 411 \\
Lines & 916 \\
Elements & 5628 \\
Surfaces & 382 \\
\hline
\end{tabular}




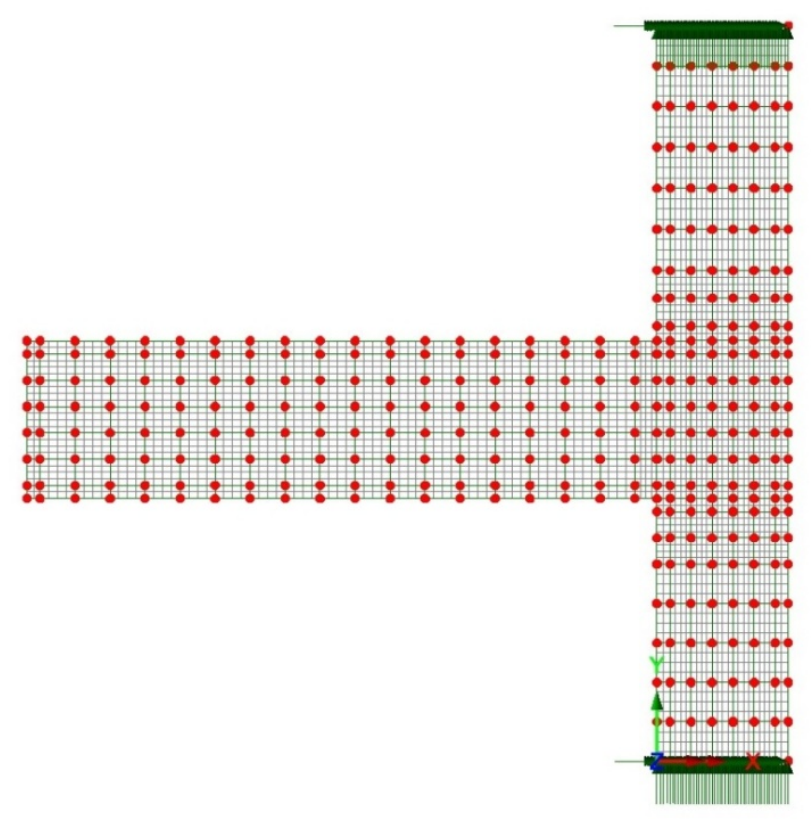

Figure 27. The mesh arrangement of the author's final proposed BC joint model

\subsubsection{Joint Member Characteristics}

The joint member (Figure 28) is the most important part of the structure. It works as a connection between the cantilever bars and column bars as they intersect together in the joint. Any failure of the structure during the analysis will mostly occur at this part. Therefore, the author has taken this into consideration by providing more reinforcement bars/hoops during the design phase. By doing this the structure will sustain high cyclic loads and successfully handle real earthquakes. The joint member has a cross sectional area of $0.3 \mathrm{~m}^{2}$.

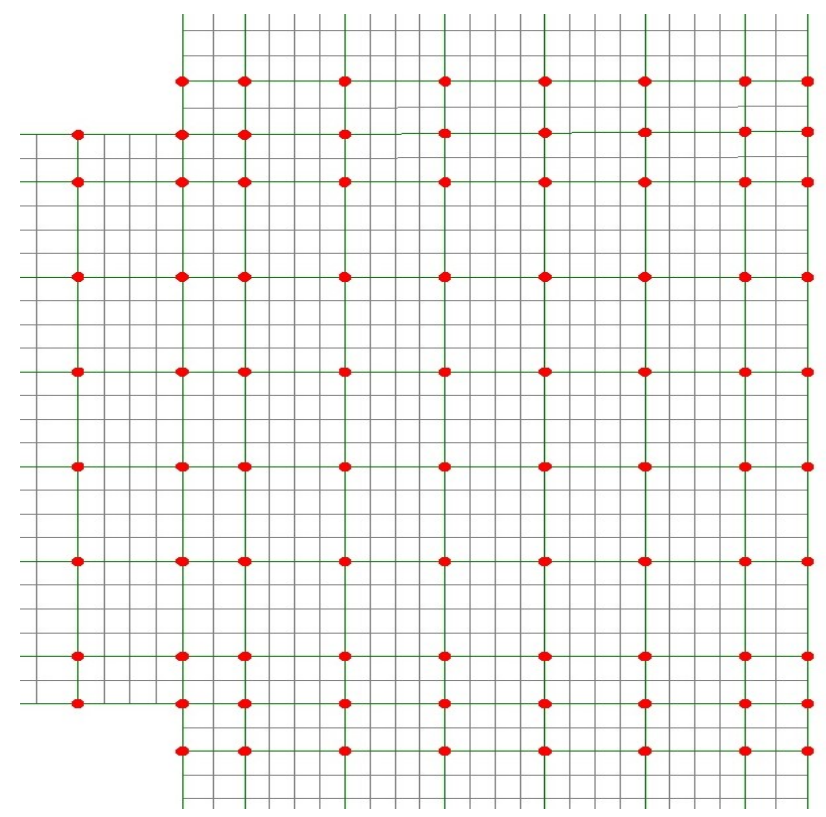

Figure 28. The joint member

\subsubsection{Cantilever/beam Member Characteristics}

The cantilever/beam member (Figure 29) is connected to the column through the main joint of the structure. The beam is free from the end. This is due to the cyclic loading analysis by which the cyclic loading will be applied on the free end of the beam to record the displacement at different applied loads. The beam consists of six main horizontal bars (size 12mm), three top bars and three bottom bars. These bars are joined together with hoops. The number of hoops in the beam is 19 with a connecting hoop at every $150 \mathrm{~mm}$. One extra hoop was included in the design at the end of the beam near the joint. The dimensions of the cantilever are illustrated in Figure 26.

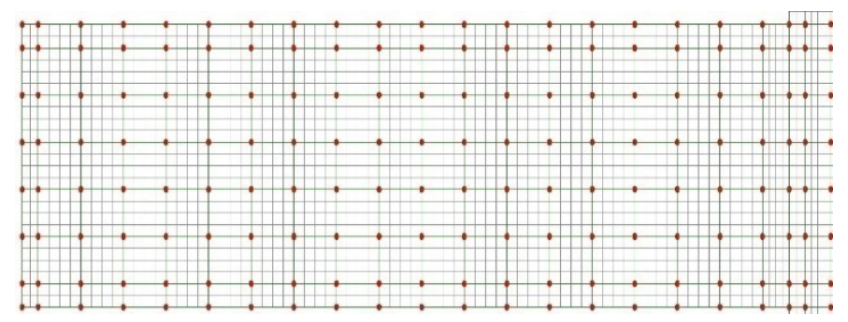

Figure 29. The cantilever/beam member

\subsubsection{Column Member Characteristics}

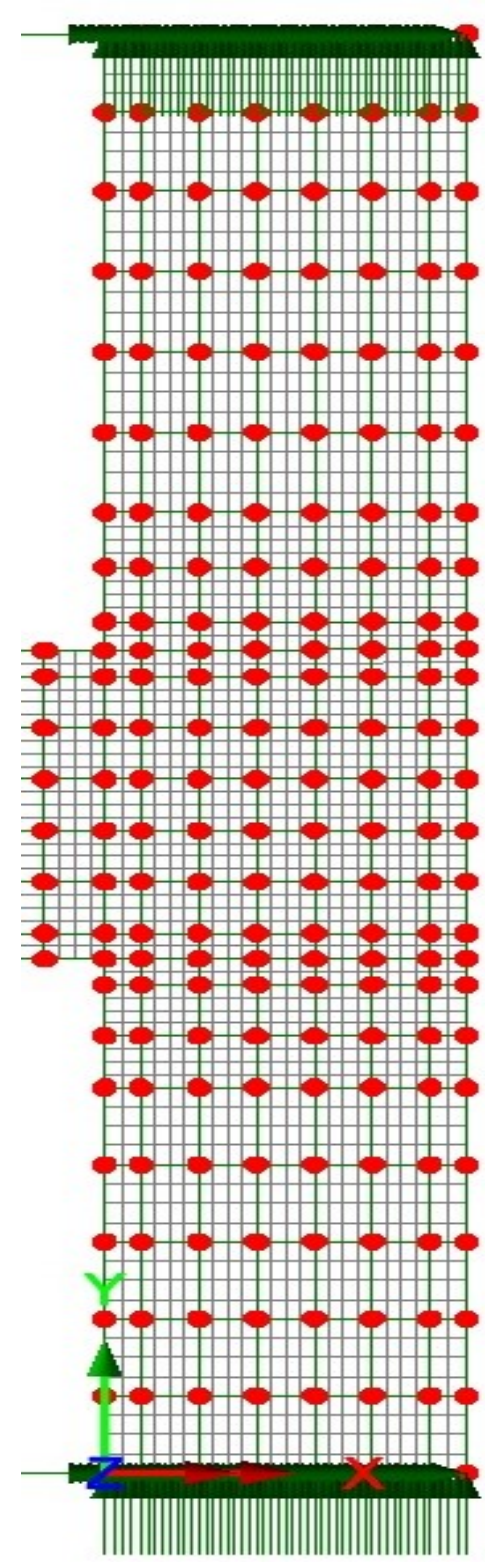

Figure 30. The column member 
The column member (Figure 30) is fixed from top and bottom to represent a real life situation of the element during the event of an earthquake. During carrying out the non-linear dynamic real earthquake analysis, the earthquake accelerations will be applied on the bottom fixed end of the column, which is assumed to be the ground level. This gives a realistic indication of the earthquake strike since they are generated from the ground/soil to the structure. The column has four main bars (size $16 \mathrm{~mm}$ ) and hoops connect these bars at $100 \mathrm{~mm}$ intervals. Two extra hoops were also included in the design near the joint to provide more strength to the joint during earthquake simulations. The dimensions of the column are shown in Figure 26.

\subsection{Types of Earthquakes Applied on the Author's Proposed Model}

\subsubsection{Applied Historic Real Earthquake 1 - Athens, Greece (1999)}

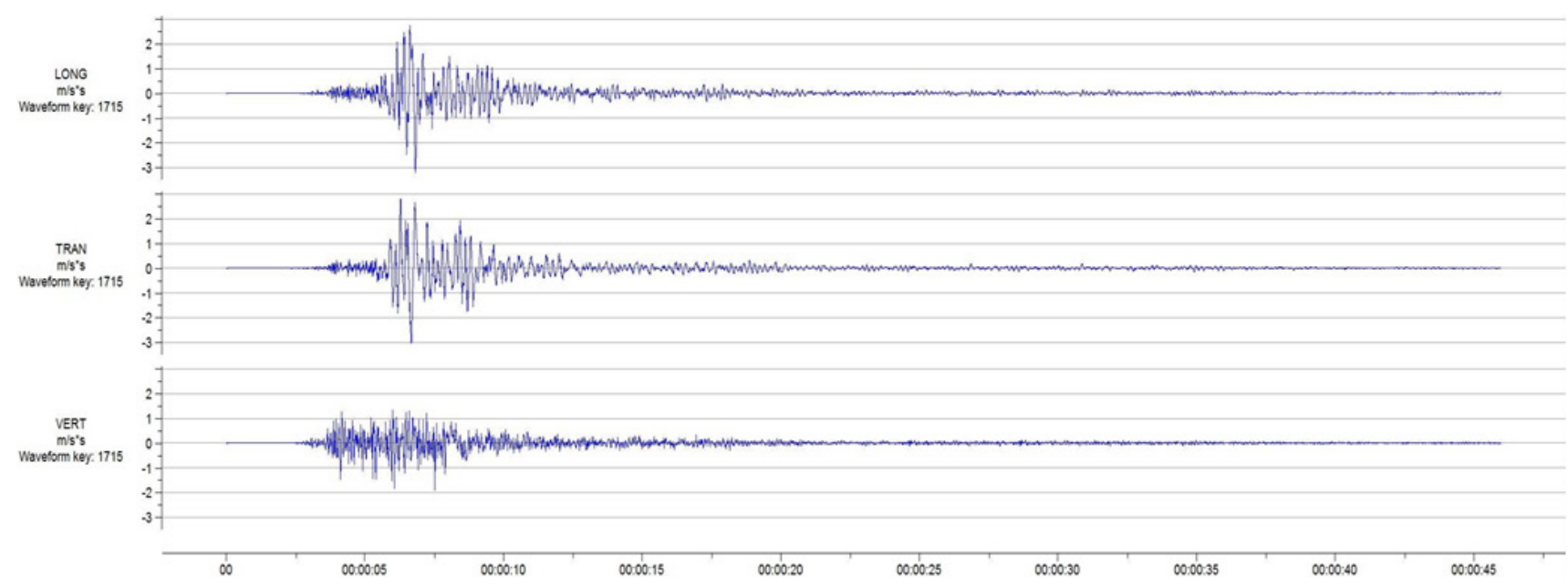

Graph 10. The acceleration $\left(\mathrm{m} / \mathrm{s}^{2}\right)$ path of $\mathrm{x}, \mathrm{y}$ and $\mathrm{z}$ coordinates (Earthquake 1 - Athens)
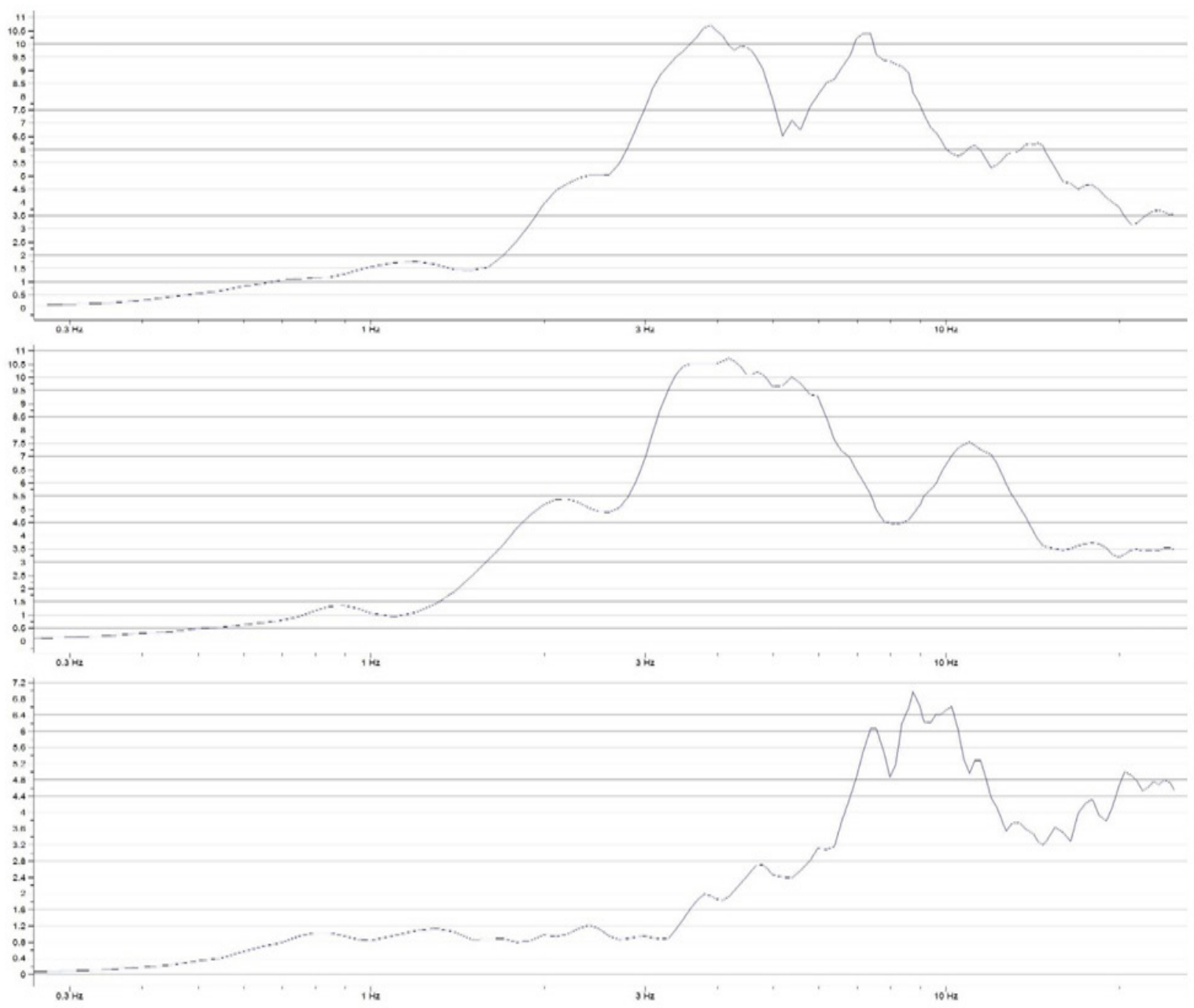

Graph 11. The path of frequency of spectra's for $x, y$ and $z$ coordinates (Earthquake 1 - Athens) 
The first real earthquake that the model will be assiged to is the Athens earthquake that took place in Greece in 1999. The magnitude of this earthquake on the richter scale was not recorded with a depth of $9 \mathrm{~km}$ and a normal source mechanism. Graph 10 above presents the frequency of the Athens earthquake and its accelerations in $\mathrm{x}, \mathrm{y}$ and $\mathrm{z}$ directions. As shown above the maximum acceleration exists in the $x$ direction with a magnitude of $2.9 \mathrm{~m} / \mathrm{s}^{2}$ and occurs at approximately 6.5 seconds. Moreover, the highest range of all acceleration magnitudes for $\mathrm{x}, \mathrm{y}$ and $\mathrm{z}$ directions takes place between 4 and 10 seconds. These accelerations will be used as a method for assigning them to the proposed model in order to achieve the displacements, bar forces in $\mathrm{x}$-direction, stresses and strains of the model under the effect of this earthquake.

The direction of highest acceleration is mostly considered during earthquakes. As shown in the frequency spectra (Graph 11), the highest acceleration of all frequency spectra's existed in $\mathrm{x}$ and $\mathrm{y}$ direction with a value of $10.75 \mathrm{~m} / \mathrm{s}^{2}$ at 3.8 Hertz and 4.2 Hertz respectively. Moreover, the maximum acceleration in y-direction was $7 \mathrm{~m} / \mathrm{s}^{2}$ at 1.75 Hertz. Alternatively, the y direction had the lowest acceleration $8 \mathrm{~m} / \mathrm{s}^{2}$ occurring at 9 Hertz.

\subsubsection{Applied historic real earthquake 2 - Friuli, Italy} (1976)

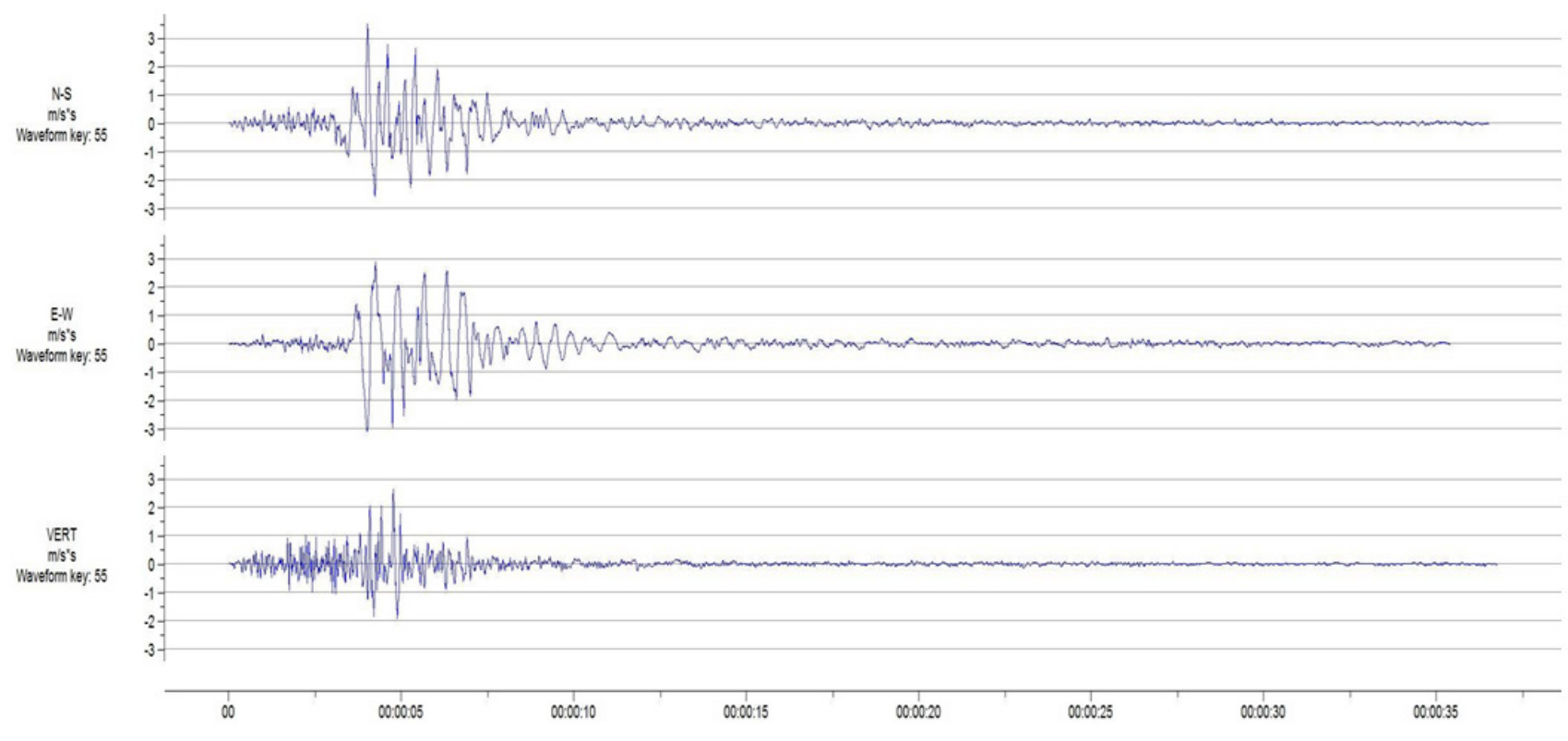

Graph 12. The acceleration $\left(\mathrm{m} / \mathrm{s}^{2}\right)$ path of $\mathrm{x}, \mathrm{y}$ and $\mathrm{z}$ coordinates (Earthquake 2 - Friuli)

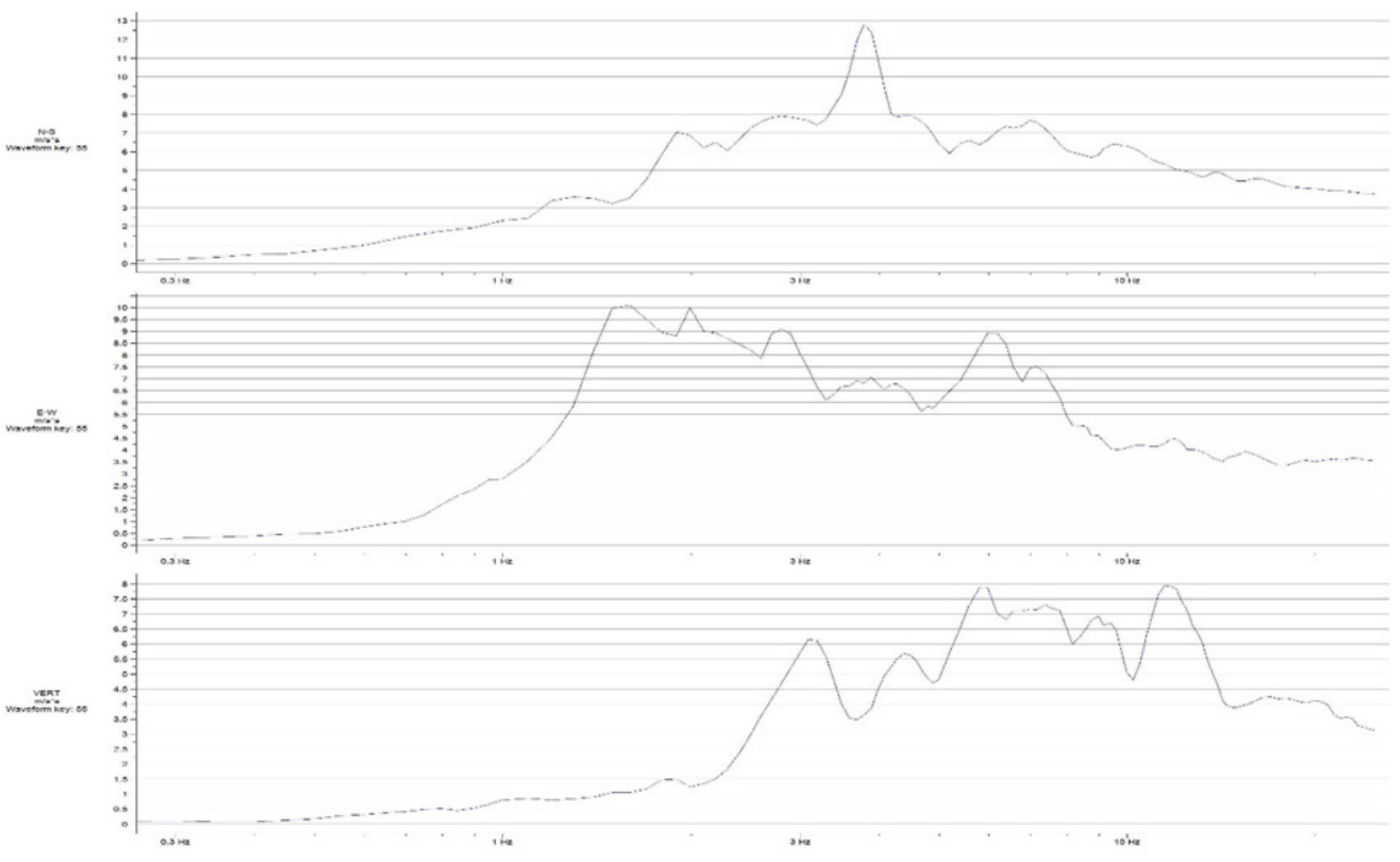

Graph 13. The path of frequency of spectra's for $\mathrm{x}, \mathrm{y}$ and $\mathrm{z}$ coordinates (Earthquake 2 - Friuli) 
The second real earthquake that the model will be assiged to is the Friuli earthquake that took place in Italy in 1976. The magnitude of this earthquake on the richter scale was 6.3 with a depth of $6 \mathrm{~km}$ and thrust source mechanism. Moreover, the magnitude of this earthquake was the highest among the other applied earthquakes. Graph 12 above presents the frequency of the Friuli earthquake and its accelerations in $\mathrm{x}, \mathrm{y}$ and $\mathrm{z}$ directions. This graph is obtained from the SMDN (Strong Motion Database Navigator). As shown above the maximum acceleration exists in the $x$ direction and was $3.5 \mathrm{~m} / \mathrm{s}^{2}$ in terms of magnitude and occurs at approximately 3 seconds. Moreover, the highest range of all acceleration magnitudes for $\mathrm{x}, \mathrm{y}$ and $\mathrm{z}$ directions takes place between 3.5 and 7.5 seconds. These accelerations will be used as a method of assigning them to the proposed model in order to achieve the displacements, bar forces, stresses and strains of the model under the effect of this earthquake.

The direction in $\mathrm{x}, \mathrm{y}$ or $\mathrm{z}$ of the highest acceleration is mostly considered during earthquakes. As shown in the frequency spectra (Graph 13), the highest accelerations existed in the $\mathrm{x}$ direction with a value of $12.8 \mathrm{~m} / \mathrm{s}^{2}$ at 3.8 Hertz. Moreover, the maximum acceleration in the $y$ direction was $10 \mathrm{~m} / \mathrm{s}^{2}$ at 1.75 Hertz. Alternatively, the $\mathrm{z}$ direction had the lowest acceleration with an $8 \mathrm{~m} / \mathrm{s}^{2}$ taking place at 10 Hertz.

\subsubsection{Applied Historic Real Earthquake 3 - Izmir, Turkey (1977)}

The third real earthquake which the model will be assiged to is Izmir earthquake that took place in Turkey in 1977. The magnitude of this earthquake on the richter scale was 5.1 with a depth of $5 \mathrm{~km}$ and a normal source mechanism. Graph 14 presents the frequency of the Izmir earthquake and its accelerations in $\mathrm{x}, \mathrm{y}$ and $\mathrm{z}$ directions. As shown above the maximum acceleration exists in the $\mathrm{x}$ direction with a magnitude of $2 \mathrm{~m} / \mathrm{s}^{2}$ and occurs at approximately 0.5 seconds. Moreover, the highest range of all acceleration magnitudes for $\mathrm{x}, \mathrm{y}$ and $\mathrm{z}$ directions takes place between 0.4 and 0.7 seconds. These accelerations will be used as a method for assigning them to the proposed model in order to achieve the displacements, bar forces, stresses and strains of the model under the effect of this earthquake.

The direction of highest acceleration is mostly considered during earthquakes. As shown in the frequency spectra (Graph 15), the highest acceleration of all frequency spectra's existed in the $\mathrm{x}$ and $\mathrm{y}$ direction with a value of $7 \mathrm{~m} / \mathrm{s}^{2}$ at 5 Hertz and 5.2 Hertz respectively. Moreover, the maximum acceleration in the y direction was $2.5 \mathrm{~m} / \mathrm{s}^{2}$ at $4.75 \mathrm{Hertz}$. Alternatively, the y direction had the lowest acceleration of $1.5 \mathrm{~m} / \mathrm{s}^{2}$ occurring at 7.5 Hertz.

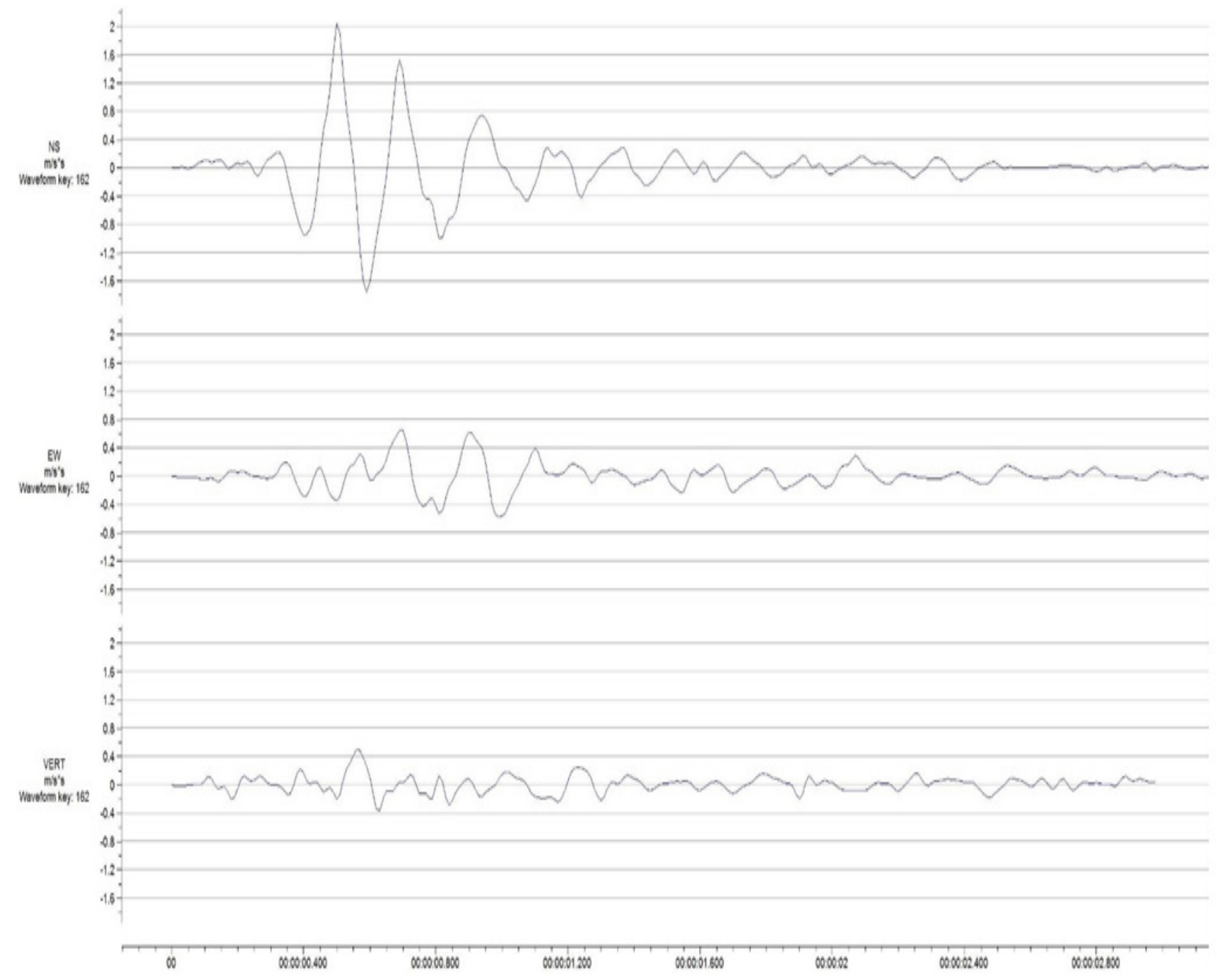

Graph 14. The acceleration $\left(\mathrm{m} / \mathrm{s}^{2}\right)$ path of $\mathrm{x}, \mathrm{y}$ and $\mathrm{z}$ coordinates (Earthquake 3 - Izmir) 

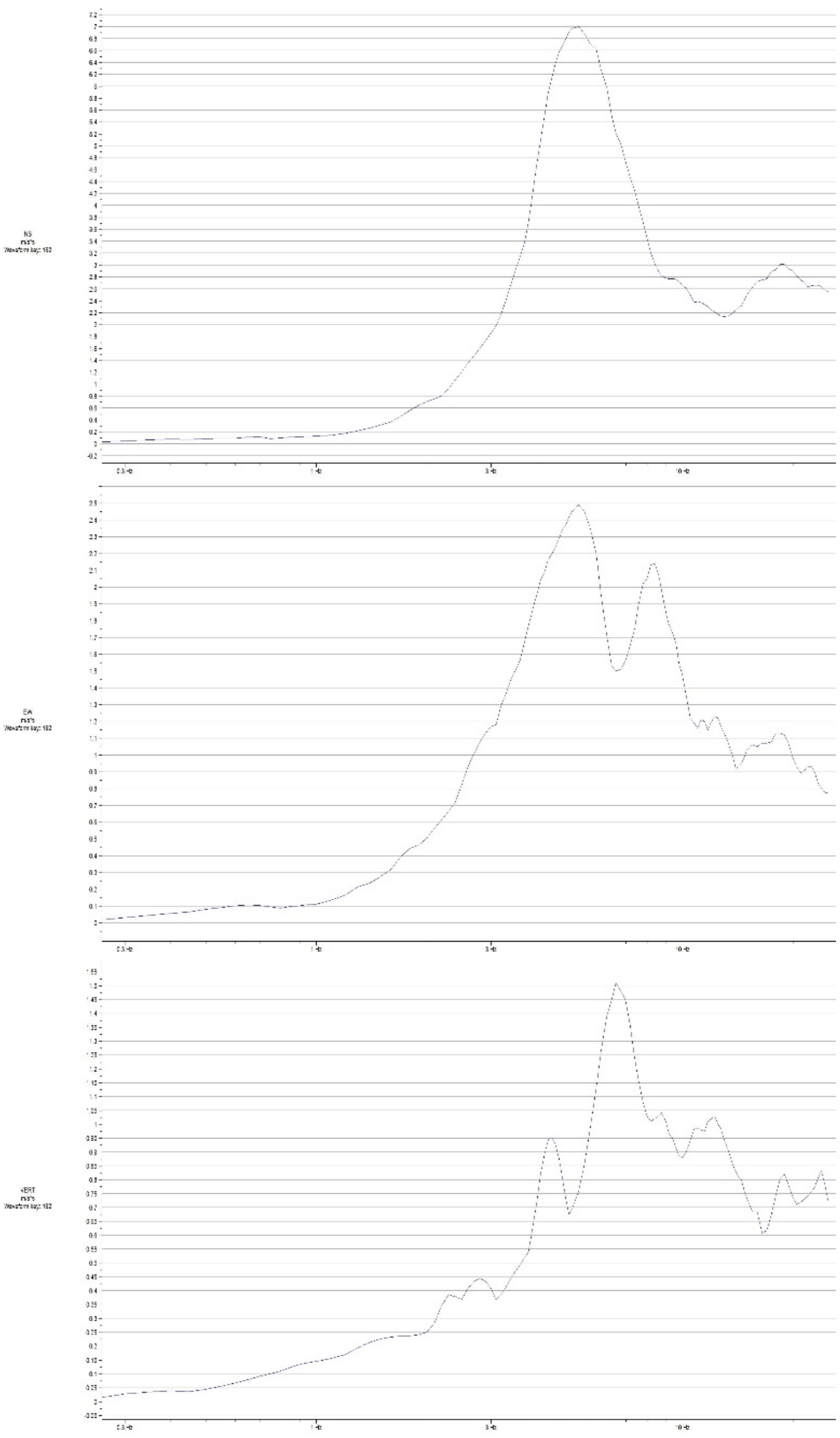

Graph 15. The path of frequency of spectra's for $\mathrm{x}, \mathrm{y}$ and $\mathrm{z}$ coordinates (Earthquake 3 - Izmir) 


\subsubsection{Cyclic Earthquake Loading}

The cyclic earthquake loading consisted of five cycles. Each cycle had a different magnitude set in terms of maximum displacement at load points 7 and 8 . The magnitude of maximum displacement at load points 7 and 8 was increased for each cycle. Table 12 illustrates the magnitude of the maximum displacements for each cycle. Moreover, the analysis of each cycle consisted of two stages. The first stage was applying the loads at point 8 of the beam edge downward (Figure 31), this represent half a cycle. The second stage was applying the loads at point 7 of the beam edge upwards (Figure 31). Stage 1 and stage 2 represents a full cycle.

Table 12. The magnitudes of the maximum displacement set at load points 7 and 8 for each cycle

\begin{tabular}{cc}
\hline Cycle No. & Maximum displacement at load points 7 and $8(\mathrm{~mm})$ \\
\hline 1 & 12 \\
2 & 25 \\
3 & 50 \\
4 & 100 \\
5 & 150 \\
\hline
\end{tabular}

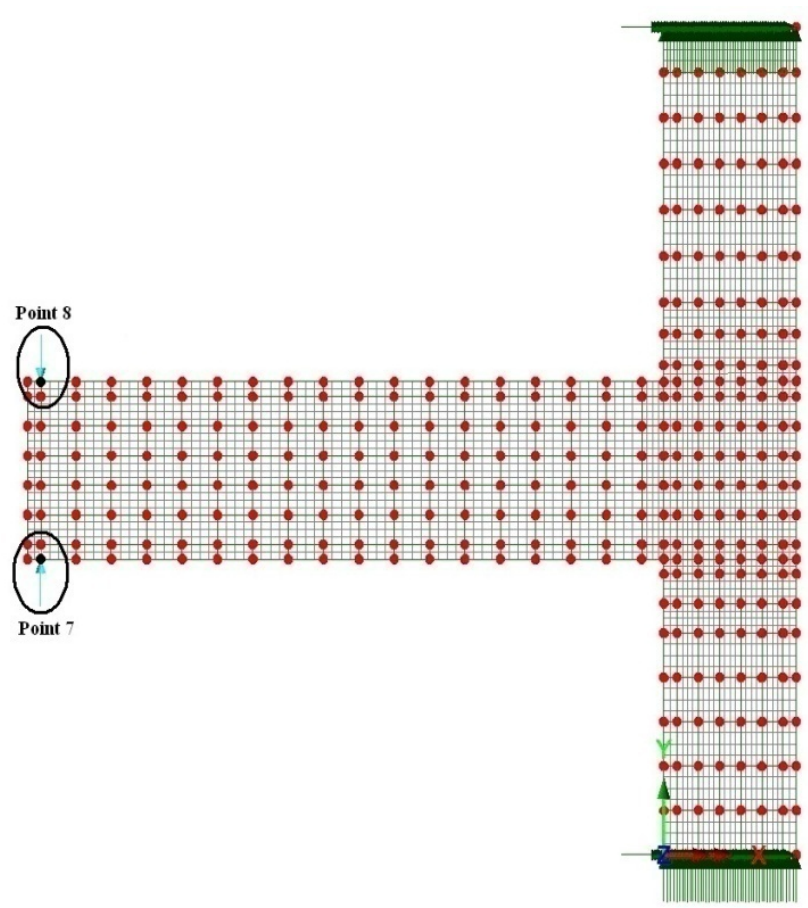

Figure 31. Applying cyclic loading on point 8 at the beam edge (Stage 1)

Table 13. The magnitudes of the applied loads at load point 8 in $y$ direction (Stage 1)

\begin{tabular}{cccc}
\hline Load No. & Load $(\mathrm{kN})$ & Load No. & Load $(\mathrm{kN})$ \\
\hline 1 & -10 & 11 & -110 \\
2 & -20 & 12 & -120 \\
3 & -30 & 13 & -130 \\
4 & -40 & 14 & -140 \\
5 & -50 & 15 & -150 \\
6 & -60 & 16 & -160 \\
7 & -70 & 17 & -170 \\
8 & -80 & 18 & -180 \\
9 & -90 & 19 & -190 \\
10 & -100 & 20 & -200 \\
\hline
\end{tabular}

For each cycle the analysis consisted of 40 different simulations adjusted on the model (20 simulations in stage 1 and 20 in stage 2). Therefore, the cyclic earthquake loading analysis will cover 200 simulations for the five cycles. This will be maintained by running the analysis for a set of different loads. The applied loads $(\mathrm{kN})$ represents the cyclic earthquake loading as a result the displacements, bar forces in the $\mathrm{x}$ direction, cracking pattern, and stresses and strains will be determined. Additionally, the results will be plotted and presented in graphical form. Table 13 illustrates the magnitudes of loads applied on the model at load point 8 (Stage 1) and Table 14 shows the magnitudes of loads applied on the model at load point 7 (Stage 2). Although 40 simulations were carried out for each cycle with a range between $-200 \mathrm{kN}$ to $200 \mathrm{kN}$, the range that has been taken for plotting displacement against deflection were between the loads $-60 \mathrm{kN}$ to $60 \mathrm{kN}$ for the five cycles. This has been decided for the sake of comparison with other experimental results within this limitation.

Table 14. The magnitudes of the applied loads at load point 7 in $y$ direction (Stage 2)

\begin{tabular}{cccc}
\hline Load No. & Load $(\mathrm{kN})$ & Load No. & Load $(\mathrm{kN})$ \\
\hline 1 & 10 & 11 & 110 \\
2 & 20 & 12 & 120 \\
3 & 30 & 13 & 130 \\
4 & 40 & 14 & 140 \\
5 & 50 & 15 & 150 \\
6 & 60 & 16 & 160 \\
7 & 70 & 17 & 170 \\
8 & 80 & 18 & 180 \\
9 & 90 & 19 & 190 \\
10 & 100 & 20 & 200 \\
\hline
\end{tabular}

\subsection{Analysis Procedures}

\subsubsection{Non-linear Static Analysis}

The conduct of non-linear analysis will be established which includes plastic analysis. This will be maintained due to the expectation of a non-linear behavior of the model under cyclic earthquake loading by which material yields and becomes non-linear. Generally speaking, there will be no linearity in terms of stress-strain curve. Another reason for that would be the difference in the properties of the materials used, for instance, reinforcement steel bars and concrete. Each of these two materials behaves in a different way during the analysis. This supports the assumption made on the non-linear behavior of the structure. Initially, the body force, which represents the self-weight of the structure, was assigned with a magnitude of $9.81 \mathrm{~m} / \mathrm{s}^{2}$. This load was applied on all of the structure including lines and surfaces in the y-direction to make sure the model sustains its self-weight before the conduct of further analysis. After running the model including its applied self-weight successfully, the cyclic loading was then applied on the structure as discussed before. In addition, the deformations of the model from the simulations carried out on the cyclic loading will be plotted against loads applied to form an historic graph. It is believed that this sort of analysis will aid in determining the static response, the distribution of loading on the 
model and gives an appropriate indication of the behavior of the joint under cyclic earthquake loading testing.

\subsubsection{Non-linear Dynamic Analysis}

The dynamic analysis is an essential part of conducting the research successfully. This is due to applied real historic earthquakes input on joints, which makes the dynamic analysis an important tool. In this situation, the assigned real historic data have a variation in time, which makes the conduct of such an analysis necessary to understand the dynamic behavior of the structure under real earthquakes. Furthermore, the dynamic analysis was carried out on three real historic earthquakes with different magnitudes and frequencies as discussed earlier. Moreover, the analysis included the self-weight of the structure with a magnitude of $9.81 \mathrm{~m} / \mathrm{s}^{2}$ and UDL (floor load) on the beam. The UDL (floor load) consisted of two loads, live and dead loads. The live load was recognized as $2.5 \mathrm{kN} / \mathrm{m}$ and the dead load had a magnitude of $5 \mathrm{kN} / \mathrm{m}$. For each earthquake the accelerations in the $\mathrm{x}$ and $\mathrm{y}$ directions was taken from Strong Motion Database Navigator (SMDN) and converted through the Seismic Data file to time and factor data. Then the time and factor data for each of the accelerations ( $\mathrm{x}$ and $\mathrm{y}$ directions) were taken and inserted into the load curve. Therefore, two load curves were identified for example, acceleration in $\mathrm{x}$ direction and acceleration in y direction. Subsequently, two new acceleration loadings were identified one for acceleration in the $\mathrm{x}$ direction and the other for acceleration in the y direction. For each of the acceleration loadings the value was 1 in the intended direction either in $\mathrm{x}$ or in $\mathrm{y}$ direction. This procedure was carried out on the real historic earthquakes. Finally, this kind of analysis allows the conduct of important dynamic calculations and determination of the structures frequency. Then they can both be used to give a clear indication of the dynamic behavior under each historic earthquake.

\subsubsection{Cracking Pattern Analysis}

The crack pattern tool, which is available in LUSAS software, gives the opportunity to produce a crack pattern of the mode of failure in concrete. The design codes allow some cracking in concrete but within certain limits and under a specific range. The acceptable range of the crack's depth and distance is given in millimeters. Thus, the crack pattern that will be obtained can provide adequate knowledge of the capability of the proposed model in terms of checking if the cracks are within the acceptable range. The cracking pattern obtained can then be compared with the pattern of crack observations done by [22] and [25]. Additionally, the cracking pattern will also be compared with that obtained by [9] in his experimental study on the strengthening of reinforced concrete beamcolumn joints with steel fiber during earthquake loading.

\subsubsection{Seismic Analysis}

The seismic analysis was carried out on the applied real earthquake model to examine the seismic behavior of the model at a specific node and element for different historic earthquakes. The node and the element will be chosen according to the maximum magnitude it carries in terms of displacement, and stress or strain within the joint. The seismic analysis was only carried out on the applied historic earthquakes and not on the cyclic earthquake loading. This is due to the fact that the behavior of the cyclic earthquake load is not variable like the real earthquakes, which means the motion is known, as the load is manually set. On the other hand, the historic earthquakes act in a totally different way and are set automatically since it is not predicted in terms of its motion. Therefore, the seismic analysis is essential to investigate the seismic motion of the joint element or node within the structure. For each historic earthquake the response time will be plotted against displacements, plain stresses and plain strains at specific elements and nodes within the joint member. This will give a valuable clearance of the seismic citations of the joint. Additionally, the results obtained from this analysis will be used for plotting a graph of deflection $(\mathrm{mm})$ versus load $(\mathrm{kN})$. Finally, the results attained will be presented in graphical form.

\subsection{Comparison of Results}

The results will include load against displacement graphs, stresses against strain graphs and bar forces in the $\mathrm{x}$ direction. The presented results will be in the form of graphs, tables and contour maps.

The cyclic earthquake loading results will be compared with previous experimental published results while the results attained from the three historic real earthquakes will be compared with each other. The comparison between the three historic earthquakes will be established to: (1) check if the model can sustain these earthquakes and (2) to investigate under which earthquake the joint is affected most.

The cyclic and seismic results obtained from LUSAS will be tabulated and presented in graphical form to be compared in the discussion stage of this study. The results obtained will be compared with both published experimental studies and real life situations (investigations from the literature review). This will help in identifying the reliability of the results achieved and the capabilities of the model in terms of handling historic earthquakes. The comparison will include comparing the crack pattern, displacements, stresses, strains and seismic citation.

\subsection{The Production of Some Recommendations}

The recommendations part of this study will be considering Eurocode 8: Design of structures for earthquake resistance. General rules, seismic actions and rules for buildings (2004) BS EN 1998-1: 2004 [27]. This comprises the improvement of some sections and suggesting improvements including the designing of beam-column joints by providing the designers with more information to improve the resistance against seismic loading. The preparation of recommendations and guidelines for the utilization of modelling for studying $\mathrm{RBC}$ joints can then be of benefit to researchers and industry practitioners. 


\section{Results Presentation}

Initially, the self weight of the model was analyzed to make sure that the structure are capable and can sustain its own weight before conducting further analysis, for instance, static and dynamic. Appendix 7.1 presents contour maps of non-linear static analysis of model's self weight. Figures 48, 49, 50 and 51 (contour maps) in Appendix 7.1 illustrates displacement in $\mathrm{x}$-direction, displacement in y-direction, stress - plane stress and force - bar (Fx) respectively. Moreover, the contour maps showed symmetry within the structure in terms of displacements, stresses with small magnitudes which indicates that the structure is capable of handling its self weight and ready to be seismically analyzed.

\subsection{Non-linear Static Analysis (Cyclic Earthquake Loading)}

The deflection of the beam-column joint results under different loads for the full five cycles is shown below in Graph 16 and maximum load-deflection observed in each cycle is presented in Table 15 .

The stress against strain graph for cycles 1, 2, 3, 4 and 5 is presented in Graphs 17, 18, 19, 20 and 21 respectively.
The yield point of the structure for each cycle is given in Table 16.

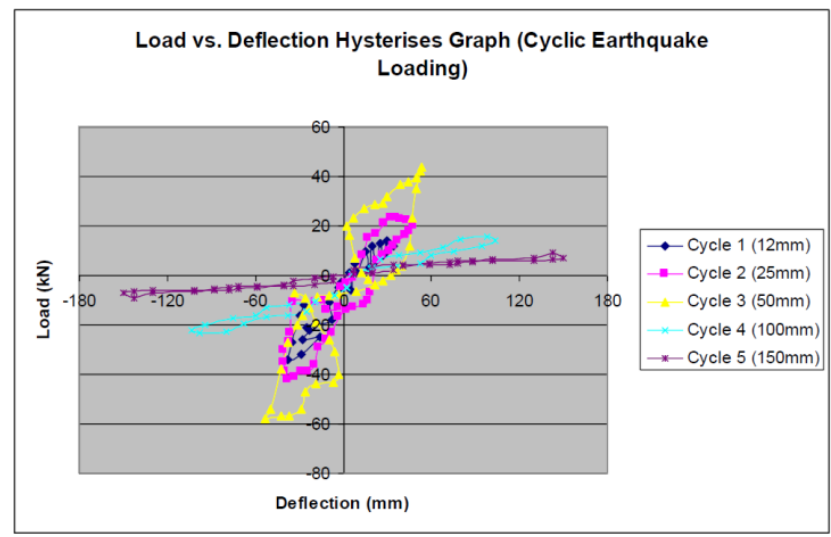

Graph 16. Hysterises graph (Deflection vs. Load) for the five cycles

Table 15. Hysterises graph summary of cyclic earthquake loading.

\begin{tabular}{lll}
\hline Cycle & Maximum deflection $(\mathrm{mm})$ & Load $(\mathrm{kN})$ \\
1 & -38 & -34 \\
2 & -48 & -20 \\
3 & -53 & -58 \\
4 & -103 & -22 \\
5 & -150 & -7 \\
\hline
\end{tabular}

July 27,2011 LUSAS Modeller 14.5-2

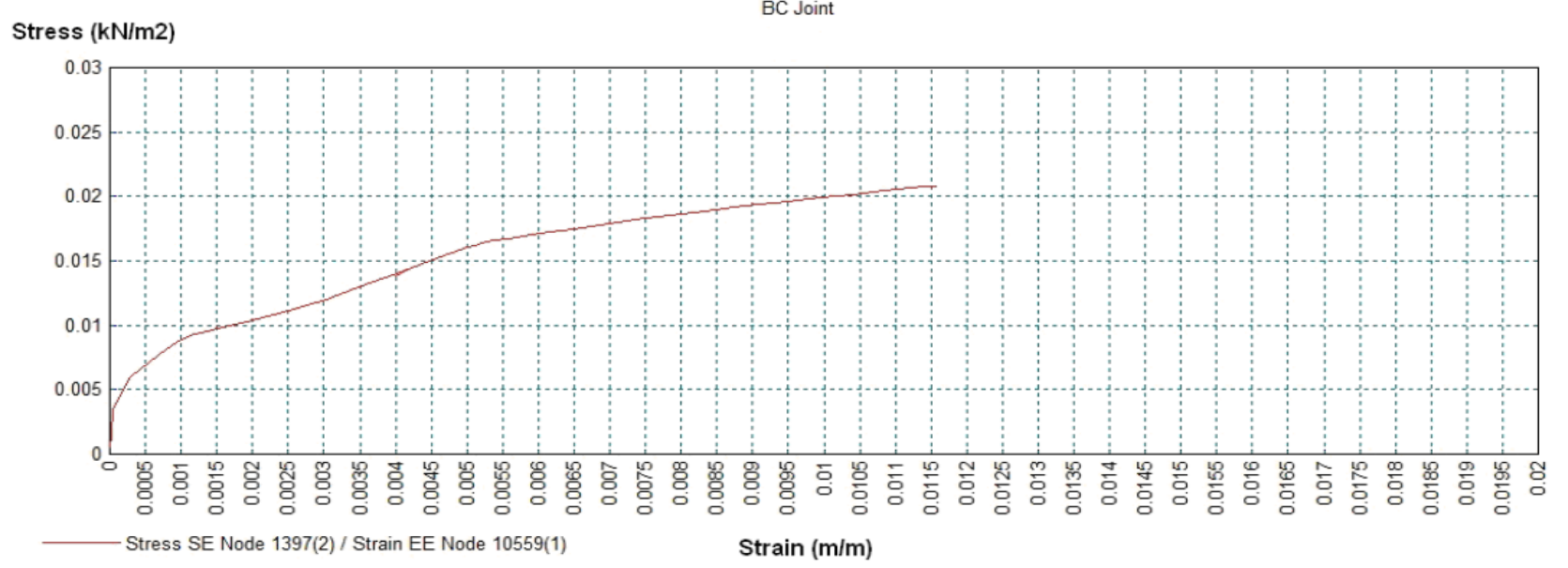

Graph 17. Stress against strain graph for cycle 1 (12mm)

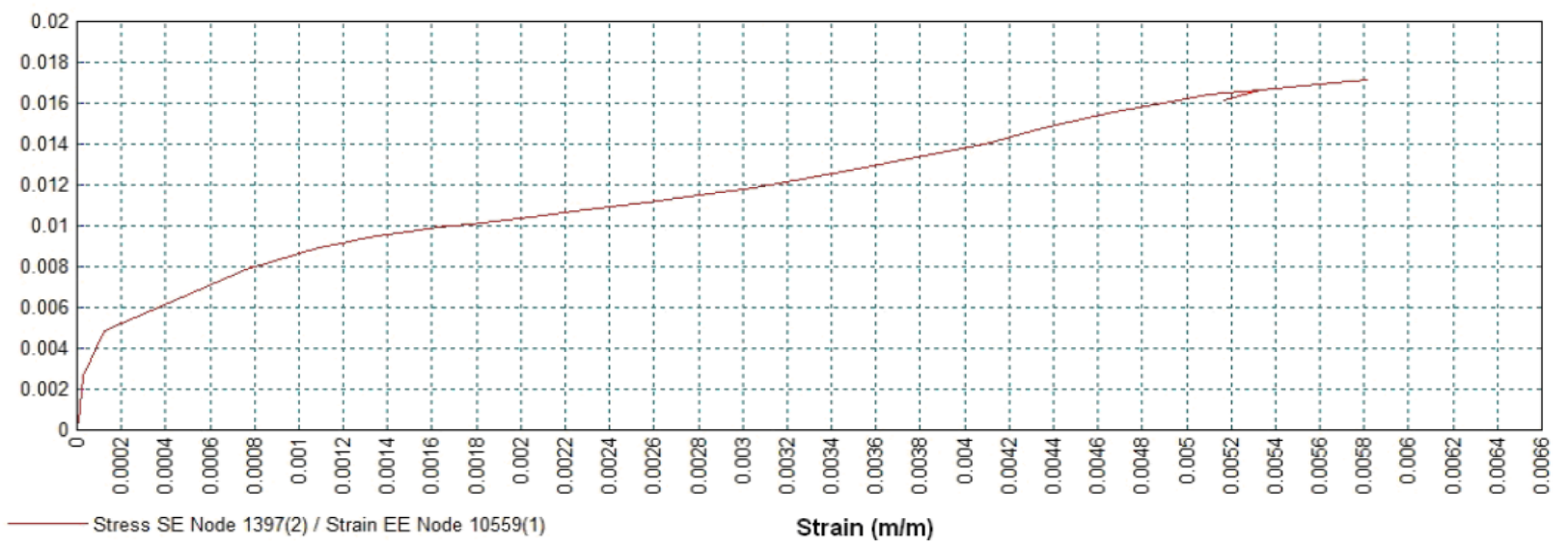


LUSAS Modeller 14.5-2

Stress (kN/m2)

BC Joint

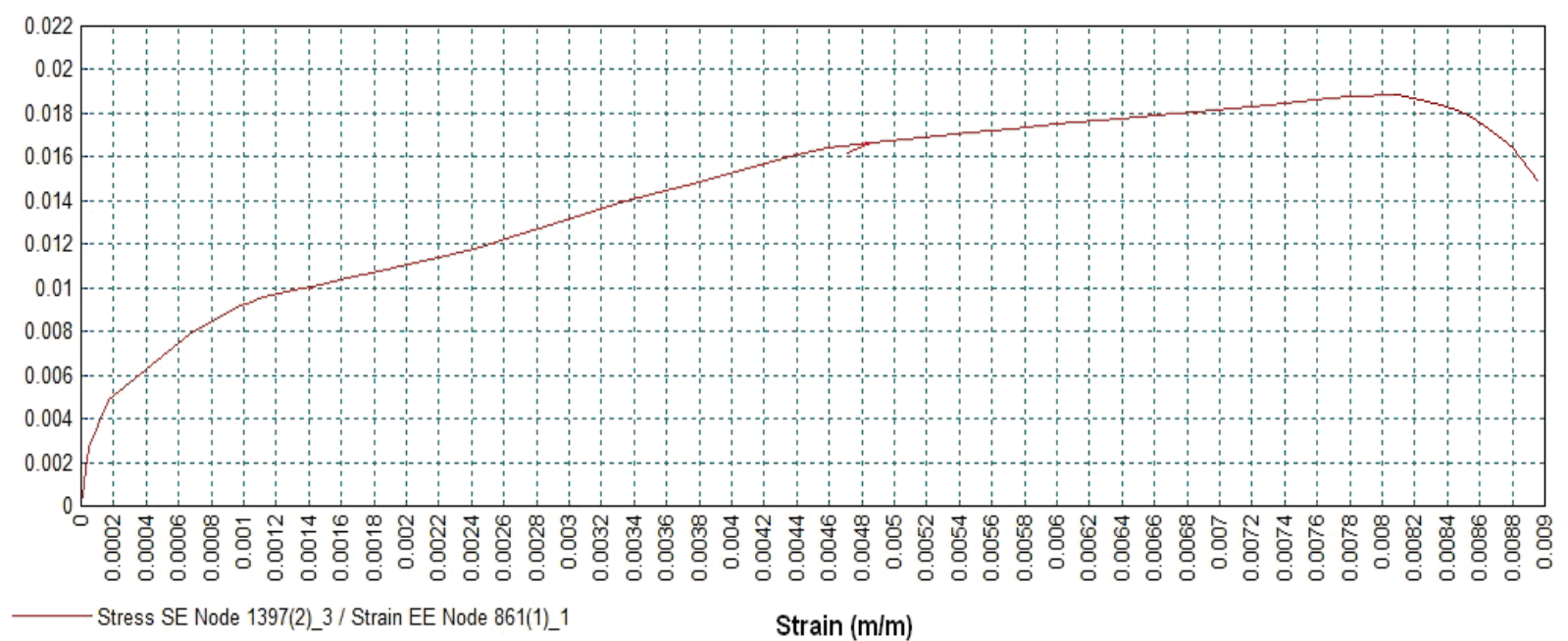

Graph 19. Stress against strain graph for cycle $3(50 \mathrm{~mm})$

LUSAS Modeller 14.5-2

\section{Stress (kN/m2)}

BC Joint

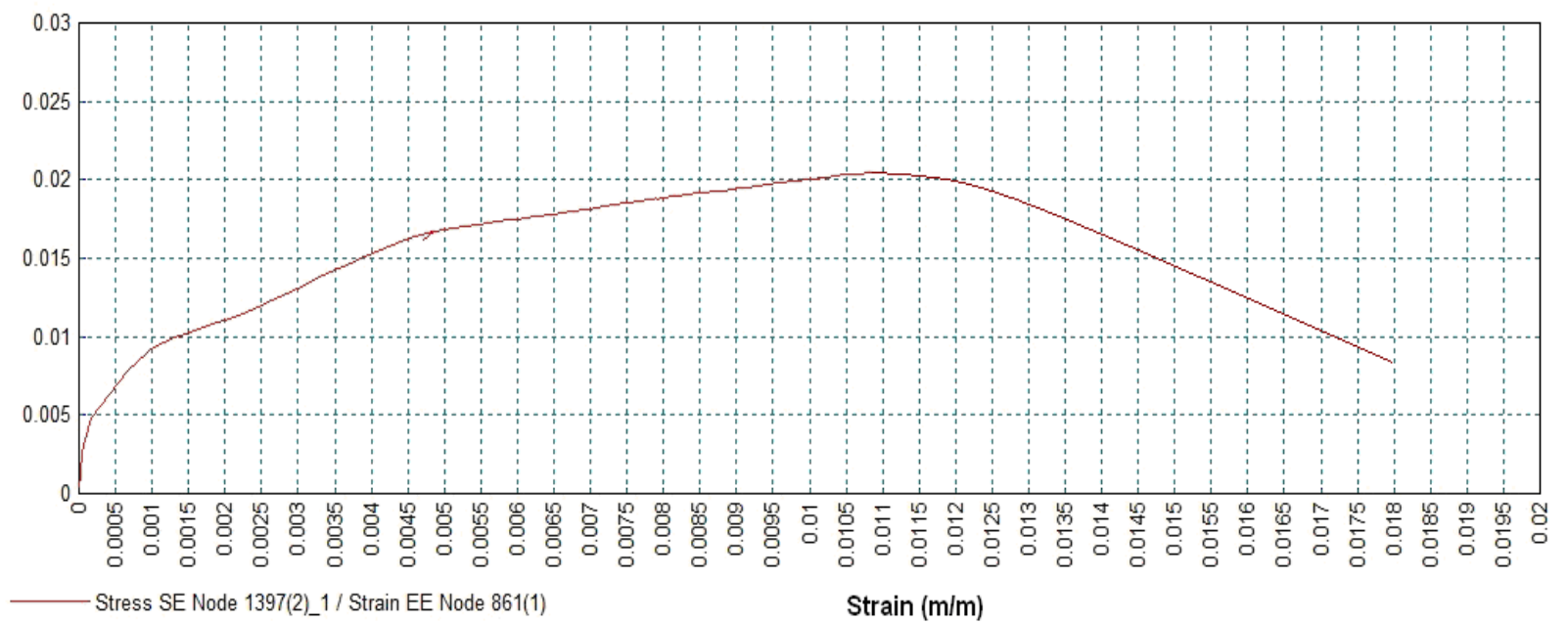

Graph 20. Stress against strain graph for cycle $4(100 \mathrm{~mm})$

\section{Stress (kN/m2)}

BC Joint

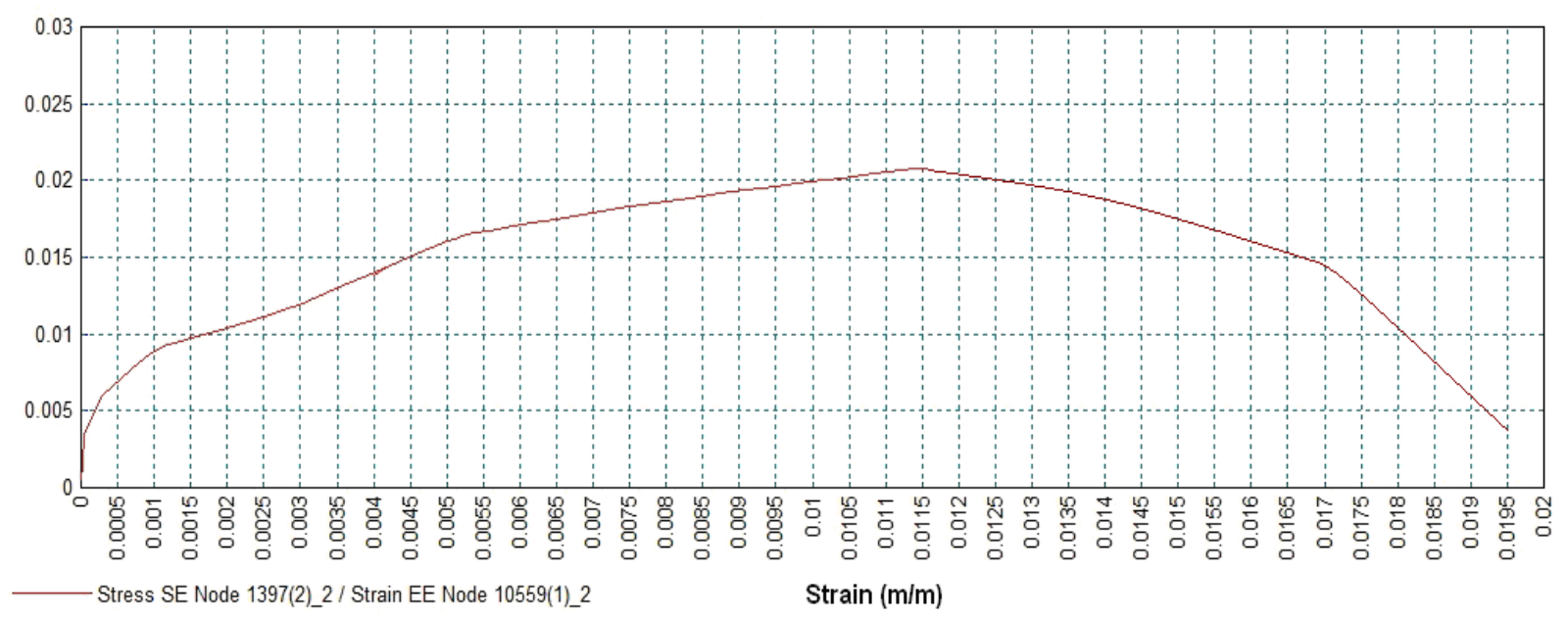

Graph 21. Stress against strain graph for cycle $5(150 \mathrm{~mm})$ 
Table 16. Stress vs. strain graphs summary of cyclic earthquake loading

\begin{tabular}{ccc}
\hline Cycle & Yield point & \\
\hline & Stress $(\mathrm{m} / \mathrm{m})$ & Strain $\left(\mathrm{kN} / \mathrm{m}^{2}\right)$ \\
2 & Not yielding at this cycle \\
3 & Not yielding at this cycle \\
4 & 0.019 & 0.008 \\
5 & 0.021 & 0.011 \\
& 0.021 & 0.0115 \\
\hline
\end{tabular}

The deformed mesh of the author's model under cyclic earthquake loading for the 5 cycles at stage 1 (downward) are presented in Appendix 7.2.1 (Figure 52 to Figure 56). While, the deformed mesh under cyclic earthquake loading for the 5 cycles at stage 2 (upward) are shown in Appendix 7.2.2 (Figure 57 to Figure 61).

\subsection{Non-linear Dynamic Analysis (Historic Earthquakes)}

The deformed meshes of the author's model for the three applied real earthquakes are presented in Appendix 7.2.3 (Figure 62 to Figure 64), which shows haw the mesh behaving under each earthquake.

\subsubsection{Historic Earthquake 1 - Athens}

The loading distribution of the $\mathrm{BC}$ joint under Athens' historic earthquake is demonstrated in Figure 32 below.

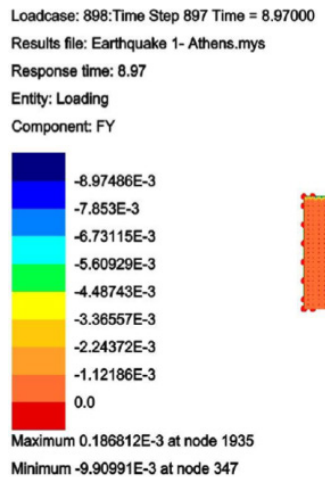

Figure 32. Loading (Fy) contour map of Athens' historic earthquake

The contour map (Figure 32) of the loading (Fy) shows that the maximum load occurs at node 1935. Accordingly, the load vs. displacement graph for the Athens earthquake was plotted at this node and presented in Graph 22.

In terms of stress and strain it has been discovered that maximum magnitude occurs at node 5918. Therefore, the stress against strain graph for the Athens earthquake at this node is shown in Graph 23.

LUSAS Modeller 14.5-2

BC Joint

July 28, 2011

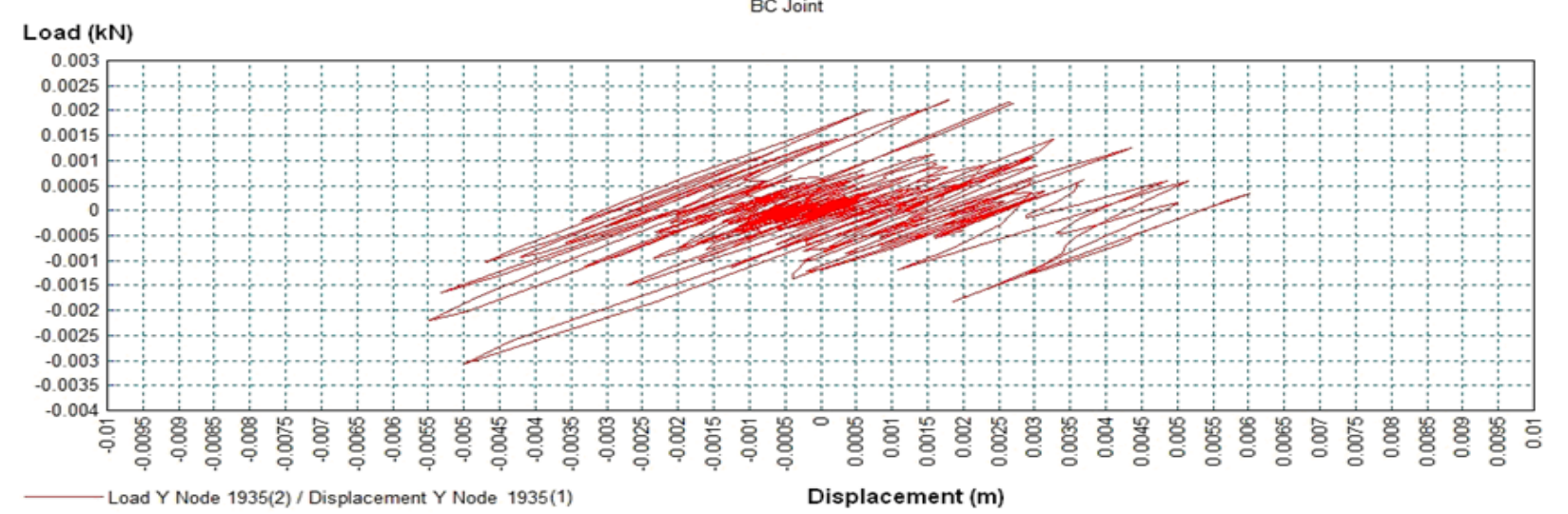

C:IUsersWhalidDesktopWNon-linear Dynamic Analysis Earthquake 1- Athens.mdl

Graph 22. Load vs. displacement graph of Athens' historic earthquake

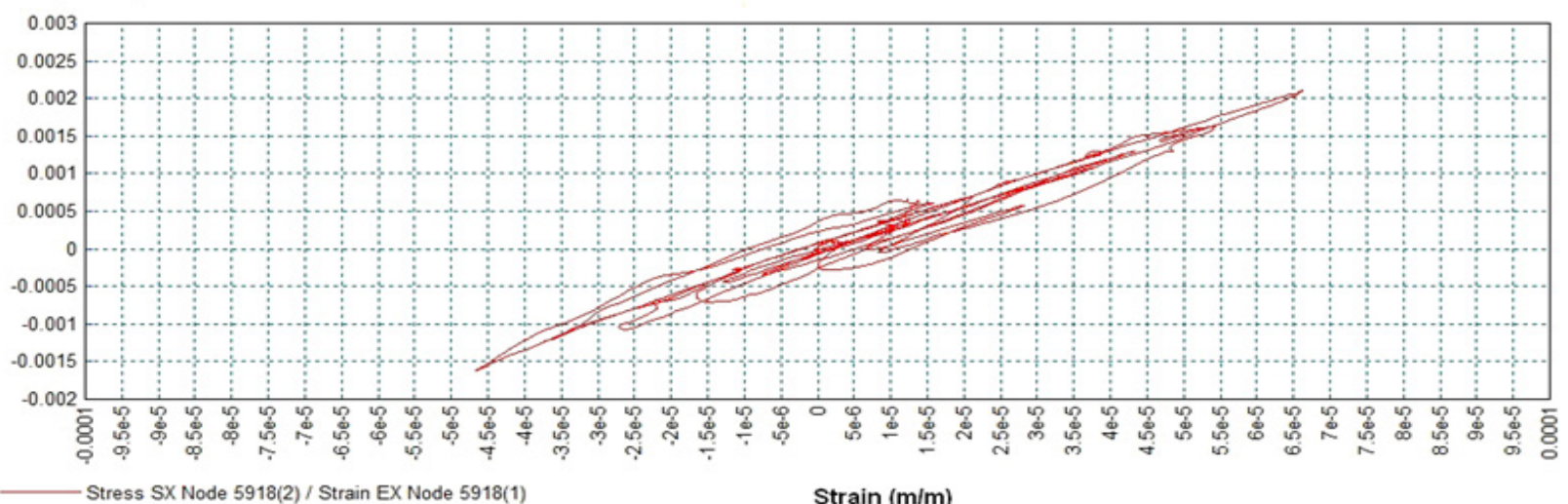


LUSAS Modeller $14.5-2$

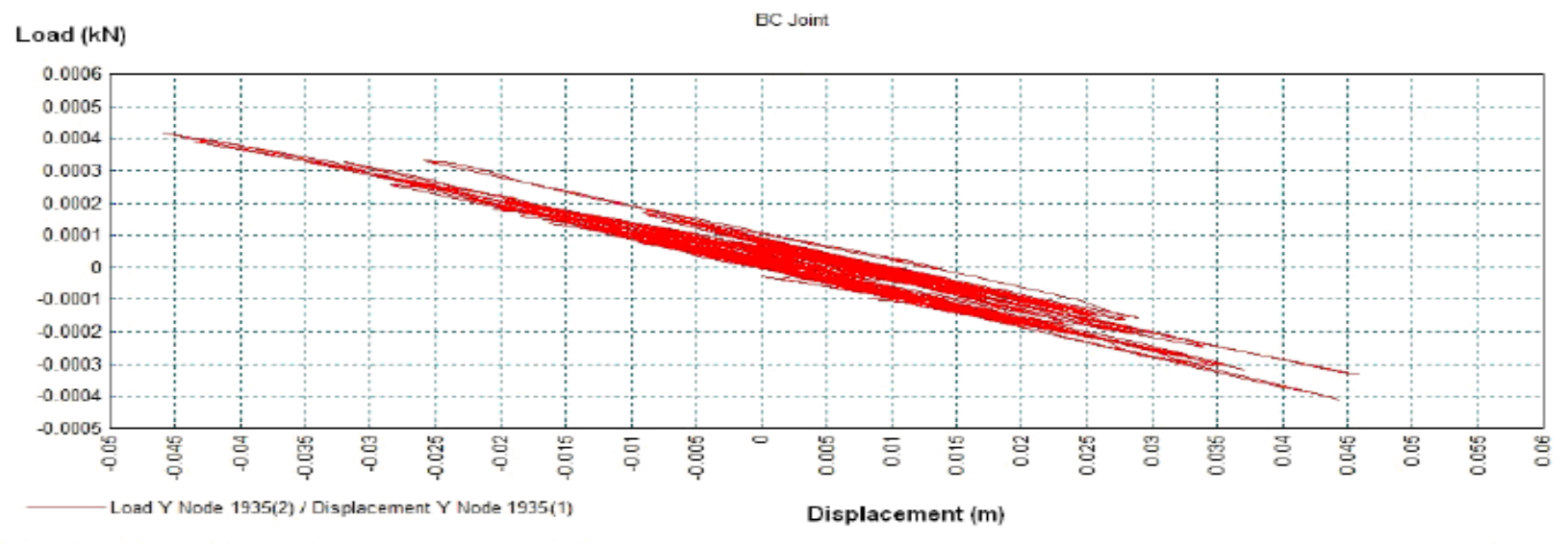

C.1Users'KhalidDesktopWon-linear Dynamic AnalysisłEarthquake 2- Fruili.mdl

Graph 24. Load vs. displacement graph of Friuli's historic earthquake

\subsubsection{Historic Earthquake 2 - Friuli}

The loading distribution of the BC joint under Friuli's historic earthquake is demonstrated in Figure 33 below.

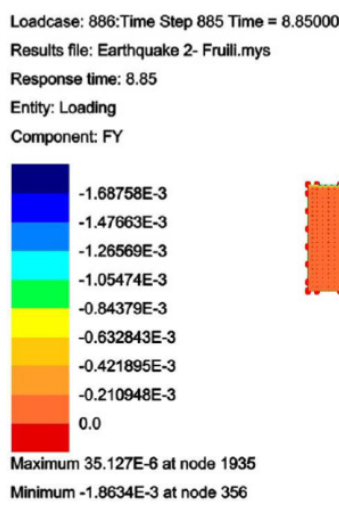

Figure 33. Loading (Fy) contour map of Friuli's historic earthquake

The contour map (Figure 33) of the loading (Fy) shows that the maximum load occurs at node 1935. Accordingly, the load vs. displacement graph for the Friuli earthquake was plotted at this node and presented in Graph 24.

In terms of stress and strain it has been discovered that maximum magnitude occurs at node 5725. Therefore, the stress against strain graph for the Friuli earthquake at this node is shown in Graph 25.

\subsubsection{Historic Earthquake 3 - Izmir}

The loading distribution of the BC joint under Izmir's historic earthquake is demonstrated in Figure 34 below.

The contour map (Figure 34) of the loading (Fy) shows that the maximum load occurs at node 347 . Accordingly, the load vs. displacement graph for the Izmir earthquake was plotted at this node and presented in Graph 26.

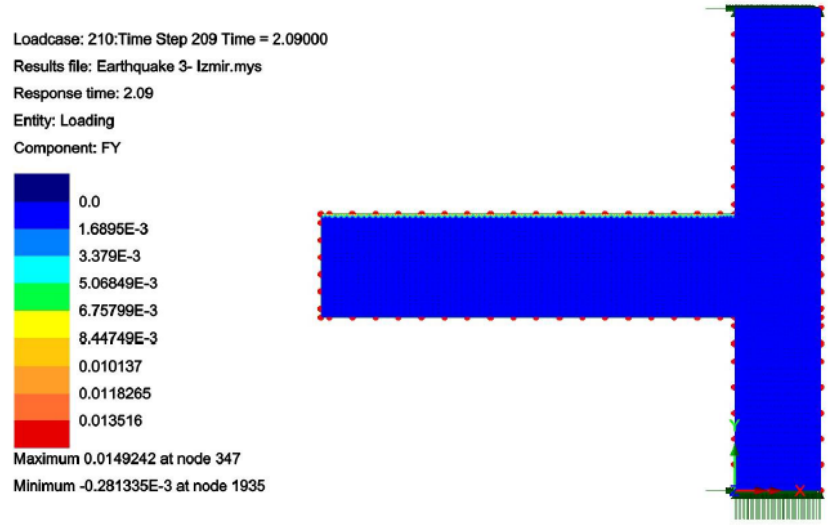

Figure 34. Loading (Fy) contour map of Izmir's historic earthquake

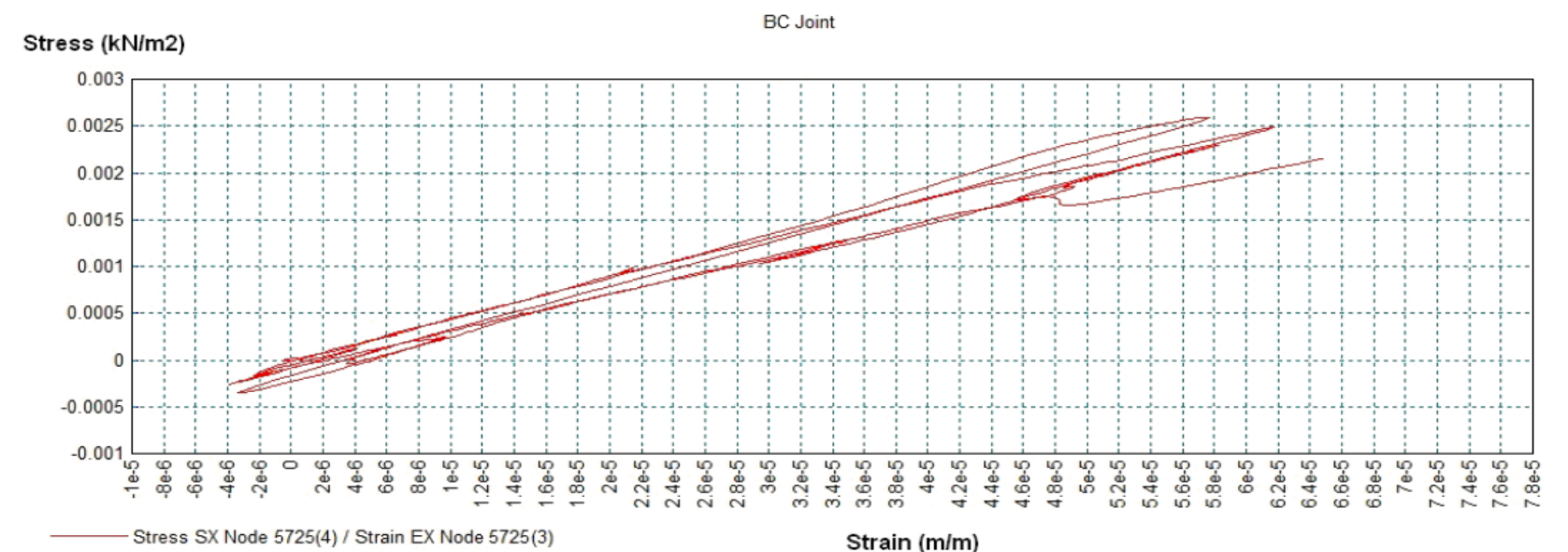




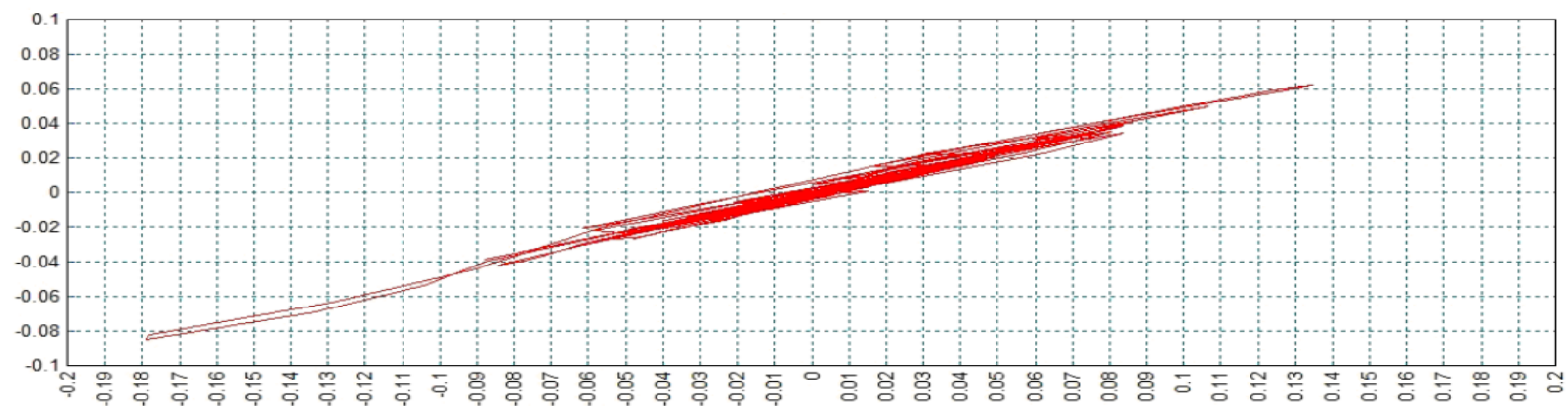

Graph 26. Load vs. displacement graph of Izmir's historic earthquake

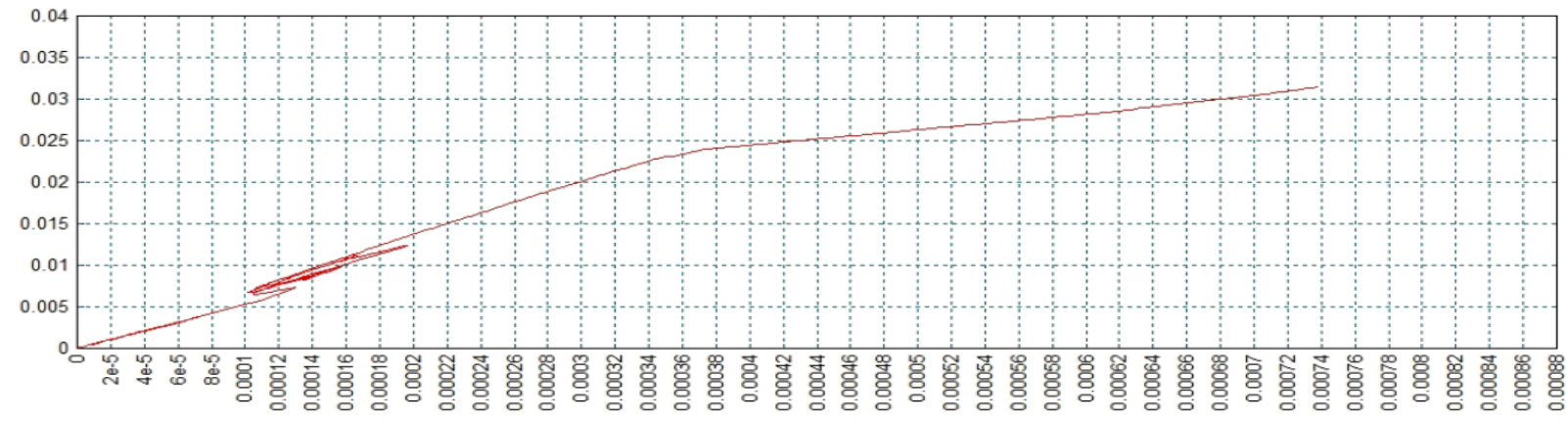

Graph 27. Strain vs. stress graph of Izmir's historic earthquake

In terms of stress and strain it has been discovered that maximum magnitude occurs at node 110 . Therefore, the stress against strain graph for the Izmir earthquake at this node is shown in Graph 27.

\subsection{Cracking Pattern Analysis}

\subsubsection{Cyclic Earthquake Loading}

The crack pattern for cyclic earthquake loading is shown below (Figure 35 - Figure 39) for the five downward cycles, while Figure 40 presents the crack pattern for upward cycle 5 (150mm).

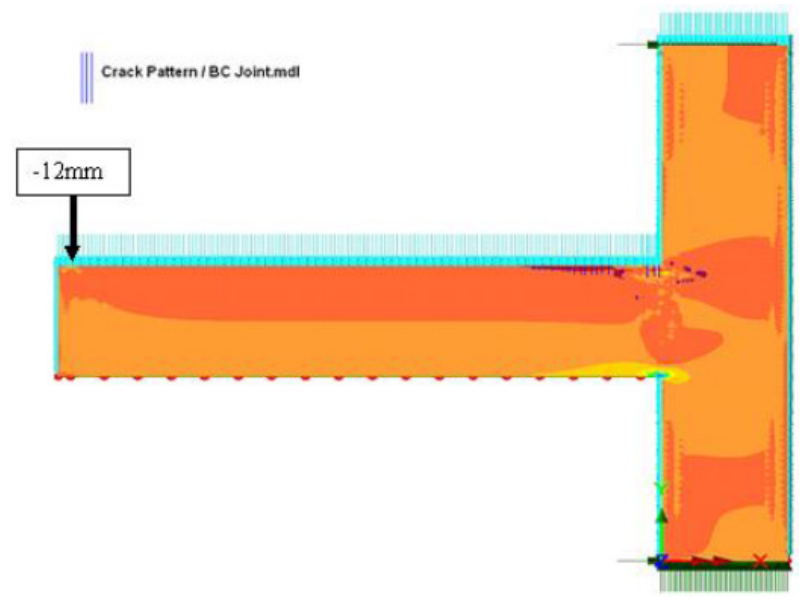

Figure 35. Cracking pattern under cycle 1 downward (-12mm)

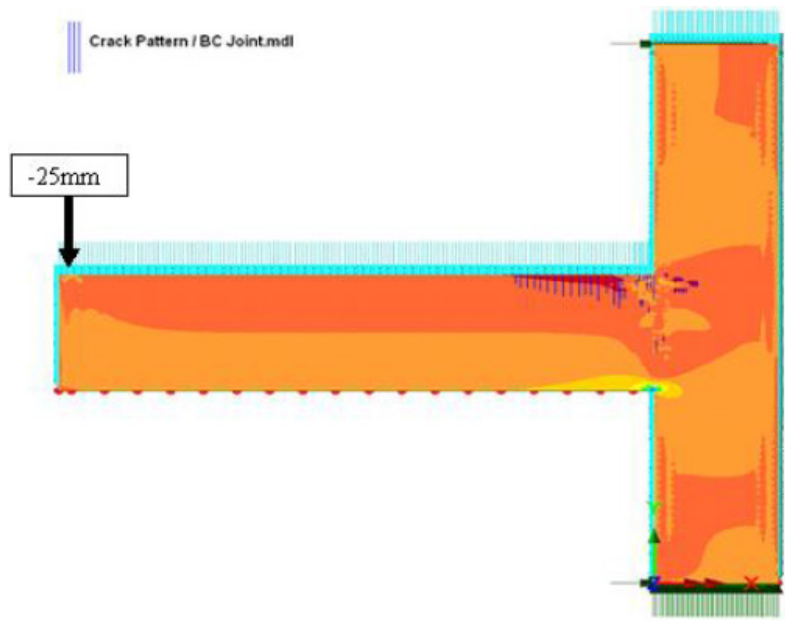

Figure 36. Cracking pattern under cycle 2 downward (-25mm)

A summary of the cracking pattern for the five cycles is presented in Table 17 below, which includes the level of cracks, the location of cracks within the structure and the assumption if the level of cracks is acceptable or unacceptable by the design codes in terms of repairing the cracks after the event of an earthquake. The cracking pattern analysis was carried out for five downward cycles and one upward cycle $(150 \mathrm{~mm})$. As shown in Table 17 , the joint is affected during all the cycles with a variation in level of cracks under a certain cycle. Downward cyclic loading during cycles 4 and 5 also influenced the upper part of the beam. On the other hand, the results achieved 
for the crack pattern of the upward cycle $(150 \mathrm{~mm})$ demonstrated cracks across the joint and the lower part of the beam next to the joint. In the case of a full cycle the crack pattern of the joint is a combination of both the downward and upward cycles. The author has decided not to present the full cycle cracking pattern to avoid confusion and to have a clear discussion of the results.

Table 17. Cracking pattern summary of cyclic earthquake loading

\begin{tabular}{|c|c|c|c|}
\hline Cycle No. & $\begin{array}{c}\text { Level of } \\
\text { cracks }\end{array}$ & Location & Summary \\
\hline 1 Downward & Minor & $\begin{array}{c}\text { Joint, upper part of beam } \\
\text { next to joint }\end{array}$ & Acceptable \\
\hline 2 Downward & Intermediate & $\begin{array}{c}\text { Joint, upper part of beam } \\
\text { next to joint }\end{array}$ & Acceptable \\
\hline 3 Downward & $\begin{array}{c}\text { Intermediate } \\
\text { And major }\end{array}$ & $\begin{array}{c}\text { Joint, upper part of beam } \\
\text { next to joint and some parts } \\
\text { of column }\end{array}$ & Un-accept. \\
\hline 4 Downward & Major & $\begin{array}{c}\text { Joint, half of Upper part of } \\
\text { beam next to joint }\end{array}$ & Un-accept. \\
\hline 5 Downward & Major & $\begin{array}{c}\text { Joint, more than half of the } \\
\text { upper part of beam next to } \\
\text { joint }\end{array}$ & Un-accept. \\
\hline 6 Upward & Major & $\begin{array}{c}\text { Joint, more than half of the } \\
\text { lower part of beam next to } \\
\text { joint }\end{array}$ & Un-accept. \\
\hline
\end{tabular}

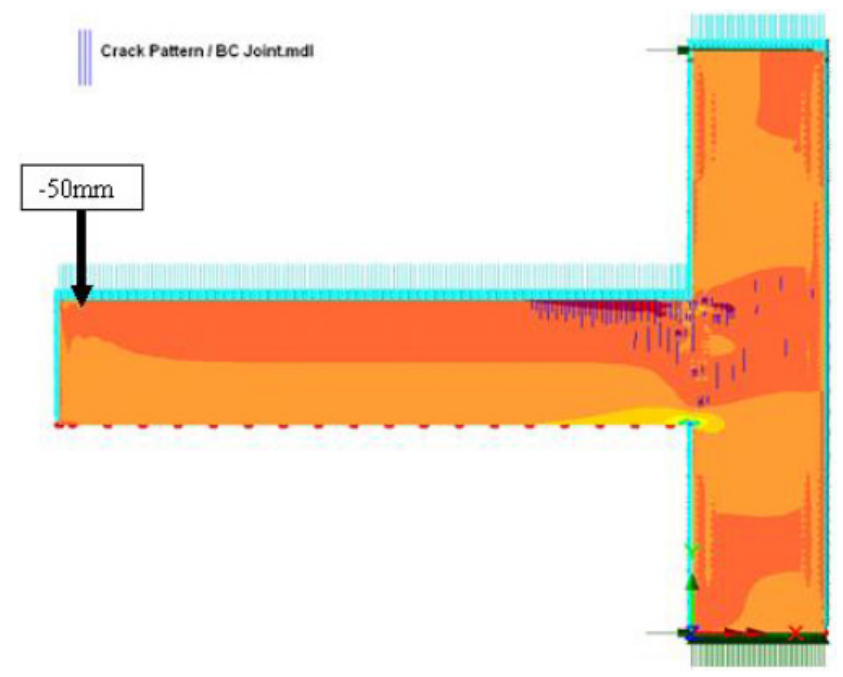

Figure 37. Cracking pattern under cycle 3 downward (-50mm)

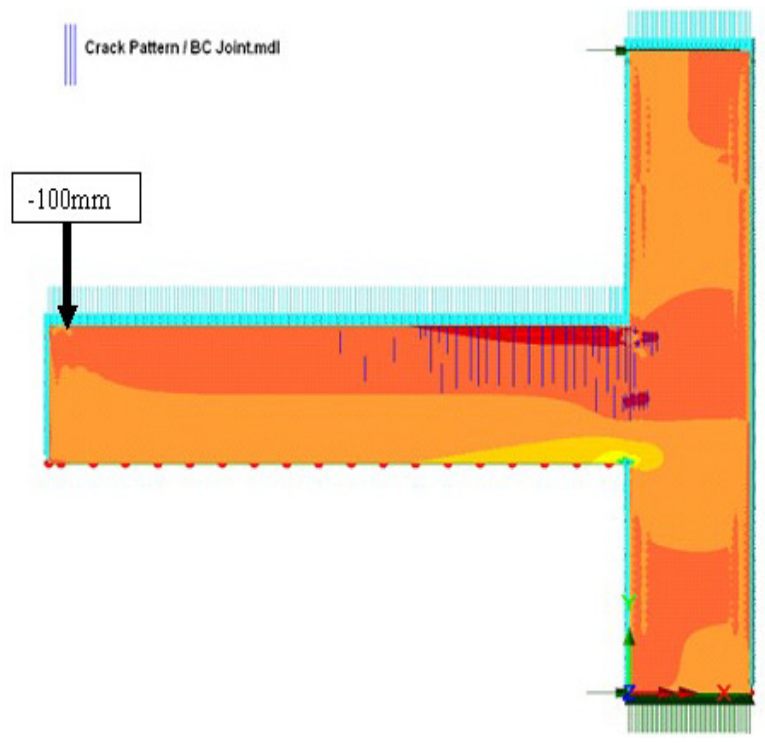

Figure 38. Cracking pattern under cycle 4 downward $(-100 \mathrm{~mm})$

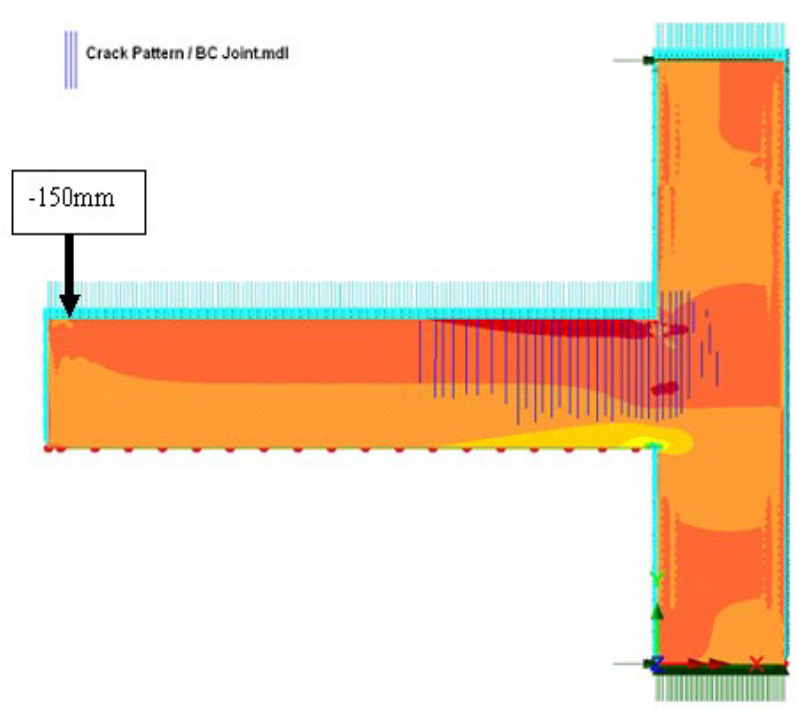

Figure 39. Cracking pattern under cycle 5 downward (-150mm).

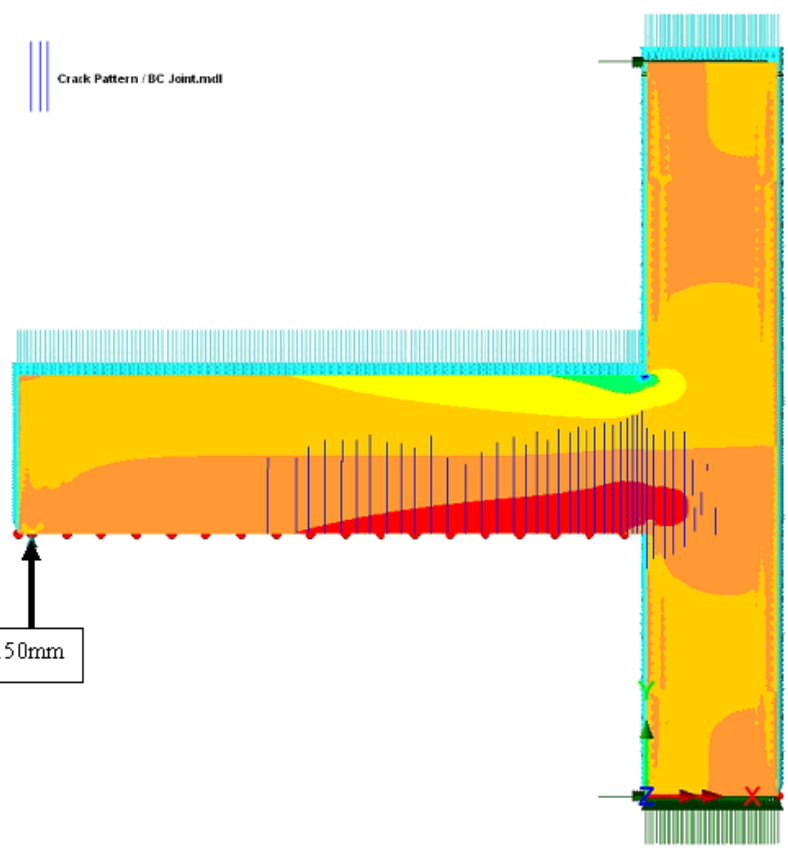

Figure 40. Cracking pattern under cycle 5 upward $(150 \mathrm{~mm})$

\subsubsection{Historic Earthquake 1 - Athens}

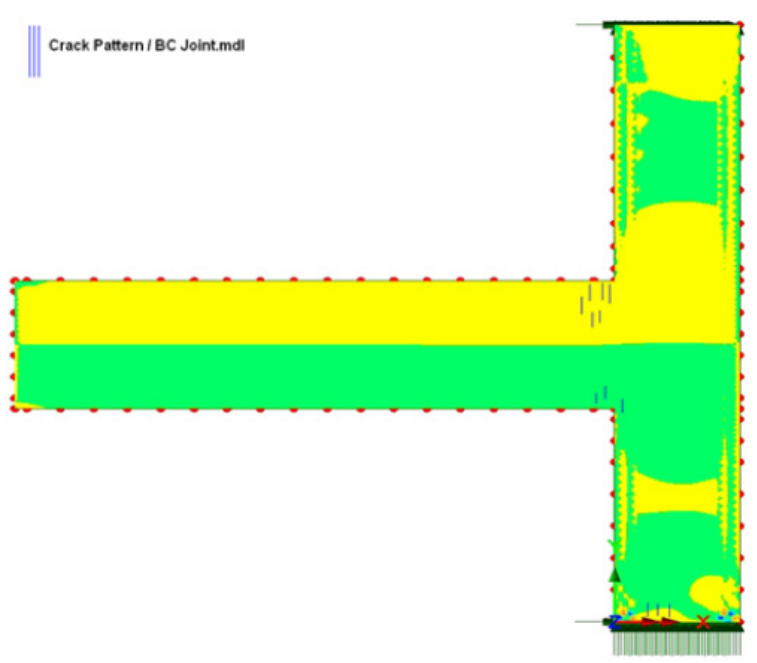

Figure 41. Cracking pattern under Athens' historic earthquake 
Tension

Compression

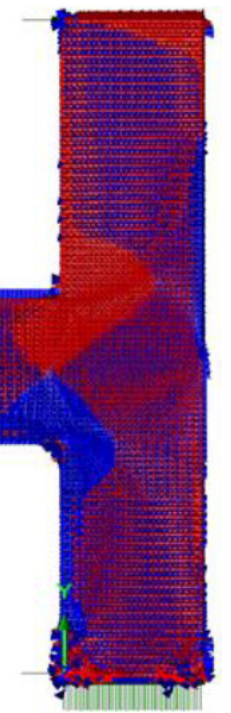

Figure 42. Tension and compression contour map of Athen's historic earthquake

The cracking pattern that has been obtained after applying the Athens earthquake is presented in Figure 41. The tension and compression contour map of the structure for the Athens earthquake is shown in Figure 42.

\subsubsection{Historic Earthquake 2 - Friuli}

The cracking pattern that has been obtained after applying the Friuli earthquake is presented in Figure 43. The tension and compression contour map of the structure for the Friuli earthquake is shown in Figure 44.

\subsubsection{Historic Earthquake 3 - Izmir}

The cracking pattern that has been obtained after applying the Izmir earthquake is presented in Figure 45. The tension and compression contour map of the structure for the Izmir earthquake is shown in Figure 46.

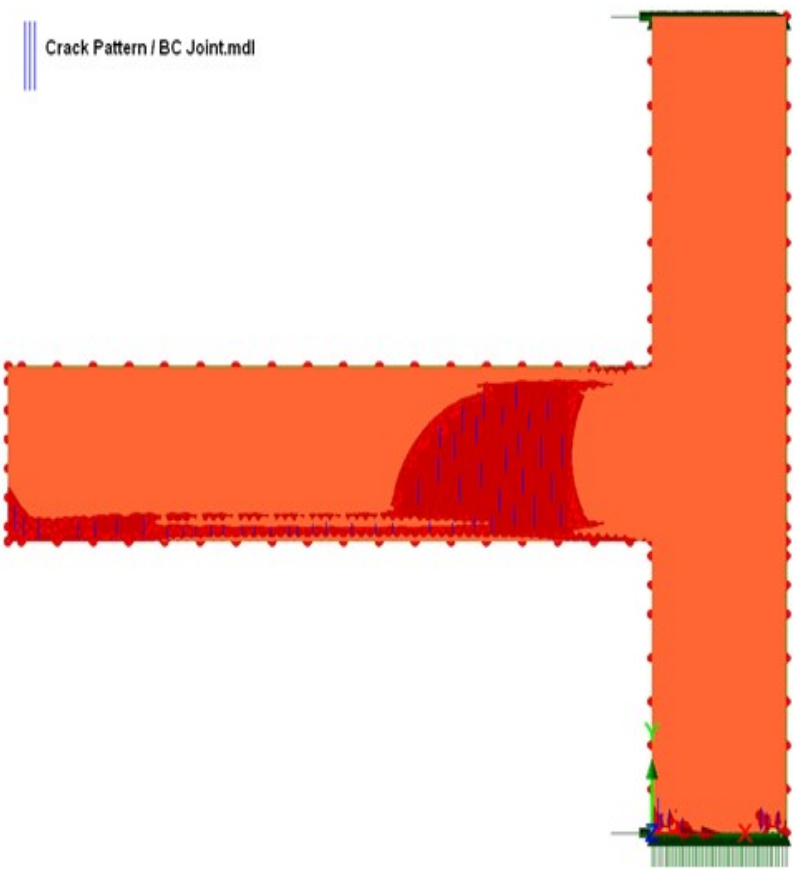

Figure 43. Cracking pattern under Friuli's historic earthquake

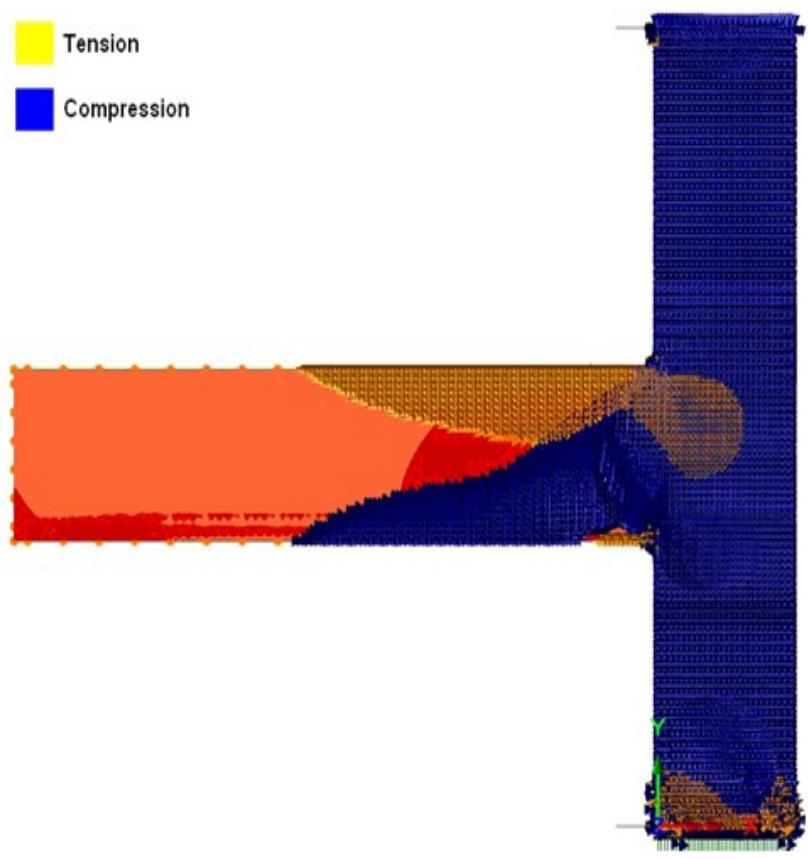

Figure 44. Tension and compression contour map of Friuli's historic earthquake

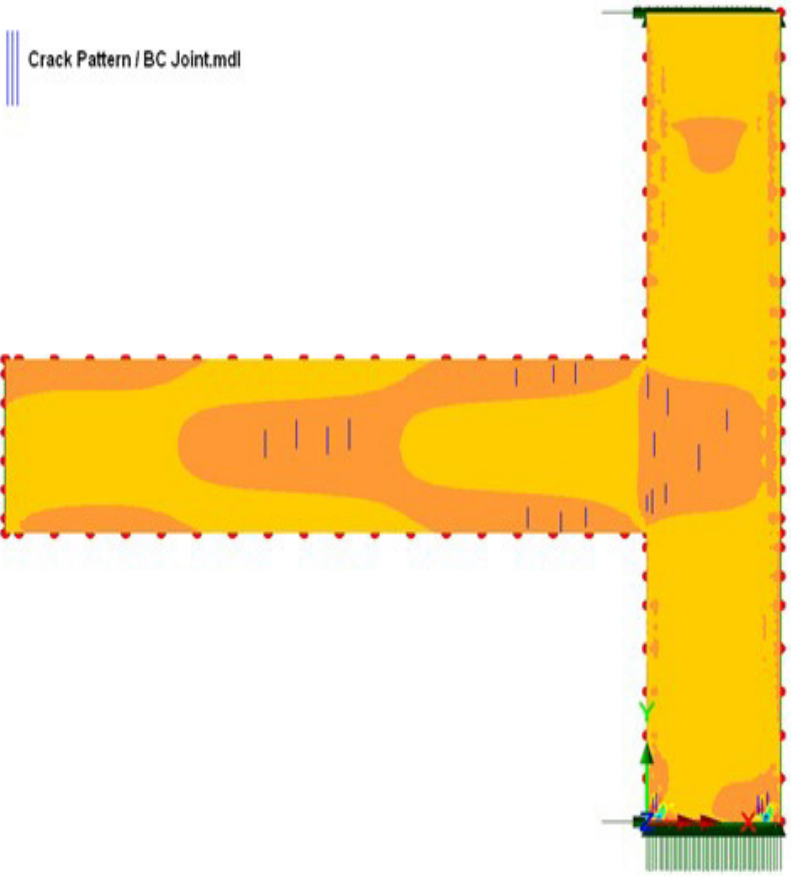

Figure 45. Cracking pattern under Izmir's historic earthquake

The tension and compression within the model during the Izmir historic earthquake is presented in Figure 46. Where the red color represents the tension and the blue color demonstrates compression. Table 18 below provides a summary of the cracking pattern for the three applied historic real earthquakes

Table 18. Cracking pattern summary of the applied real historic earthquakes

\begin{tabular}{|c|c|c|c|}
\hline $\begin{array}{c}\text { Historic } \\
\text { earthquake }\end{array}$ & Level of cracks & Location & Summary \\
\hline Athens & Minor & Joint & Acceptable \\
\hline Friuli & Intermediate & $\begin{array}{c}\text { Middle and lower parts } \\
\text { of the beam }\end{array}$ & Acceptable \\
\hline Izmir & $\begin{array}{c}\text { Minor and } \\
\text { Intermediate }\end{array}$ & $\begin{array}{c}\text { Joint, Upper, lower and } \\
\text { middle parts of the beam }\end{array}$ & Acceptable \\
\hline
\end{tabular}


Tension

Compression

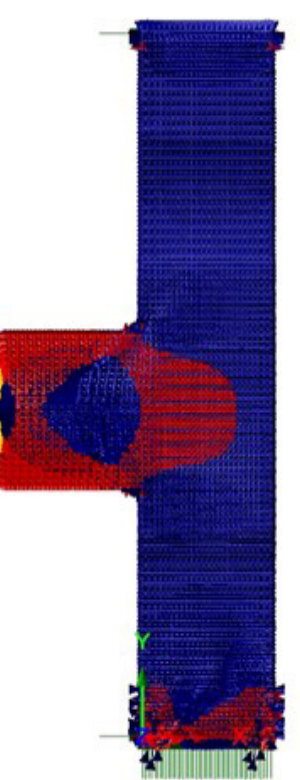

Figure 46. Tension and compression contour map of Izmir's historic earthquake

\subsection{Seismic Analysis (Historic Earthquakes)}

\subsubsection{Historic Earthquake 1 - Athens}

The distributed axial force for the response time of the Athens earthquake is presented in Graph 28. Table 19 summarizes the response time by which the maximum peaks occurred under the Athens earthquake.

The maximum axial force for the Athens earthquake occurred at the node location 1935. The critical time of the Athens earthquake by which the axial force is the most at this node will be discussed further in the next chapter and comparisons with the other two real earthquakes will be drawn, for instance, Friuli and Izmir.

The distributed displacement for the response time of the Athens earthquake is presented in Graph 29. Table 20 summarizes the response time by which the maximum peaks occurred under the Athens earthquake.
The maximum displacement for the Athens earthquake occurred at the node location 1935. The critical time of the Athens earthquake by which the displacement is the most at this node will be discussed further in the next chapter and comparisons with the other two real earthquakes will be drawn, for instance, Friuli and Izmir.

The distributed stress for the response time of the Athens earthquake is presented in Graph 30. Table 21 summarizes the response time by which the maximum peaks occurred under the Athens earthquake.

The maximum stress for the Athens earthquake occurred at the node location 5918. The critical time of the Athens earthquake by which the stress is the most at this node will be discussed further in the next chapter and comparisons with the other two real earthquakes will be drawn, for instance, Friuli and Izmir.

Table 19. Summary of Maximum Peaks with Respect to Time and Axial Force (Earthquake 1 - Athens)

\begin{tabular}{ccc}
\hline Unit & Time (Seconds) & Axial Force $(\mathrm{kN})$ \\
\hline Maximum positive peak & 3.6 & 0.002 \\
Maximum negative peak & 3 & 0.003 \\
Absolute Peak & 3 & 0.003 \\
\hline
\end{tabular}

Table 20. Summary of maximum peaks with respect to time and displacement (Earthquake 1 - Athens)

\begin{tabular}{ccc}
\hline Unit & Time (Seconds) & Displacement (M) \\
\hline Maximum positive peak & 4.58 & 0.006 \\
Maximum negative peak & 3.58 & -0.0057 \\
Absolute Peak & 4.58 & 0.006 \\
\hline
\end{tabular}

Table 21. Summary of maximum peaks with respect to time and stress (Earthquake 1 - Athens)

\begin{tabular}{|c|c|c|}
\hline Unit & Time (Seconds) & Stress $\left(\mathrm{kN} / \mathrm{m}^{2}\right)$ \\
\hline Maximum peak 1 & 3.75 & 0.00135 \\
\hline Maximum peak 2 & 7.3 & 0.0015 \\
\hline Absolute Peak & 7.3 & 0.0015 \\
\hline
\end{tabular}

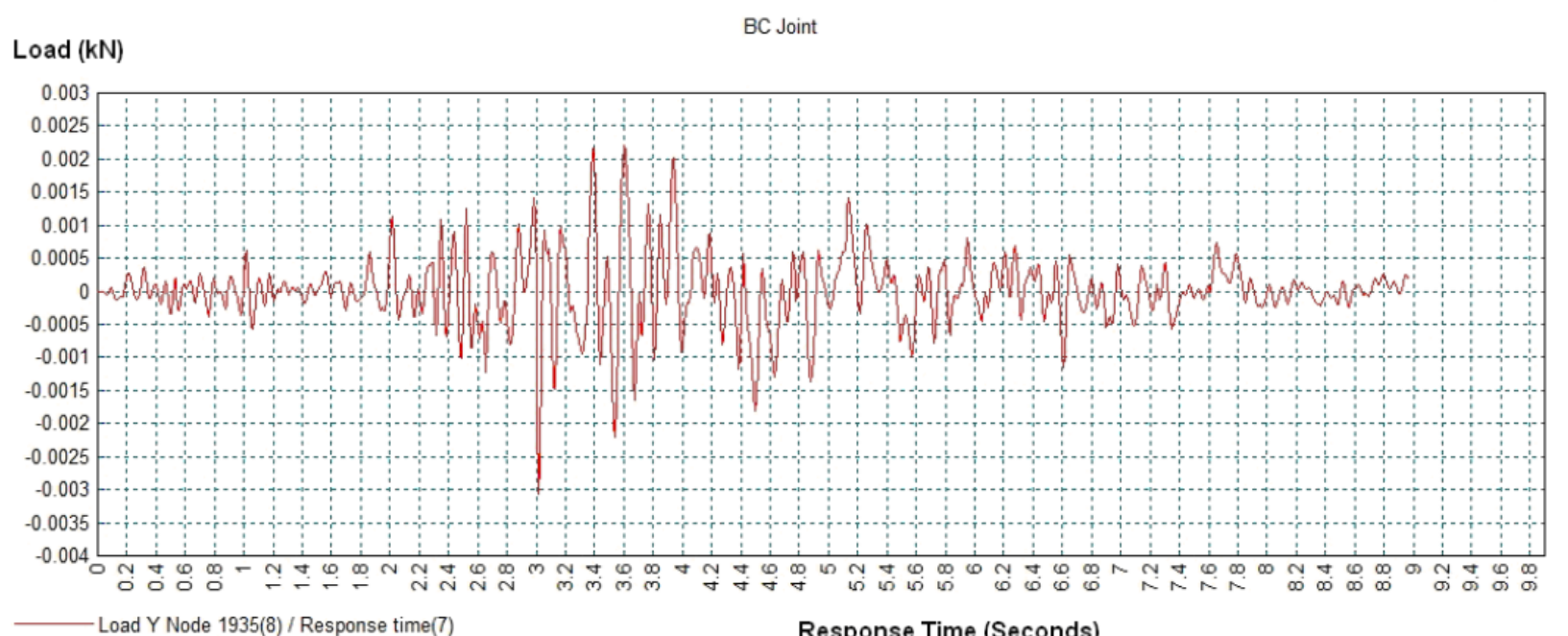




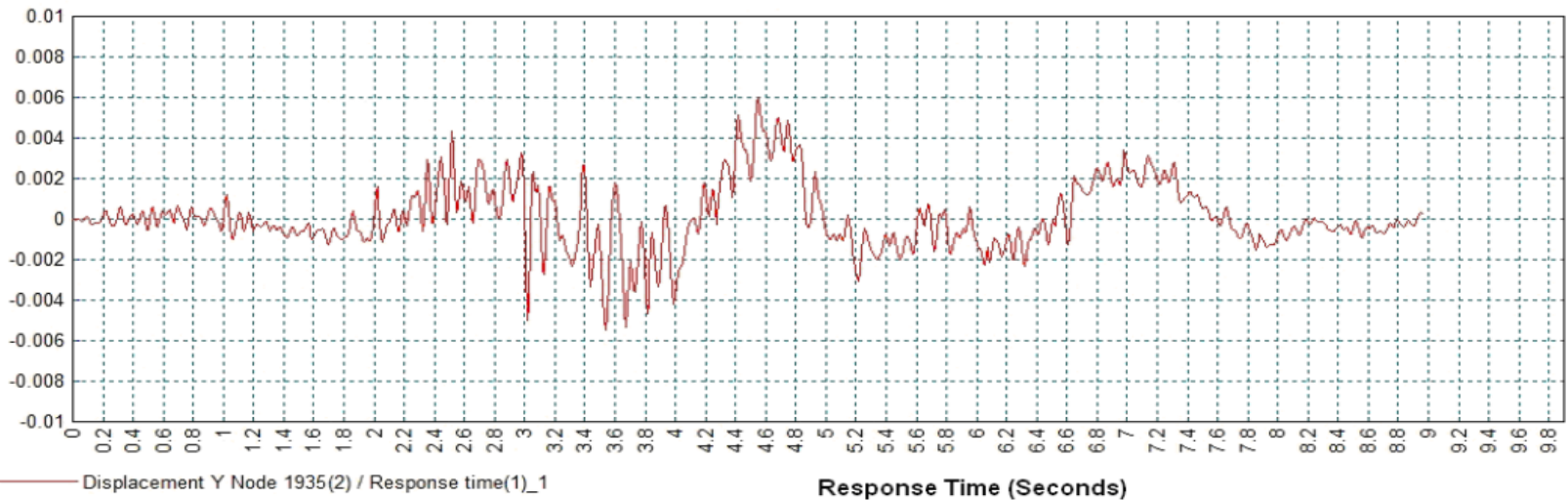

C: IUsers\KhalidiDesktoplNon-linear Dynamic Analysis\Earthquake 1- Athens.mdl

Graph 29. Response time vs. displacement graph of Athens' historic earthquake

\section{Stress $(\mathrm{kN} / \mathrm{m} 2)$}

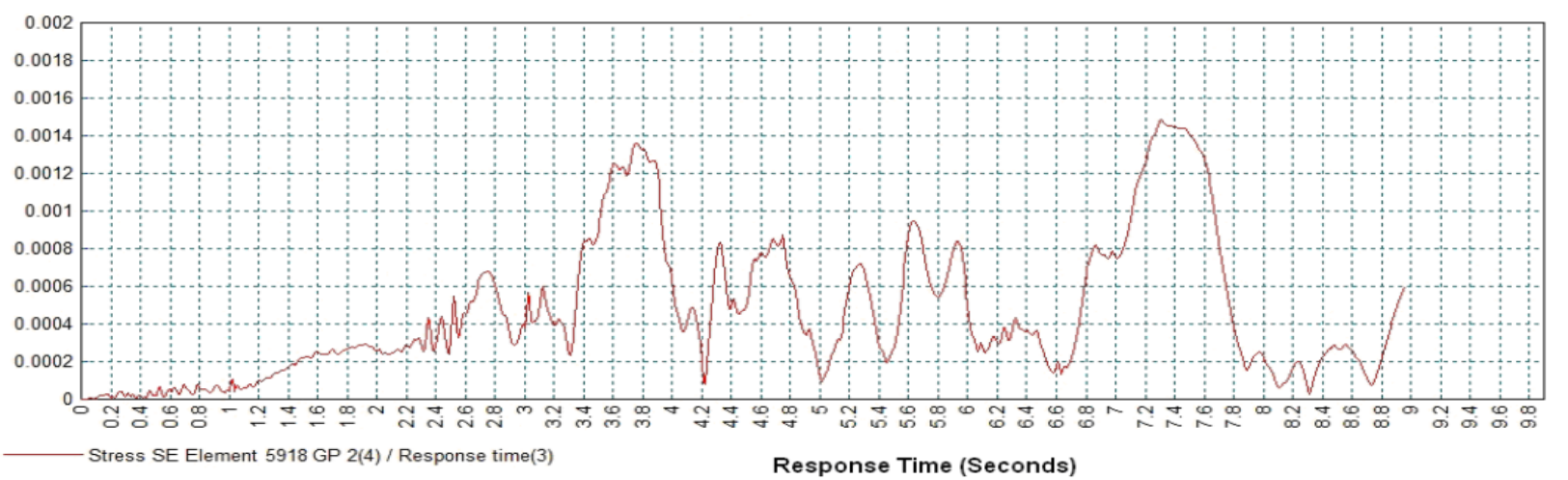

C:IUsers Khalid Desktop\Non-linear Dynamic Analysis \Earthquake 1- Athens.mdl

Units: $\mathrm{kN}, \mathrm{m}, \mathrm{kt}, \mathrm{s}, \mathrm{C}$

Graph 30. Response time vs. stress graph of Athens' historic earthquake

\subsubsection{Historic Earthquake 2 - Friuli}

The distributed axial force for the response time of the Friuli earthquake is presented in Graph 31. Table 22 summarizes the response time by which the maximum peaks occurred under the Friuli earthquake.

The maximum axial force for Friuli earthquake occurred at the node location 1935. The critical time of the Friuli earthquake by which the axial force is the most at this node will be discussed further in the next chapter.

Table 22. Summary of maximum peaks with respect to time and axial force (Earthquake 2 - Friuli)

\begin{tabular}{|c|c|c|}
\hline Unit & Time (Seconds) & Axial Force $(\mathrm{kN})$ \\
\hline Maximum positive peak & 2.75 & 0.00042 \\
\hline Maximum negative peak & 3 & -0.0004 \\
\hline Absolute Peak & 2.75 & 0.00042 \\
\hline
\end{tabular}

The distributed displacement for the response time of the Friuli earthquake is presented in Graph 32. Table 23 summarizes the response time by which the maximum peaks occurred under the Friuli earthquake.

The maximum displacement for the Friuli earthquake occurred at the node location 1935. The critical time of the Friuli earthquake by which the displacement is the most at this node will be discussed further in the next chapter.
Table 23. Summary of maximum peaks with respect to time and displacement (Earthquake 2 - Friuli)

\begin{tabular}{|c|c|c|}
\hline Unit & Time (Seconds) & Displacement (M) \\
\hline Maximum positive peak & 4.2 & 0.046 \\
\hline Maximum negative peak & 2.75 & -0.045 \\
\hline Absolute Peak & 4.2 & 0.046 \\
\hline
\end{tabular}

The distributed stress for the response time of the Friuli earthquake is presented in Graph 33. Table 24 summarizes the response time by which the maximum peaks occurred under the Friuli earthquake.

Table 24. Summary of maximum peaks with respect to time and stress (Earthquake 2 - Friuli)

\begin{tabular}{|c|c|c|}
\hline Unit & Time (Seconds) & Stress $\left(\mathrm{kN} / \mathrm{m}^{2}\right)$ \\
\hline Maximum peak 1 & 1.15 & 0.0042 \\
\hline Maximum peak 2 & 4.35 & 0.0041 \\
\hline Absolute Peak & 1.15 & 0.0042 \\
\hline
\end{tabular}

The maximum stress for the Friuli earthquake occurred at the node location 5725. The critical time of the Friuli earthquake by which the stress is the most at this node will be discussed further in the next chapter. 


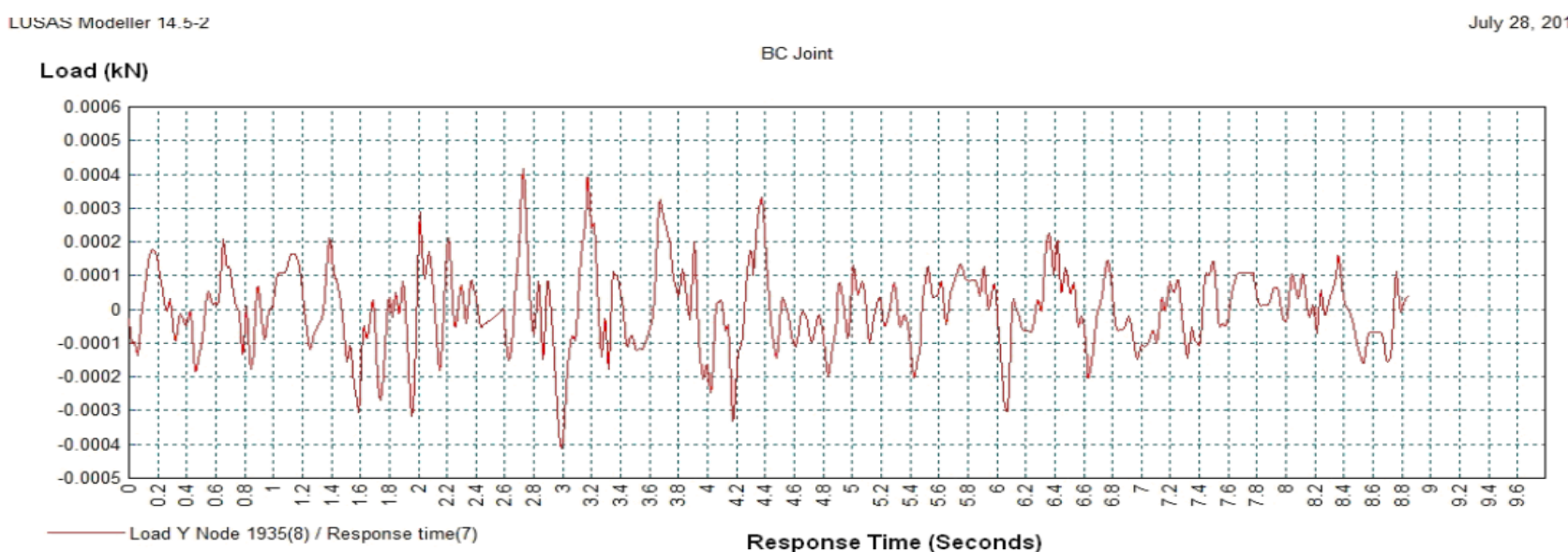

C:IUsers \Khalid\Desktop\Non-linear Dynamic Analysis\Earthquake 2- Fruili.mdl

Units: $\mathrm{kN}, \mathrm{m}, \mathrm{kt}, \mathrm{s}, \mathrm{C}$

Graph 31. Response time vs. axial force (Fy) graph of Friuli’s historic earthquake

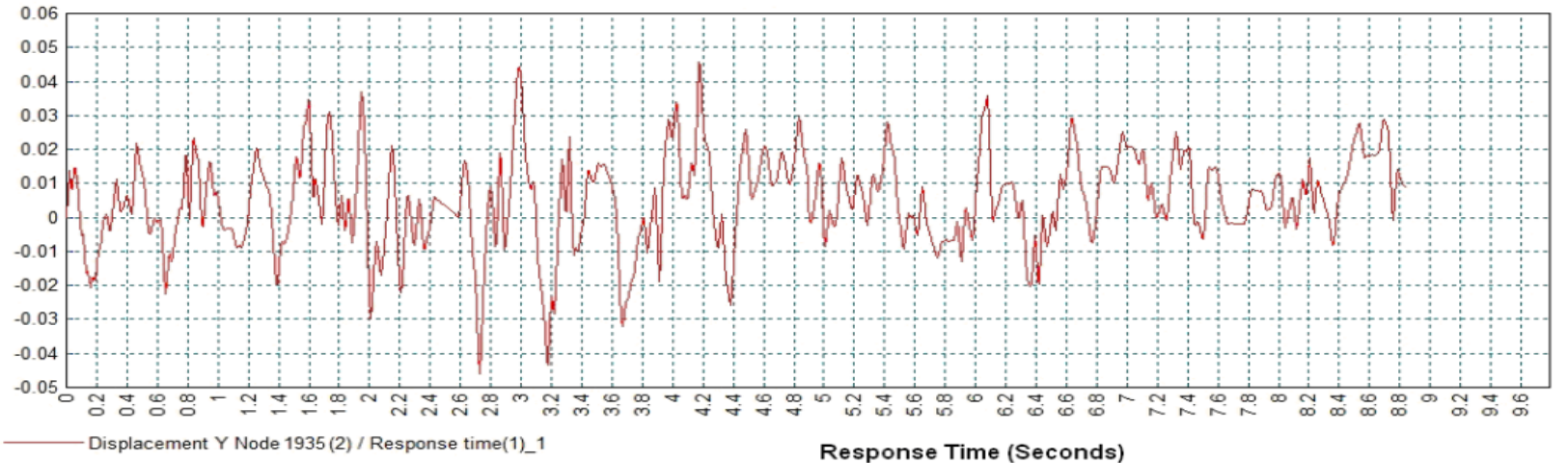

Graph 32. Response time vs. displacement graph of Friuli’s historic earthquake

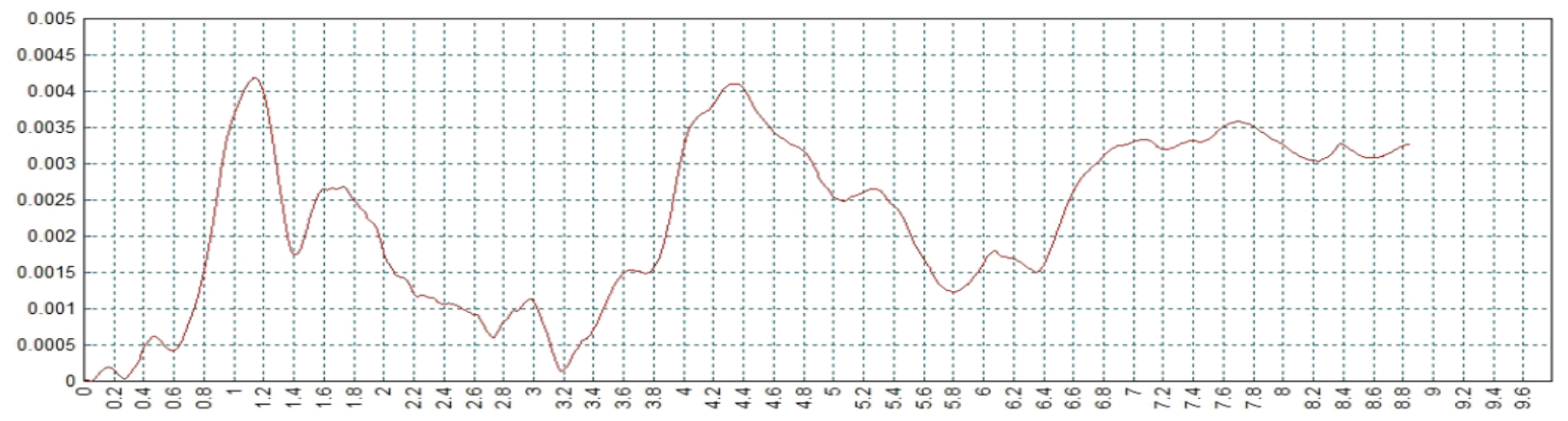

Stress SE Element 5725 GP 2(4)/Response time(3)

Response Time (Seconds)

Graph 33. Response time vs. stress graph of Friuli's historic earthquake

\subsubsection{Historic Earthquake 3 - Izmir}

The distributed axial force for the response time of the Izmir earthquake is presented in Graph 34. Table 25 summarizes the response time by which the maximum peaks occurred under the Izmir earthquake.

The maximum axial force for the Izmir earthquake occurred at the node location 347 . The critical time of the Izmir earthquake by which the axial force is the most at this node will be discussed further in the next chapter.
Table 25. Summary of maximum peaks with respect to time and axial force (Earthquake 3 - Izmir)

\begin{tabular}{|c|c|c|}
\hline Unit & Time (Seconds) & Axial Force $(\mathrm{kN})$ \\
\hline Maximum positive peak & 0.62 & 0.06 \\
\hline Maximum negative peak & 0.57 & -0.082 \\
\hline Absolute Peak & 0.57 & 0.082 \\
\hline
\end{tabular}




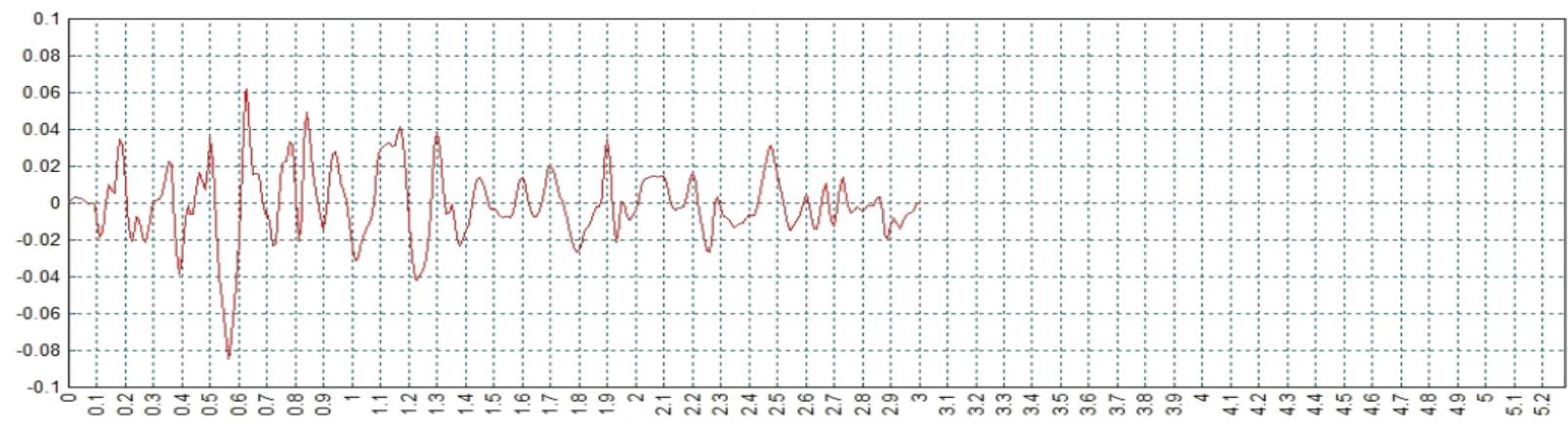

Graph 34. Response time vs. axial force (Fy) graph of Izmir's historic earthquake

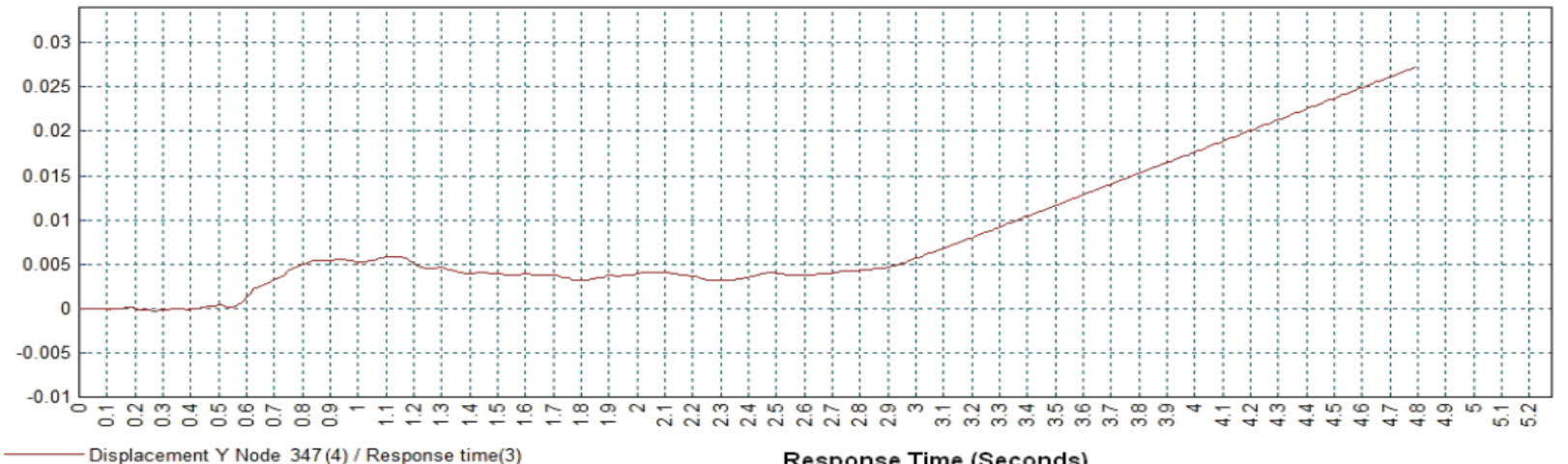

Graph 35. Response time vs. displacement graph of Izmir's historic earthquake

\section{Stress (kN/m2)}

BC Joint

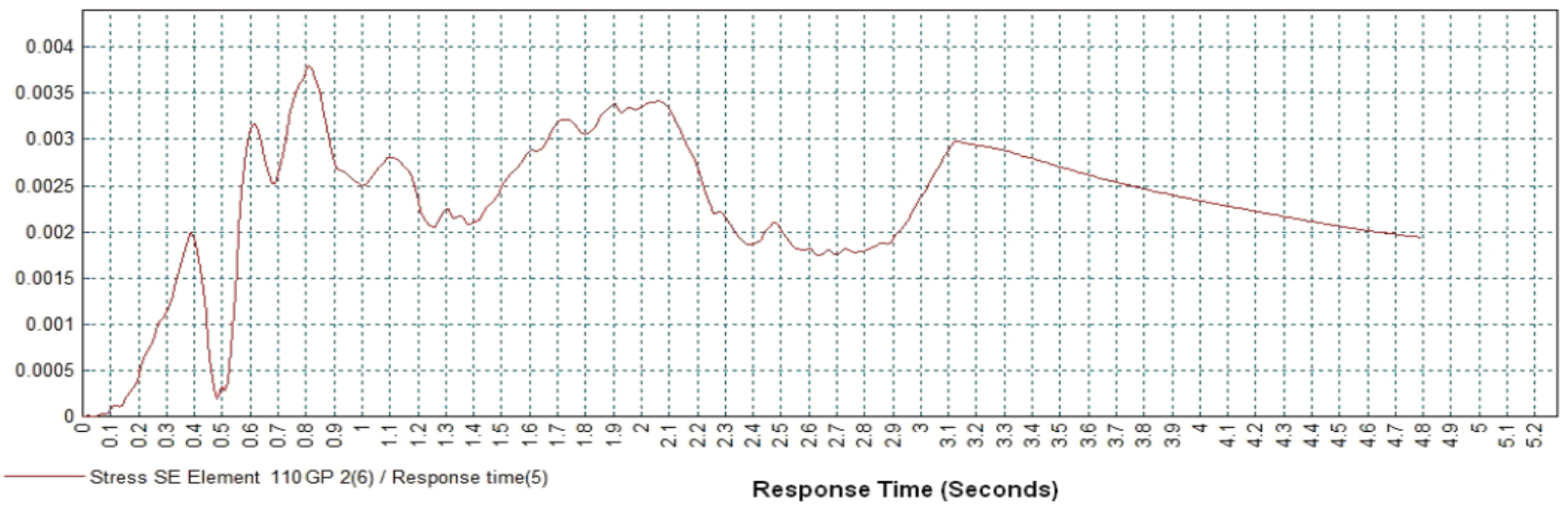

C:IUsers \KhalidIDesktopINon-linear Dynamic Analysis\Earthquake 3- Izmir.md!

Units: $\mathrm{kN}, \mathrm{m}, \mathrm{kt}, \mathrm{s}, \mathrm{C}$

Graph 36. Response time vs. stress graph of Izmir's historic earthquake

The distributed displacement for the response time of the Izmir earthquake is presented in Graph 35. Table 26 summarizes the response time by which the maximum peaks occurred under the Izmir earthquake.

The maximum displacement for the Izmir earthquake occurred at the node location 347 . The critical time of the Izmir earthquake by which the displacement is the most at this node will be discussed further in the next chapter.
The distributed stress for the response time of the Izmir earthquake is presented in Graph 36. Table 27 summarizes the response time by which the maximum peaks occurred under the Izmir earthquake.

The maximum stress for the Izmir earthquake occurred at the node location 110. The critical time of the Izmir earthquake by which the stress is the most at this node will be discussed further in the next chapter. 
Table 26. Summary of maximum peaks with respect to time and displacement (Earthquake 3 - Izmir)

\begin{tabular}{|l|c|c|}
\hline Unit & Time (Seconds) & Displacement (M) \\
\hline Maximum positive peak & 4.8 & 0.027 \\
\hline Maximum negative peak & - & - \\
\hline Absolute Peak & 4.8 & 0.027 \\
\hline
\end{tabular}

Table 27. Summary of maximum peaks with respect to time and stress (Earthquake 3 - Izmir)

\begin{tabular}{|l|c|c|}
\hline Unit & Time (Seconds) & Stress $\left(\mathrm{kN} / \mathrm{m}^{2}\right)$ \\
\hline Maximum peak 1 & 0.8 & 0.0038 \\
\hline Maximum peak 2 & 2.05 & 0.0034 \\
\hline Absolute Peak & 0.8 & 0.0038 \\
\hline
\end{tabular}

\section{Results Analysis and Discussion}

\subsection{Non-linear Static Analysis (Cyclic Earthquake Loading)}

According to the comparison Graph 37, the failure of the model started to occur in the third cycle with a maximum deflection of $50 \mathrm{~mm}$ under $58 \mathrm{kN}$ load. Similarly, the results obtained by [9] shows that the beam-column joint fails in the third cycle with a deflection exceeding $50 \mathrm{~mm}$ under a load between $50 \mathrm{kN}$ to $60 \mathrm{kN}$. Alternatively, the model created by [12] demonstrates failure in the fourth cycle under a $12 \mathrm{kN}$ load with a deflection of $46 \mathrm{~mm}$. The author's model results and those of [9] show a non-linear relationship between deflection and load, while [12] showed a linear relationship between cycles with a decrease in load results and an increase in the deflection. It is clear that there is variation in the amount of load carried by each model; for instance, the experimental model created by [9] can handle more load during the first cycle than the model created by [12] and the author's model. Conversely, the author's model can handle up to $58 \mathrm{kN}$ load during the third cycle before the joint fails, while [9] experimental model carried a load up to $30 \mathrm{kN}$ and [12] had a $12.5 \mathrm{kN}$ load. This indicates that during the third cycle the author's proposed model performed better in terms of taking more load before failure of the joint than [12] model and [9] experimental model. The variation in the load carrying capacity of different models is due to the difference in the size of the reinforcement bar as a result some models have higher load carrying capacity than others.

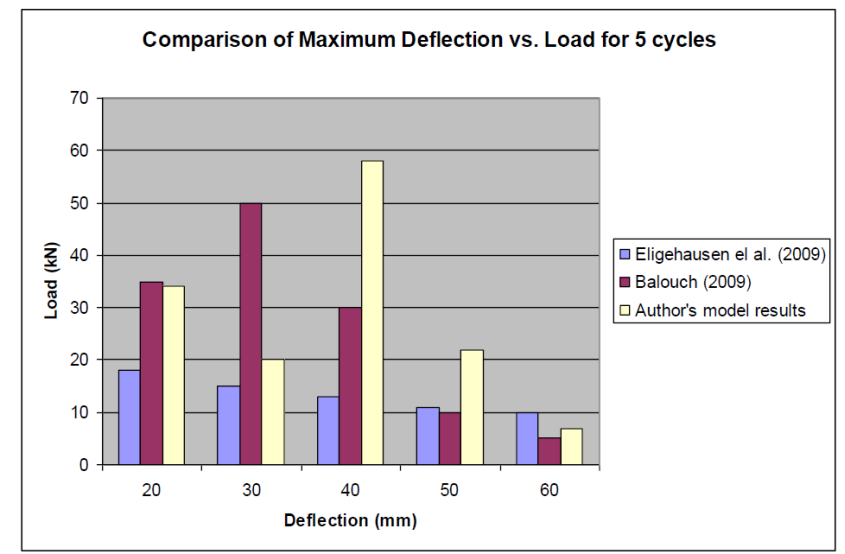

Graph 37. Comparison between author's model results and experimental published results for five cycles
It has been confirmed by the stress strain graphs that the failure in the author's proposed model started to occur in the third cycle $(50 \mathrm{~mm})$. During the first and second cycles the stress strain relationship was behaving non-linearly with an increase in stress with respect to strain. Although the stress value was higher in the first cycle than the second and third cycles due to the shear transfer mechanism within the beam bars, the failure of the joint took place during the third cycle at a yield point of $0.008 \mathrm{~m} / \mathrm{m}$ and $0.019 \mathrm{kN} / \mathrm{m}^{2}$. Similarly, the stress strain graphs for the fourth and fifth cycle showed yield point failure. This can be expressed as the bond between the reinforced bars and concrete disconnect (bond failure) and as a result the beam column joint loses its resistance. As shown in Figure 47, the maximum bar force (Fx) was in the joint member reinforcement bars (node 10981). The bar force is accumulated within the joint beam reinforcement bars leading to tension and stress coming from this part of the structure to the column zone and by the time the load is increased cracks start to occur. After applying the third cycle the tension increases at this point forcing the beam upper reinforcement at node 10981 to come out in an opposite direction of the applied load. As a result, the steel yield and anchorage failure of the longitudinal embedded reinforcement of the beam-column joint starts to take place.

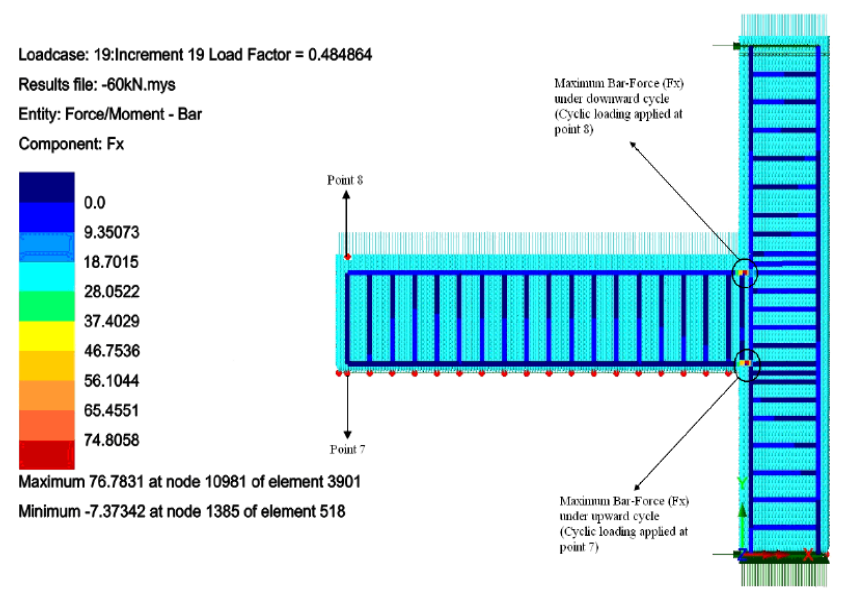

Figure 47. Maximum Force-Bar (Fx) during stage 1 and stage 2 of cyclic earthquake loading (upward and downward loads).

\subsection{Non-linear Dynamic Analysis (Real Earthquakes)}

The results that have been obtained for the applied real earthquakes demonstrated different behavior of the structure under each earthquake. It is believed that this is normal due to the fact that each earthquake has a different frequency, magnitude and source mechanism. According to the results the earthquakes had minor effects on the structure.

As evident from the displacement against load graph for the Athens earthquake there is a cyclic behavior of the structure at node 1935 (joint zone). The maximum displacement that has been recorded for the Athens earthquake was $0.006 \mathrm{~m}$ and the maximum load was $0.0022 \mathrm{kN}$. Similarly, the relationship between displacement and load graph for Friuli earthquake showed cyclic behavior with a maximum load of $0.0004 \mathrm{kN}$ and maximum 
displacement of $0.045 \mathrm{~m}$. In opposition, the maximum displacement recorded under the Izmir earthquake was $0.13 \mathrm{~m}$ at $0.06 \mathrm{kN}$ load. This means that the highest displacement recorded among all three earthquakes was Izmir. It is believed that Izmir earthquake had the highest displacement due to high acceleration produced by this earthquake in a short time ( 0.5 seconds $)$ causing irregular cyclic behavior between displacement and load.

In terms of stress against strain graphs for the three earthquakes both the Athens and Friuli earthquakes showed cyclic stress strain relationships, while the stress against strain graph for the Izmir earthquake was totally different from the others. This is because less acceleration peaks generated by the Izmir earthquake than other earthquakes showed a non-linear relation stress strain graph similar to that of cyclic earthquake loading. This is due to the small response time of the Izmir earthquake, for instance, the maximum acceleration occurring at approximately 0.5 seconds. Generally speaking, the author's proposed model sustained the three earthquakes with minor effects in terms of displacements and loads.

\subsection{Cracking Pattern Analysis}

\subsubsection{Cyclic Earthquake Loading}

The cracking pattern for the cyclic earthquake loading was analyzed for downward cycle. This has been decided due to the fact that the cracking pattern for upward cycle will be similar to that of downward cycle but the effect will be at the lower part of the joint and cantilever instead of the upper part. Thus, the cracking pattern for a full/complete cycle will be a combination of cracks obtained from downward and upward cycles by which each represents half a cycle.

The results demonstrate that the level of cracks for cycle 1 were minor as they appear within the joint and upper part of the beam next to the joint. It is believed that these cracks are within the acceptable range of the design. After cycle 2 and as the load was increased the structure had intermediate cracks at the same location as that in cycle 1 . During the third cycle major cracks occurred and the model failed. This is due to the push and pull of the loading by which friction occurs between the reinforcement bars and concrete at the joint. This friction initiates the outer surface of the concrete, thus, cracks starts to appear. After analyzing the fourth cycle the bond between steel bars and concrete are separated and the connection between beam and column joint loses its strength. As the beam-column joint loses its resistance damage occurs and cracks take place with a loss in strength and stiffness, and this was the case during the fifth cycle with cracks across the entire joint. Similarly, the experimental half scale model done by [9] showed major cracks started to appear during the third cycle within the column, beam and joint and by the time the load was increased the cracks became denser until the model failed. In opposition, the model conducted by [22] demonstrated significant differences in failure modes with major cracks and failure of the model in the last cycle. The shear failure and flexural yielding were responsible for the occurrence of the cracks within the joints in all three cases. As evident from the comparison made as the cycle increases the crack size increases and develop until they spread across the joint and lead to the failure of the structure.

\subsubsection{Real Earthquakes}

After analyzing the cracking pattern of the real earthquakes it has been discovered that the Friuli earthquake had the major effect on the structure in terms of the cracks. The cracks were intermediate in size and this is due to the thrust source mechanism, while the other two earthquakes had normal sources mechanism and minor cracks mainly within the joint and some parts of the beam. The source mechanism indicates the way the earthquake strikes and it is evident from the results the thrust source mechanism had more effect on the joint than normal sources mechanism. The thrust sources mechanism has a different shaking behavior than normal. It's pushing force acts reverse to that of the normal sources mechanism producing more stress in the joint which means more cracks.

The distribution of tension and compression with the model under the Athens earthquake illustrates that the tension is accumulated within the upper part of the joint and the compression is concentrated in the lower part of the joint. As the earthquake accelerations transferred from the bottom of the column to joint, the tension force is carried by column longitudinal reinforcement and once it reaches the upper beam reinforcement in the joint and acts in tension it produces some cracks in the concrete. Moreover, the shear forces are carried by the concrete and transferred to the joint and initiating the lower part of the beam next to the joint to act in compression. On the other hand, the cracking analysis of the Friuli earthquake showed an extension in both tension and compression through the joint, upper and lower parts of the beam. Furthermore, the bottom part of the column was acting in tension due to being fixed to the ground and stopped the column from moving freely and producing tension at this part of the structure. Thus, the cracks occurred within the beam and bottom of the column. It is believed that the thrust mechanism of the Friuli earthquake played a major role in having a different cracking pattern from Athens and Izmir. Finally, the cracks results obtained after applying the Izmir earthquake showed symmetry in the distribution of tension and compression within the joint and beam with some tension in the bottom part of the column.

Generally speaking, the model has passed all the three applied real earthquakes with variation in distribution of tension and compression, level and location of cracks. It is believed that the level of cracks is acceptable in terms of their size with respect to design codes for safe measures.

\subsection{Seismic Analysis}

It is to be noted that nodes 1 to 15000 are situated within the joint. The nodes that have been considered in the seismic analysis were taken based on the maximum magnitude in the structure and they are all located in the joint part of the structure.

\subsubsection{Comparison of the Critical Axial Force With Respect to Response Time}

The Athens earthquake had the highest response time (3 seconds) with respect to the occurrence of the highest 
axial force at node 1935. Moreover, the maximum axial force for the Friuli earthquake takes place at 2.75 seconds (node 1935). Conversely, the highest axial force for the Izmir earthquake arises only at 0.57 seconds (node 347 ). Graph 38 shows the comparison made between the three real earthquakes in terms of the response time by which the axial force has the highest effect on the structure.

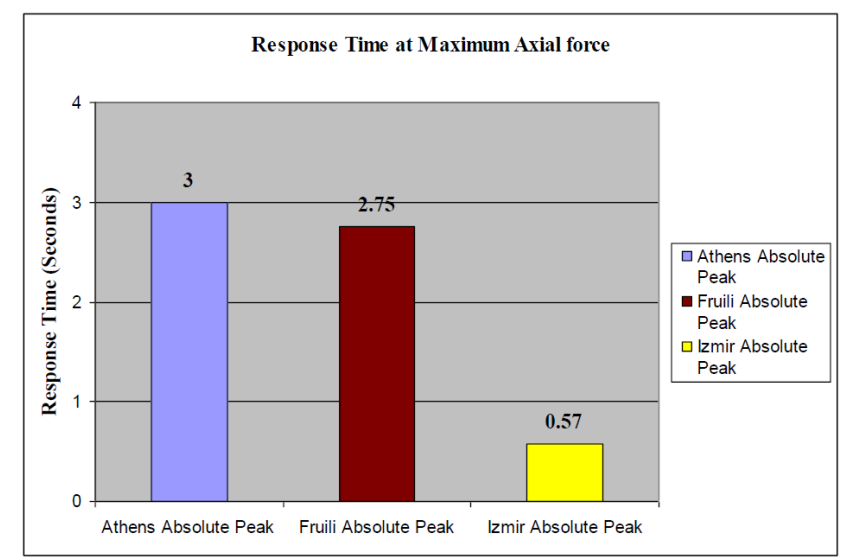

Graph 38. Comparison between the three applied real earthquakes in terms of critical maximum axial force with respect to response time

Although the Richter scale reading was not recorded for the Athens earthquake it takes a longer time to affect the structure than in Friuli and Izmir. This is due to the fact that each earthquake varies in the magnitude of frequency. The critical maximum axial force among all applied earthquakes was recorded in the Izmir earthquake, which was found to have 27 times the effect on the model compared to the Athens earthquake and 105 times the effect compared to the Friuli earthquake. Even though Izmir had the lowest response time it was the most vigorous in terms of maximum axial force. The maximum axial force of each earthquake has been tabulated and presented in Table 28.

Table 28. Summary of maximum axial force at critical response time of each earthquake

\begin{tabular}{|c|c|c|}
\hline Earthquake & $\begin{array}{c}\text { Critical Response } \\
\text { Time (Seconds) }\end{array}$ & $\begin{array}{c}\text { Maximum } \\
\text { AxialForce }(\mathrm{kN})\end{array}$ \\
\hline Athens & 3 & 0.003 \\
\hline Fruili & 2.75 & 0.00042 \\
\hline Izmir & 0.57 & 0.082 \\
\hline
\end{tabular}

\subsubsection{Comparison of the Critical Displacement with Respect to Response time}

The Izmir earthquake had the highest response time (4.8 seconds) with respect to the occurrence of the highest displacement at node 1505. Moreover, the maximum displacement for the Athens earthquake takes place at 4.58 seconds (node 13765). Conversely, the highest displacement for the Friuli earthquake arises at 4.2seconds (node 1744). Graph 39 shows the comparison made between the three real earthquakes in terms of the response time by which the displacement has the highest effect on the structure.

The Izmir earthquake had the longest time in affecting the structure than in Athens and Izmir with respect to displacement magnitude. The Izmir earthquake had the second largest Richter scale reading after Friuli with a magnitude of 5.1. Although Izmir had more time in producing action on the structure, the critical maximum displacement among all applied earthquakes was recorded in the Friuli earthquake which was found to have two times the effect on the model than the Izmir earthquake and approximately eight times the effect compared to the Athens earthquake. Even though Friuli had the lowest response time it was the most vigorous in terms of maximum displacement within the structure. This is due to the fact that the Friuli earthquake had the highest Richter scale reading between the other two earthquakes with a magnitude of 6.1. The maximum displacement of each earthquake has been tabulated and shown in Table 29.

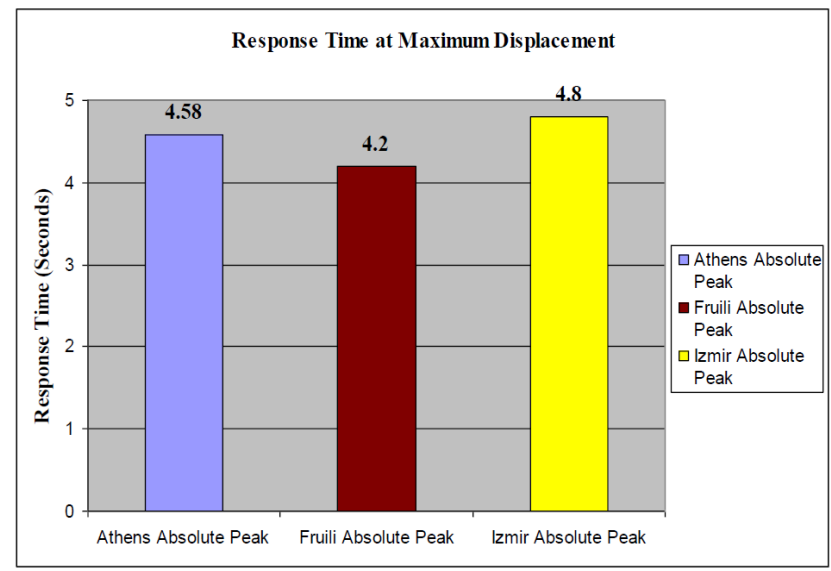

Graph 39. Comparison between the three applied real earthquakes in terms of critical maximum displacement with respect to response time

Table 29. Summary of maximum displacement at critical response time of each earthquake

\begin{tabular}{|c|c|c|}
\hline Earthquake & $\begin{array}{c}\text { Critical Response } \\
\text { Time (Seconds) }\end{array}$ & $\begin{array}{c}\text { Maximum } \\
\text { Displacement (M) }\end{array}$ \\
\hline Athens & 4.58 & 0.006 \\
\hline Fruili & 4.2 & 0.046 \\
\hline Izmir & 4.8 & 0.027 \\
\hline
\end{tabular}

\subsubsection{Comparison of the Critical Stress with Respect to Response Time}

The Athens earthquake had the highest response time (7.3 seconds) with respect to the occurrence of the highest stress at node 2559. Furthermore, the maximum stress for the Friuli and Izmir earthquakes took place at 1.15 seconds and 0.8 and the location of the node was 637 under both earthquakes. Graph 40 shows the comparison made between the three real earthquakes in terms of the response time by which the stress has the highest affect on the structure.

Although the Athens earthquake had the longest time in affecting the structure compared to Friuli and Izmir with respect to stress magnitude, the lowest stress value was found to be at this earthquake. The critical maximum stress among all applied earthquakes was recorded in the Friuli earthquake, which was found to have 3 times the effect on the model compared to the Athens earthquake and slightly higher magnitude than the Izmir earthquake. Even though Friuli had the second lowest response time after Izmir it was the most vigorous in terms of maximum stress occurring within the structure. This is due to the fact that the Friuli earthquake had the highest Richter scale 
reading between the other two earthquakes with a magnitude of 6.1. The maximum stress of each earthquake has been tabulated and illustrated in Table 30 .

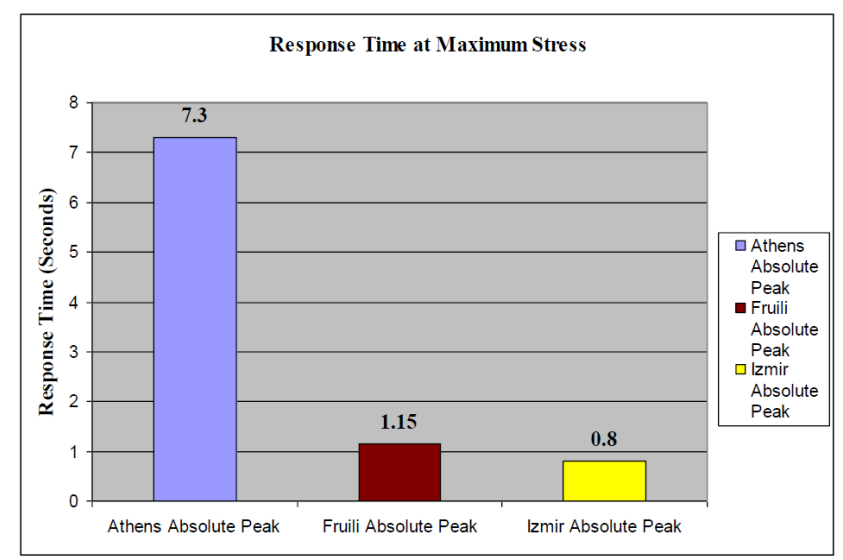

Graph 40. Comparison between the three applied real earthquakes in terms of critical maximum stress with respect to response time

Table 30. Summary of maximum stress at critical response time of each earthquake

\begin{tabular}{|c|c|c|}
\hline Earthquake & $\begin{array}{c}\text { Critical Response } \\
\text { Time (Seconds) }\end{array}$ & $\begin{array}{c}\text { Maximum Stress } \\
\left(\mathrm{kN} / \mathrm{m}^{2}\right)\end{array}$ \\
\hline Athens & 7.3 & 0.0015 \\
\hline Fruili & 1.15 & 0.0042 \\
\hline Izmir & 0.8 & 0.0038 \\
\hline
\end{tabular}

\section{Conclusion}

\subsection{Summary}

A beam-column joint was modelled using Lusas 14.4 to determine its behavior under cyclic earthquake loading. Since the structure is composite the conduct of non-linear analysis was necessary due to the assumption that there will be no relationship between stress and strain. To achieve these four types of analysis were conducted, for example, non-linear static, non-linear dynamic, cracking pattern and seismic. The findings from these analyses were as follow:

- During the comparison stage it has been found that different model's have different load carrying capacity due to difference in size of reinforcement bars.

- The failure of the joint took place during the third cycle at a maximum displacement of $50 \mathrm{~mm}$ and a yield point of $0.008 \mathrm{~m} / \mathrm{m}$ and $0.019 \mathrm{kN} / \mathrm{m}^{2}$.

- The behavior of the structure was different under each earthquake due to different frequency, magnitude and source mechanism.

- The highest displacement recorded among all three earthquakes was Izmir due to high acceleration produced by this earthquake in a short time $(0.5$ seconds) causing irregular cyclic behavior between displacement and load.

- The cracks started in the first cycle and were improved by the time the cycle is increased. It was observed that after the third cycle major cracks appeared in the joint and after conducting the fourth and fifth cycles the major cracks spread across the entire joint.
- The occurrences of the cracks are due to many reasons such as push and pull of the loading which initiates friction between reinforcement bars.

- As evident from the comparison made as the cycle increases the crack size increases and develop until they spread across the joint and lead to the failure of the structure.

- The level, size and position of the cracks appear according to the distribution of tension and compression within the model.

- The thrust source mechanism behavior of Friuli earthquake affected the joint more than normal source mechanism. This was found to be due to the reverse pushing force to that of the normal sources mechanism producing more stress in the joint which means more cracks.

- The Friuli earthquake was the most active earthquake in terms of affecting the structure. This was found to be due to the fact that the Friuli earthquake had the highest Richter scale reading between the other two earthquakes with a magnitude of 6.1 .

Generally speaking, the model has passed all the three applied real earthquakes with variation in distribution of tension and compression, level and location of cracks. Alternatively, the model failed during the third cycle with maximum displacement of $50 \mathrm{~mm}$. The failure of the model continued to develop as the cycle was increased until the structure totally collapsed under the fifth cycle (150mm).

\subsection{General Reasons for Beam-column Joint Failures}

- Disintegration of concrete joint occurs due to repeated opening and closing of cracks, this is when transverse steel crosses diagonal cracks and begins yielding.

- Distortion of panel zone occurs in each direction and contributes considerably towards lateral displacement of the structure. This source of deformation is not allowed in response of building frame.

- Anchorage features at the top and bottom of bars result in anchorage failure and is inferior in comparison to separate anchorage at the top and the bottom of bars; the same may not be the case where the column has considerable length.

- Considerable bowing of transverse steel occurring in joints demonstrates that rectangular stirrups of usual diameter are effective in confining pressure. This pressure is applicable at the corners of the test directions.

- Failure of beam column specimens occur due to a serious condition that leads to loss in moment carrying capacity of columns near joints, even in cases where plastic hinges are designed especially for beams rather than columns.

- Lack of substantial axial compression on columns can result in cracked joints under cyclic loading for resisting against shear forces.

- Cyclic loading results in repeated opening and closing of cracks that go in each direction as the direction of tension and concrete changes alternately. 


\subsection{Recommendations on Eurocode 8: Design of Structures for Earthquake Resistance. General Rules, Seismic Actions and Rules for Buildings (2004) BS EN 1998-1: 2004 [27]}

- Eurocode 8 should include section for adding fibers to the concrete to have better performance of the structure during seismic citations.

- The force deformation demand on various components while measuring lateral force and displacements by using the latest Eurocode references. Additional work could be done to further improve the constitutive models used for the component and materials.

- More study on seismic performance of exterior partial-strength composite beam-column joints can be done using monotonic and quasi-static cyclic full-scale sub assemblage tests.

- Inelastic response developed in a ductile and stable manner in the column web panel zone and the beam could be further reduced on the basis of the type of connection which is used in seismic design.

- Work on bearing failure of the concrete beam against the column flange can be on the basis of Eurocode 8 methodology for determining the capacity of the compression force transfer mechanisms.

\subsection{Future Work}

The conduct of further analysis on the model such as eigenvalue analysis could've given a clear indication of the dynamic behavior by calculating and determining the structures frequency and eigenvalues. The model results that were achieved had limitations in terms of the concrete cover depth which was fixed at $50 \mathrm{~mm}$. In the author's point of view by carrying out simulations on different cover depths the results will have a wide range of data which are capable of determining the effect of the models behavior during earthquakes with respect to cover depth.

Further work should be carried out such as conducting a parametric study. This can be achieved by changing the model's parameters and conducting necessary analysis. This helps in achieving a set of statistical data which can give the most beneficial model's parameter that can sustain earthquakes.

The boundary conditions of the model can be changed to investigate if the seismic behavior of the structure can be improved under certain boundary conditions. For instance, the force created by the earthquake citations can be absorbed by adding special spring which can be included in the design of beam-column joints at the top and bottom of the column. In addition, the boundary conditions for beam can be roller rather than free or fixed. As evident from the comparison part of this study that the bar size is essential in identifying the load carrying capacity of the model. Thus, by carrying out simulation on changing the reinforcement bar size will give better representation of the model's load carrying capacity for different bar sizes.

\section{Appendices}

\subsection{Appendix 1 - Contour Maps of Non - linear Static Analysis Including Self Weight (without any Cyclic Loading)}

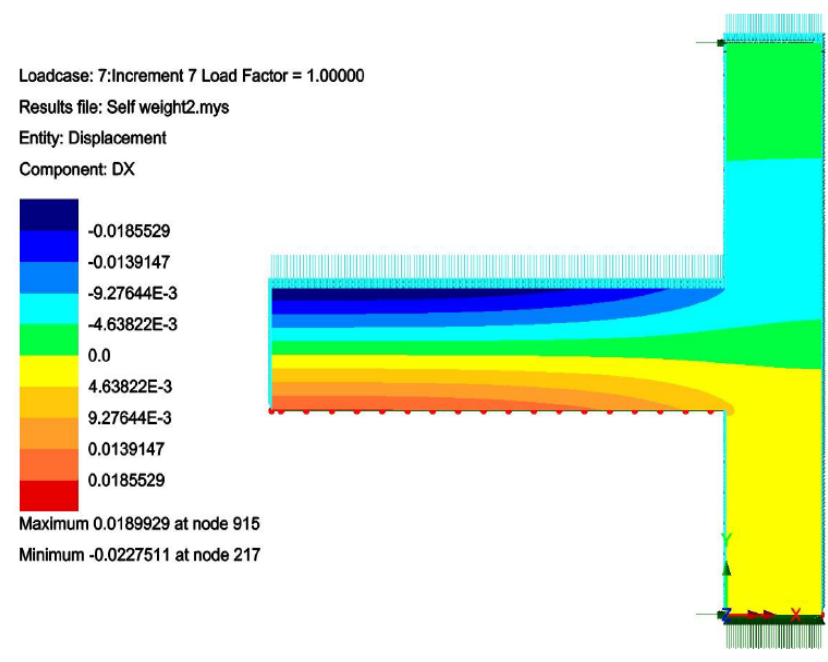

Figure 48. Displacement contour map in the x-direction

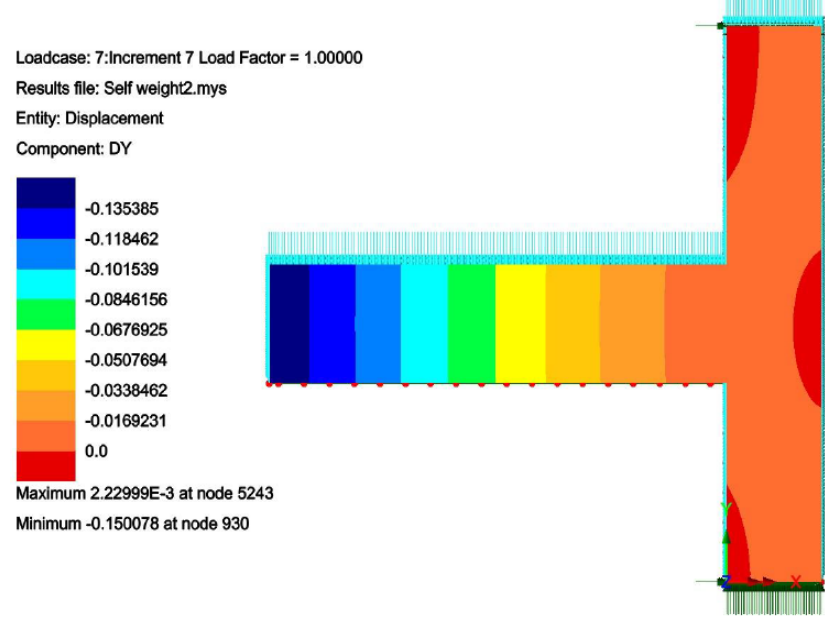

Figure 49. Displacement contour map in the y-direction

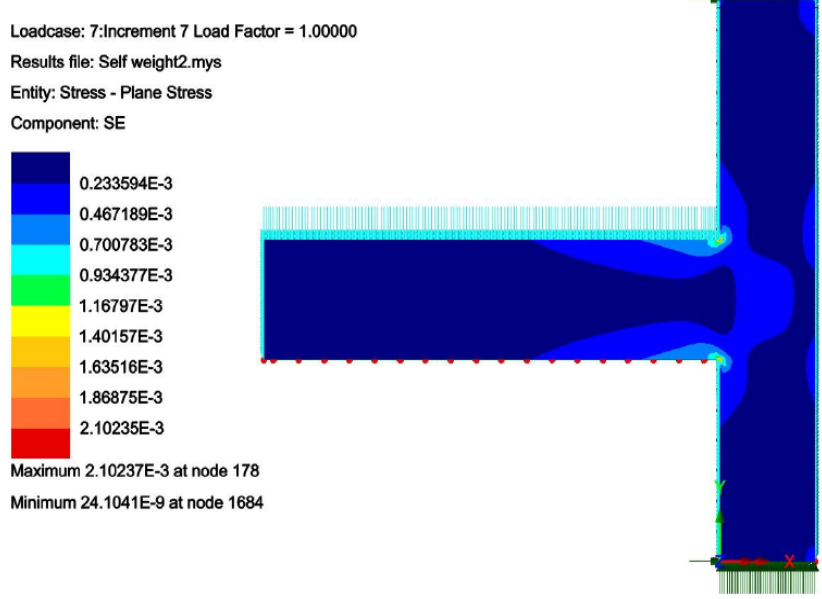

Figure 50. Stress - Plane stress contour map (SE) 


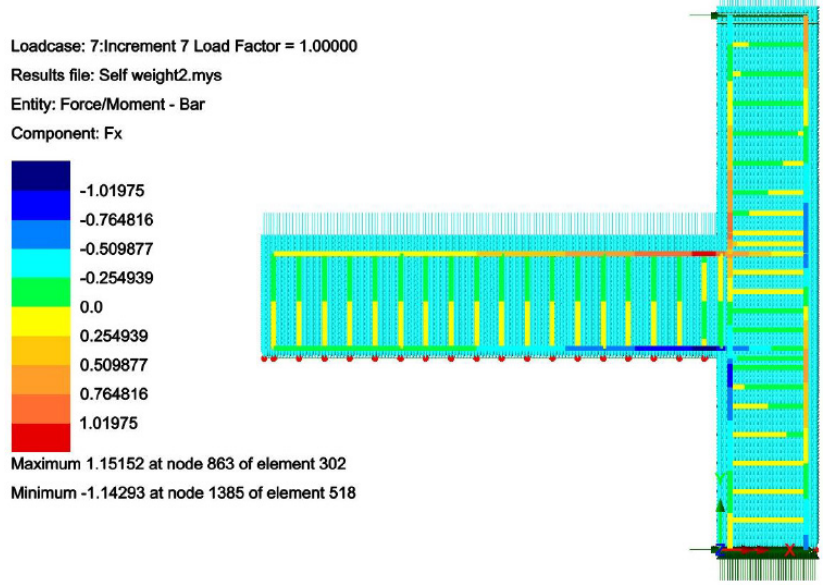

Figure 51. Force - Bar contour map (Fx)

\subsection{Appendix 2 - Deformed mesh}

7.2.1. Cyclic Earthquake Loading for the 5 Cycle's at Stage 1 (Downward)

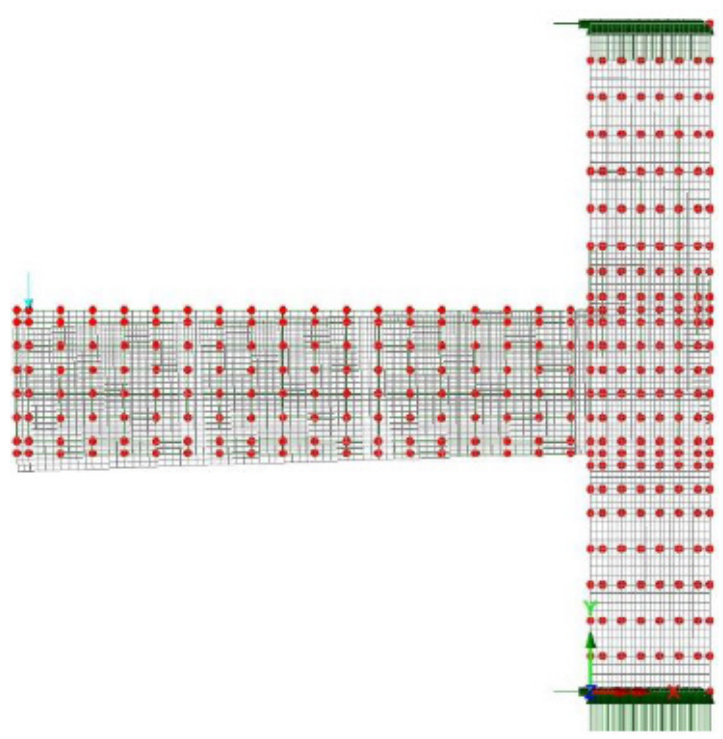

Figure 52. Cycle $1(-12 \mathrm{~mm})$.

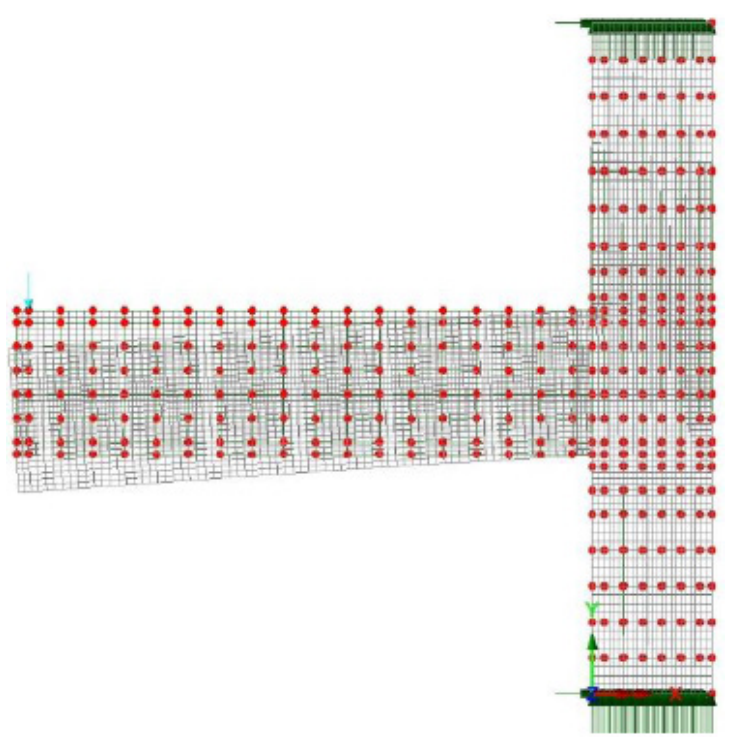

Figure 53. Cycle $2(-25 \mathrm{~mm})$

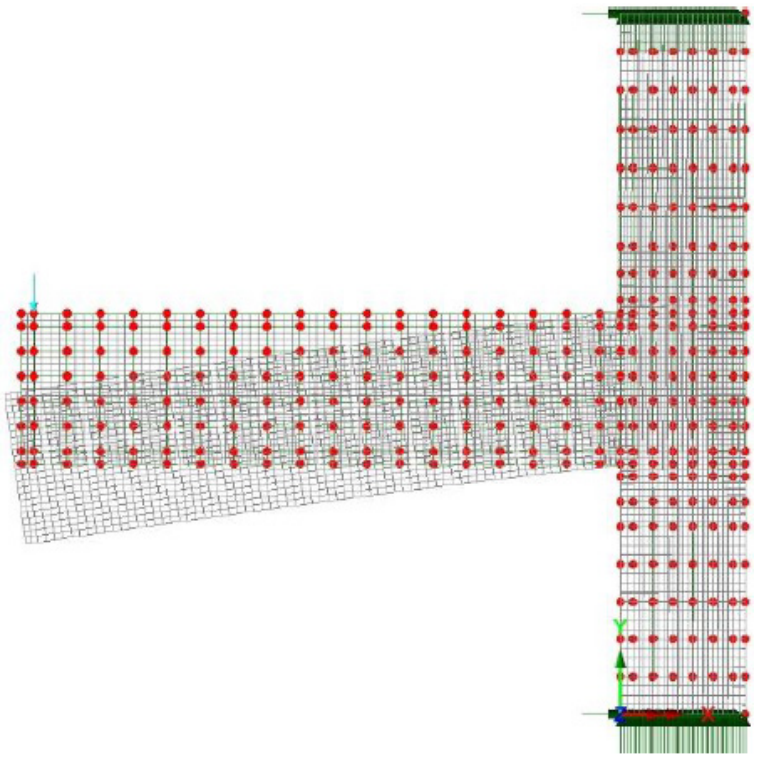

Figure 54. Cycle $3(-50 \mathrm{~mm})$

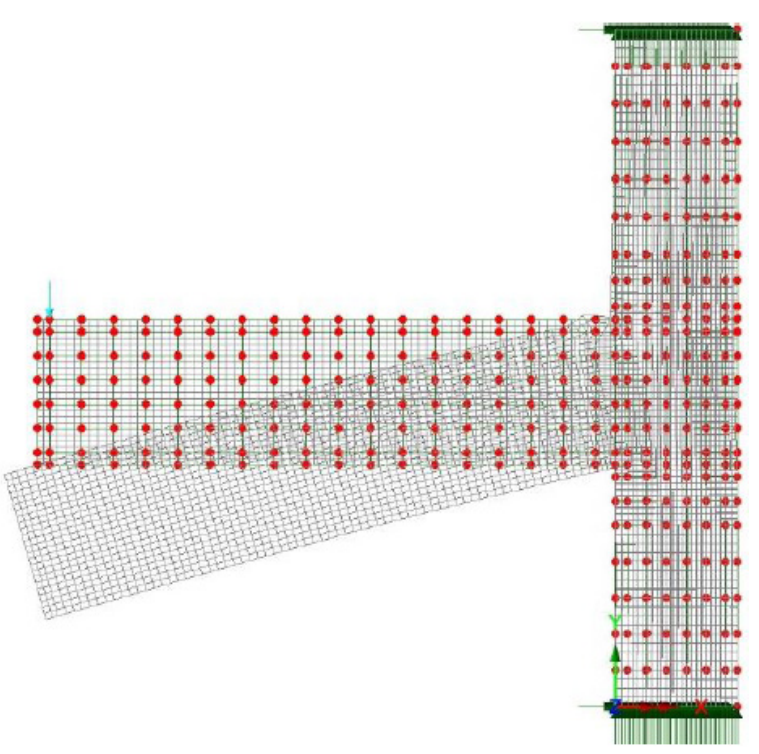

Figure 55. Cycle $4(-100 \mathrm{~mm})$

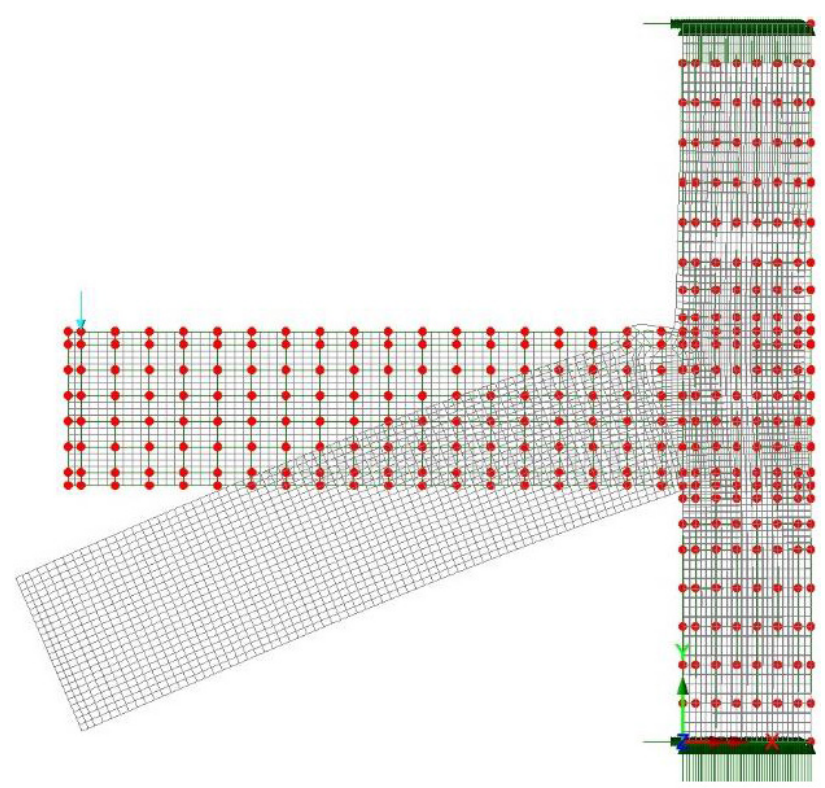

Figure 56. Cycle $5(-150 \mathrm{~mm})$ 
7.2.2. Cyclic Earthquake Loading for the 5 Cycle's at Stage 2 (Upward)

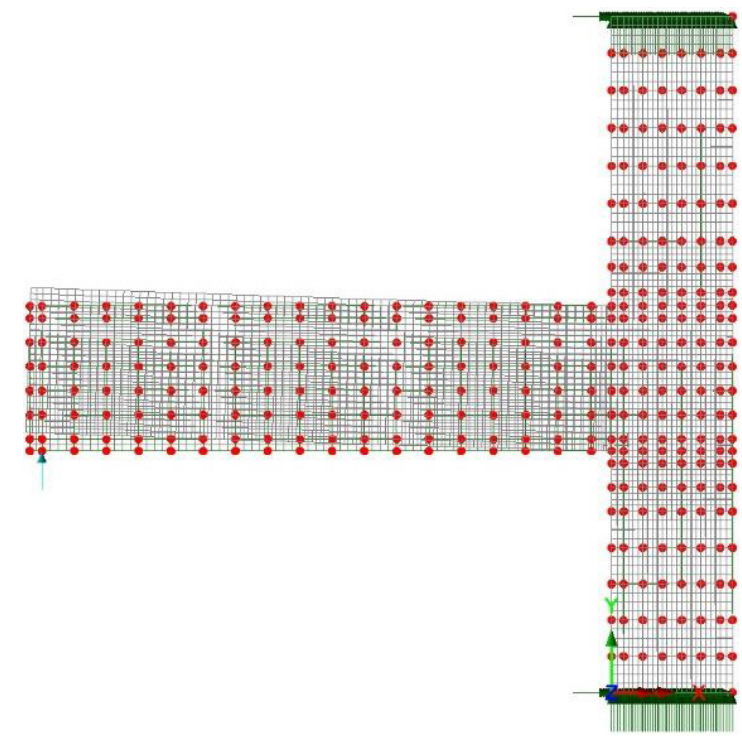

Figure 57. Cycle 1 (12mm)

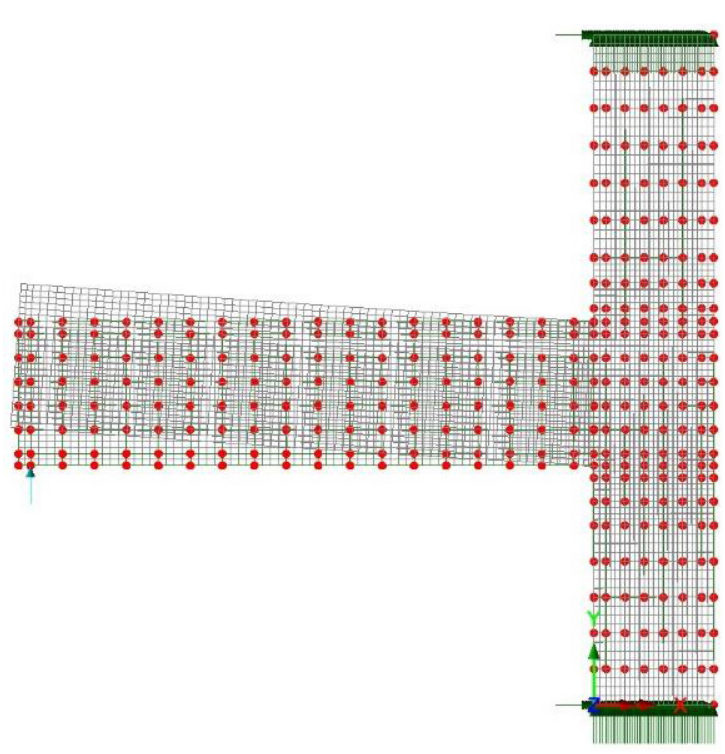

Figure 58. Cycle $2(25 \mathrm{~mm})$

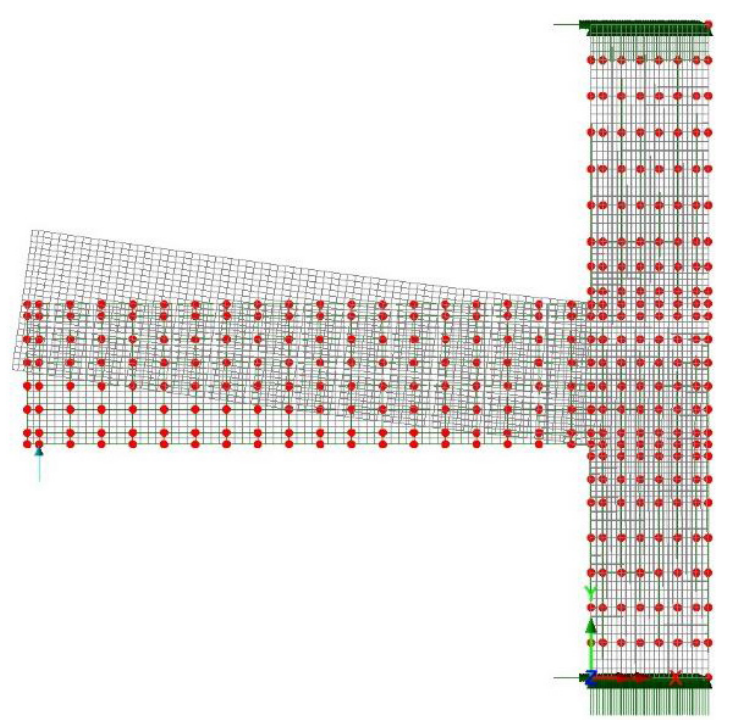

Figure 59. Cycle $3(50 \mathrm{~mm})$

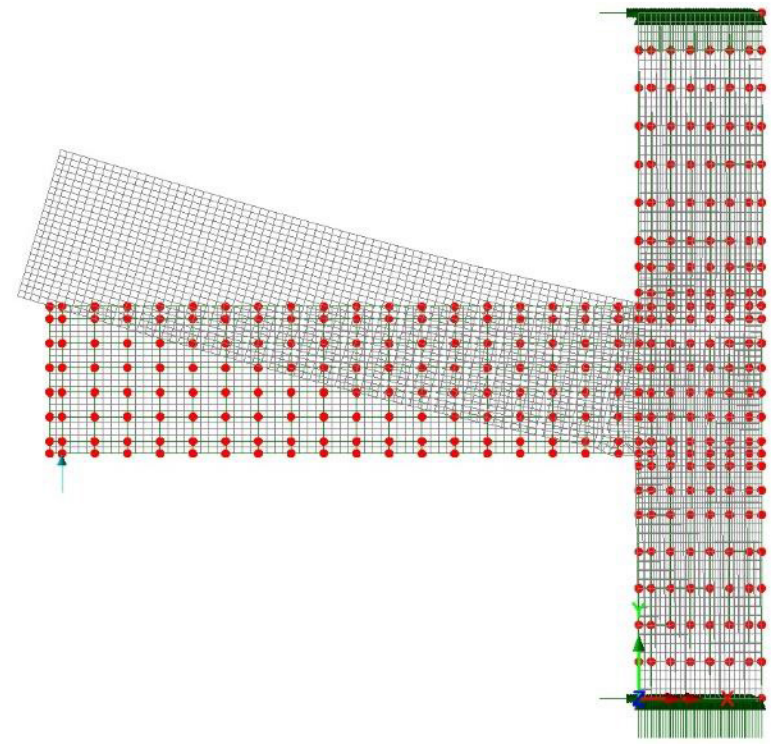

Figure 60. Cycle $4(100 \mathrm{~mm})$

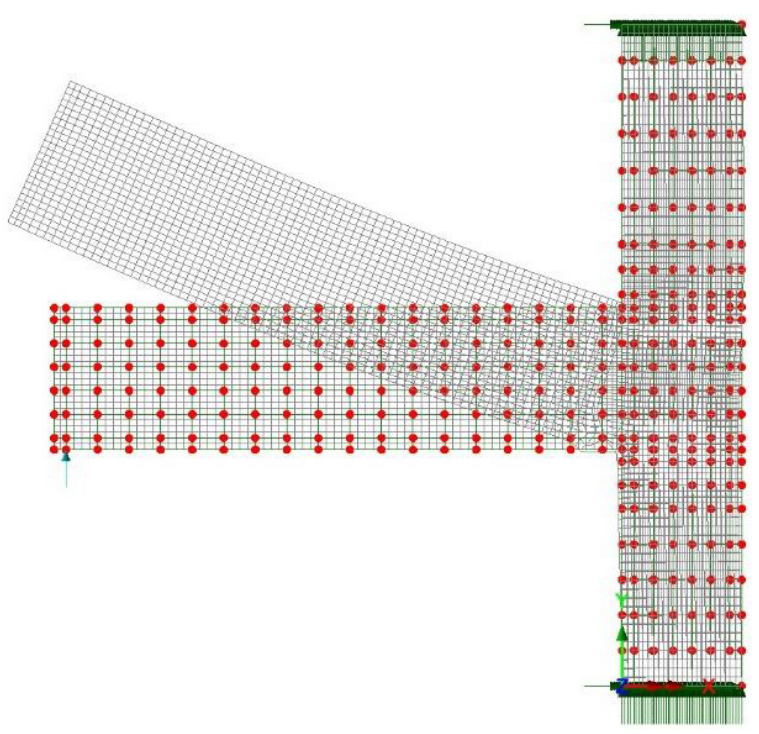

Figure 61. Cycle $5(150 \mathrm{~mm})$

\subsubsection{Applied real earthquakes}

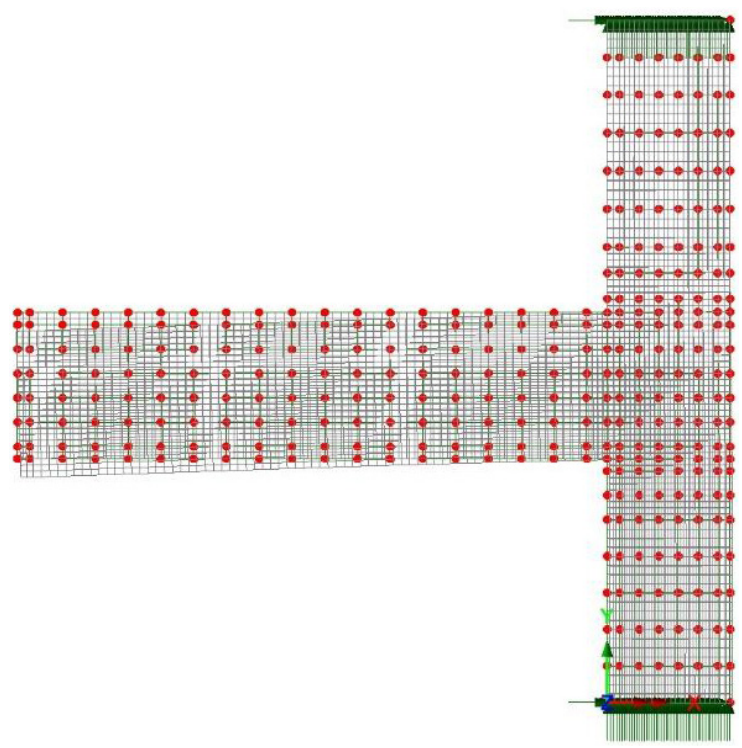

Figure 62. Applied Real Earthquake 1 (Athens). 


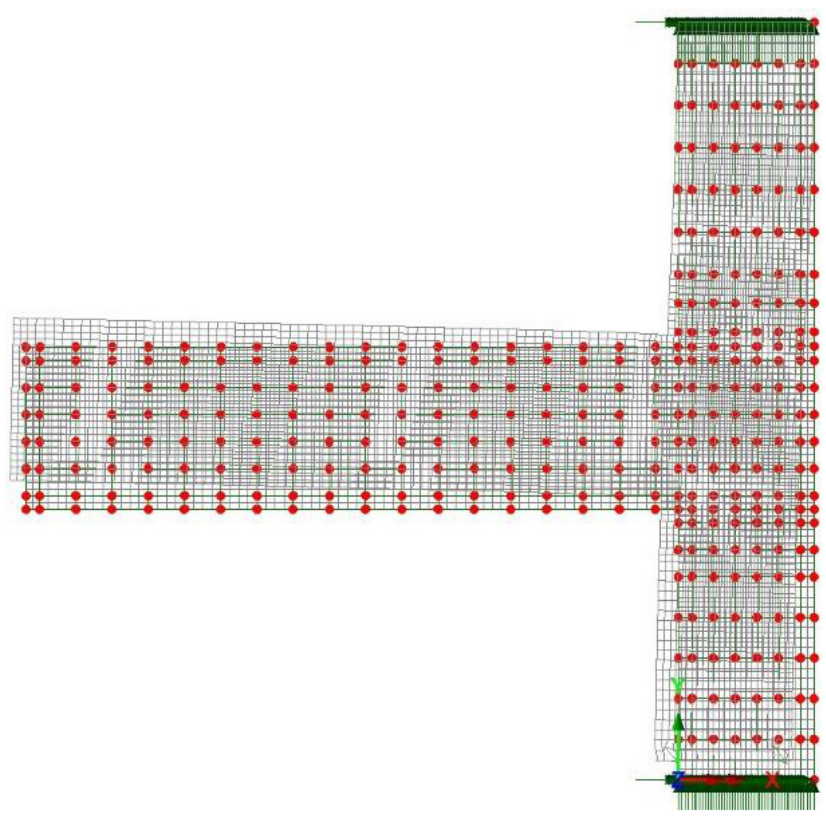

Figure 63. Applied Real Earthquake 2 (Friuli).

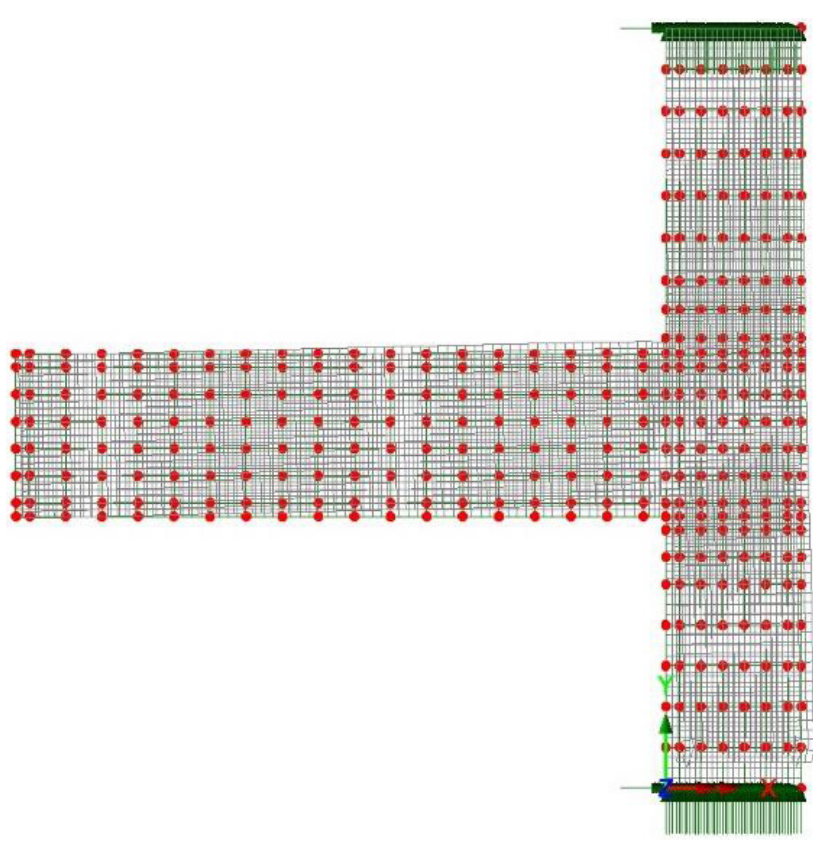

Figure 64. Applied Real Earthquake 3 (Izmir)

\section{Notations}

Ub Average bond over column for yielding beam reinforcement in compression and tension on both sides of joint

fy Strength of beam bars

Db Diameter of beam bars

He The width of column

fC: Compressive strength

BI: Bond Index between concrete and steel reinforcement bars

Vc: The concrete shear contribution

Vf' c Effective compressive strength of concrete

$\Delta$ Deflection

RBC Reinforced beam-column

DoF Degree of Freedom
FRP Fibre-reinforced plastic

NSM Near surface mounted

FE Finite Element

CFRP Carbon fibre-reinforced polymers

Open Sees an open-source, object-oriented software framework created for earthquake engineering simulations through FE methods.

\section{Acknowledgements}

This research project is not considered completed without the acknowledgements of the people and institutes who contributed directly and indirectly towards the completion of the research.

Firstly, I would like to thank my family, my mother, my father and my brothers who have really supported me morally.

I would like to thank University of Dundee for giving me the opportunity to conduct such an informative and interesting study, for making the computers, software and other research resources available. I would like to thank the librarians and Information and communication services (ICS) for their advice, help and assistance rendered during my research.

I would like to record my grateful thanks to Dr. Sana Balouch, Lecturer in University of Dundee, Faculty of Engineering, Physics and Mathematics. My thanks also extended to Dr. Ian Mackie, Structural Engineering/Course Leader, University of Dundee, for his invaluable advice at the crucial start point. Many thanks to Mr. David Husband, Computer Technician, Engineering Department, for his help with downloading the computer software and for providing support with issues related to such a matter.

Lastly but not the least, I would like to thank all my dear relatives and friends for their patience and moral support.

\section{References}

[1] Baptie, B., Ottemoller, L., Sargeant, S., Ford, G. and O'Mongain, A. (2005). The Dudley earthquake of 2002: A moderate sized earthquake in the UK, Tectonophysics Volume 401, Issues 1-2, 25, pp. 1-22.

[2] Elnasha, A. S. (2002). A very brief history of earthquake engineering with emphasis on developments in and from the British Isles. Chaos, Solitons \& Fractals Volume 13, Issue 5, April 2002, pp. 967-972.

[3] Musson, R.M.W. (2007) British earthquakes, In Proceedings of the Geologists Association, Volume 118, Issue 4, pp. 305-337.

[4] Pagni CA, Lowes LN. (2006), Fragility functions for older reinforced concrete beam-column joints. Earthquake Spectra 2006; 22(1): 215-238

[5] Pantelides CP, Clyde C, Reaveley LD. (2002), Performance-based evaluation of reinforced concrete building exterior joints for seismic excitation. Earthquake Spectra 2002; 18(3): 449-480.

[6] Sirkelis GM ,Karayannis CG, Chalioris CE. (2006), Seismic performance of RC beam-column joints retrofitted using light RC jacket-experimental study. Proceedings of the 1st European Conference on Earthquake Engineering and Seismology, Geneva, Switzerland, 2006; PN 136.

[7] Kitayama, K., Otani, S. and Aoyama, H. (1987). Earthquake resistant design criteria for reinforced concrete interior beam-column joints. Proceedings, Pacific Conference on Earthquake Engineering, Wairakei, New Zealand, August 5-8, 1987, Vol. 1, pp. 315-326 
[8] Paulay, T., R. Park and M. J. N. Priestley (1999), Reinforced Concrete Beam-Column Joints under Seismic Actions, American Concrete Institute Journal, November 1999, pp. 585-593.

[9] Balouch, S., (2009), Strengthening of reinforced concrete beam-column joint with steel fibre during earthquake loading - experimental study, University of Leeds.

[10] Youssef, M. and Ghobarah, A. (2001). Modelling of RC BeamColumn joints and structural walls. Journal of Earthquake Engineering, Vol. 5: No. 1, pp. 93-111.

[11] Ziyaeifar, M. and Noguchi, H. (2000). A refined model for beam elements and beam-column joints. Computers and Structures Vol. 76 pp. 551-564.

[12] Eligehausen, R., Genesio, G., Ožbolt, J and Pampanin, S. (2009). $3 \mathrm{D}$ analysis of seismic response of $\mathrm{RC}$ beam-column exterior joints before and after retrofit. In: Alexander et al (eds) Concrete Repair, Rehabilitation and Retrofitting II, Taylor \& Francis Group, London.

[13] Prota, A., Nanni, A., Manfredi, G. and Cosenza, E. (2000). Seismic upgrade of beam-column joints with FRP reinforcement. Industria Italiana del Cemento, August 2000.

[14] Almusallam, T.H. and Al-Salloum, Y. A. (2007). Seismic Response of Interior RC Beam-Column Joints Upgraded with FRP Sheets. II: Analysis and Parametric Study, Journal of Composites for Construction, Vol. 11, No. 6, pp. 590-600.

[15] Al-Salloum, Y. A. and Almusallam, T.H. (2007). Seismic Response of Interior RC Beam-Column Joints Upgraded with FRP Sheets. I: Experimental Study, Journal of Composites for Construction, Vol. 11, No. 6, pp. 575-589.

[16] Alsayed, S.H., Al-Salloum, Y.A., Almusallam, T.H. and Siddiqui, N.A. (2010). Seismic Response of FRP-Upgraded Exterior RC Beam-Column Joints. Journal of Composites for Construction, Vol. 14, No. 2, pp. 195-208

[17] Li, B. and. Kulkarni, S.A. (2009). Seismic Behavior of Reinforced Concrete Exterior Wide Beam-Column Joints; Journal of Structural Engineering, Vol. 136, No. 1, pp. 26-36.
[18] Shah, S.P., Wang, M-L and Chung, L. (1987). Model concrete beam-column joints subjected to cyclic loading at two rates. Materials and Structures/MatOriaux et Construction, Vol. 20, pp. 85-95.

[19] Mulas, M.G. and Filippou, F.C. (1990). Analytical procedures in the study of seismic response of reinforced concrete frames. Eng. Strut. Vol. 12

[20] Liu, J.L. (2010). Preventing progressive collapse through strengthening beam-to-column connection, Part 1: Theoretical analysis. Journal of Constructional Steel Research Vol. 66; pp. 229-237.

[21] Favvata, M.J., Izzuddin, B.A., and Karayannis, C.G. (2008) Modelling exterior beam-column joints for seismic analysis of RC frame structures; Earthquake Engineering Structures and Dynamics. Vol. 37; pp. 1527-1548.

[22] Lee, J-Y., Kim, J-Y and Oh, G-J (2009). Strength deterioration of reinforced concrete beam-column joints subjected to cyclic loading, Engineering Structures Vol. 31 pp. 2070-2085.

[23] Lowes, L. N., N. Mitra and A. Altoontash (2004). A Beam-Column Joint Model for Simulating the Earthquake Response of Reinforced Concrete Frames, PEER.

[24] Cofer, W.F., Zhang, Y. And. McLean, D.I. (2002). A comparison of current computer analysis methods for seismic performance of reinforced concrete members. Finite Elements in Analysis and Design Vol. 38 pp. 835-861.

[25] Mo, Y.L., Tsai, S. P. and Led, L. S. (1998). Seismic performance behavior of beam-column connections in prestressed concrete bridges; Materials and Structures, Vol. 31, pp. 411-417.

[26] King ES., Dakin JM (2001). Specifying detailing and achieving cover to reinforcement, Construction Industry Research and Information Association, London, 2001; CIRIA (C568).

[27] Eurocode 8: Design of structures for earthquake resistance. General rules, seismic actions and rules for buildings (2004), BS EN 1998-1: 2004 